\title{
Boosting the Extensibility Potential of Fibre Networks: A Review
}

\author{
Alexey Vishtal ${ }^{\mathrm{a}, \mathrm{b}}$ and Elias Retulainen ${ }^{\mathrm{a}, *}$ \\ Production of paper-based packaging is growing at the present moment \\ and has great future prospects. However, the development of new \\ packaging concepts is creating a demand for an improvement in the \\ mechanical properties of paper. Extensibility is one of these properties. \\ Highly extensible papers have the potential to replace certain kinds of \\ plastics used in packaging. Extensibility is also important for the sack \\ and bag paper grades and for runnability in any converting process. This \\ paper reviews the factors that affect the extensibility of fibres and paper, \\ and discusses opportunities for improving the straining potential of paper \\ and paper-like fibre networks. It is possible to classify factors that affect \\ extensibility into three main categories: fibre structure, interfibre bonding, \\ and structure of the fibre network. Extensibility is also affected by the \\ straining situation and the phase state of the polymers in the cell wall. By \\ understanding the basic phenomena related to the elongation, and by \\ combining different methods affecting the deformability of fibre network, \\ extensibility of paper can be raised to a higher level.
}

Keywords: Extensibility; Fibres; Bonding; Network; Deformation; Polymers; Papermaking

Contact information: a: VTT Technical Research Centre of Finland, Koivurannantie 1, P.O. Box 1603, FI-40101 Jyväskylä, Finland; b: Tampere University of Technology, Laboratory of Paper Converting and Packaging Technology, P.O. Box 589, FI-33101 Tampere, Finland;

*Corresponding author: elias.retulainen@vtt.fi

\section{INTRODUCTION}

Extensibility is one of the undeservedly disregarded properties of paper. It is considered to be important mainly for sack and bag paper grades (Hernandez and Selke 2001). Typically, papermakers and converters mainly operate with tensile strength, bending stiffness, tear strength, etc. However, recent trends in the development of paperbased packaging materials indicate that, in the production of advanced 3D shapes, extensibility of paper is gaining a new, key role that trumps the importance of other mechanical properties (Kunnari et al. 2007; Östlund et al. 2011; Post et al. 2011; Vishtal et al. 2013; Svensson et al. 2013; Larsson et al. 2014). In 3D-forming processes with fixed paperboard blank, extensibility is the main parameter determining the depth of the shapes produced and the formability of such paper in general (Vishtal et al. 2013). Novel paper-based materials with high extensibility are broadening the area of utilization for paper, and may help to bring the paper industry back onto a growth trajectory in some grade categories.

Despite the importance of extensibility, most of the paper-based materials that are produced at present have poor extensibility. Most paperboards have extensibility in the range of around 1 to $4 \%$ and 3 to $6 \%$ in $\mathrm{MD}$ and $\mathrm{CD}$, respectively. Such values are obviously too low for the development of many new applications. The question is how far and by which means the extensibility potential of paper can be further boosted? 
The extensibility of paper has been specifically addressed by only a few researchers (Steenberg 1947, 1949; Brecht and Erfurt 1960; Dodson 1970; Seth 2005). It has been commonly studied together with the other stress-strain properties of paper. Therefore, an extensive summary of the previous fundamental research together with the analysis of the methods for the improvement of extensibility can be a useful addition to the current knowledge in this field.

This paper aims to review extensibility as a mechanical property of paper, and discusses the factors that control it. The influence of the straining situation is also considered. The overarching goal is to find tools to increase the extensibility of paper to a qualitatively new level. The methods that can be used for the improvement of extensibility are comprehensively reviewed, with the focus on the industrial applicability of such methods.

\section{GENERAL OUTLOOK ON THE EXTENSIBILITY OF PAPER}

\section{Stress-strain Behaviour of Paper}

The extensibility of paper can be defined as the ability of paper to increase its linear length, due to elastic, viscoelastic, and plastic deformations under the action of external mechanical forces. The most widely studied type of mechanical deformation in paper is tensile deformation, where extensibility is determined as the strain at break value of the stress-strain curve (Fig. 1.).

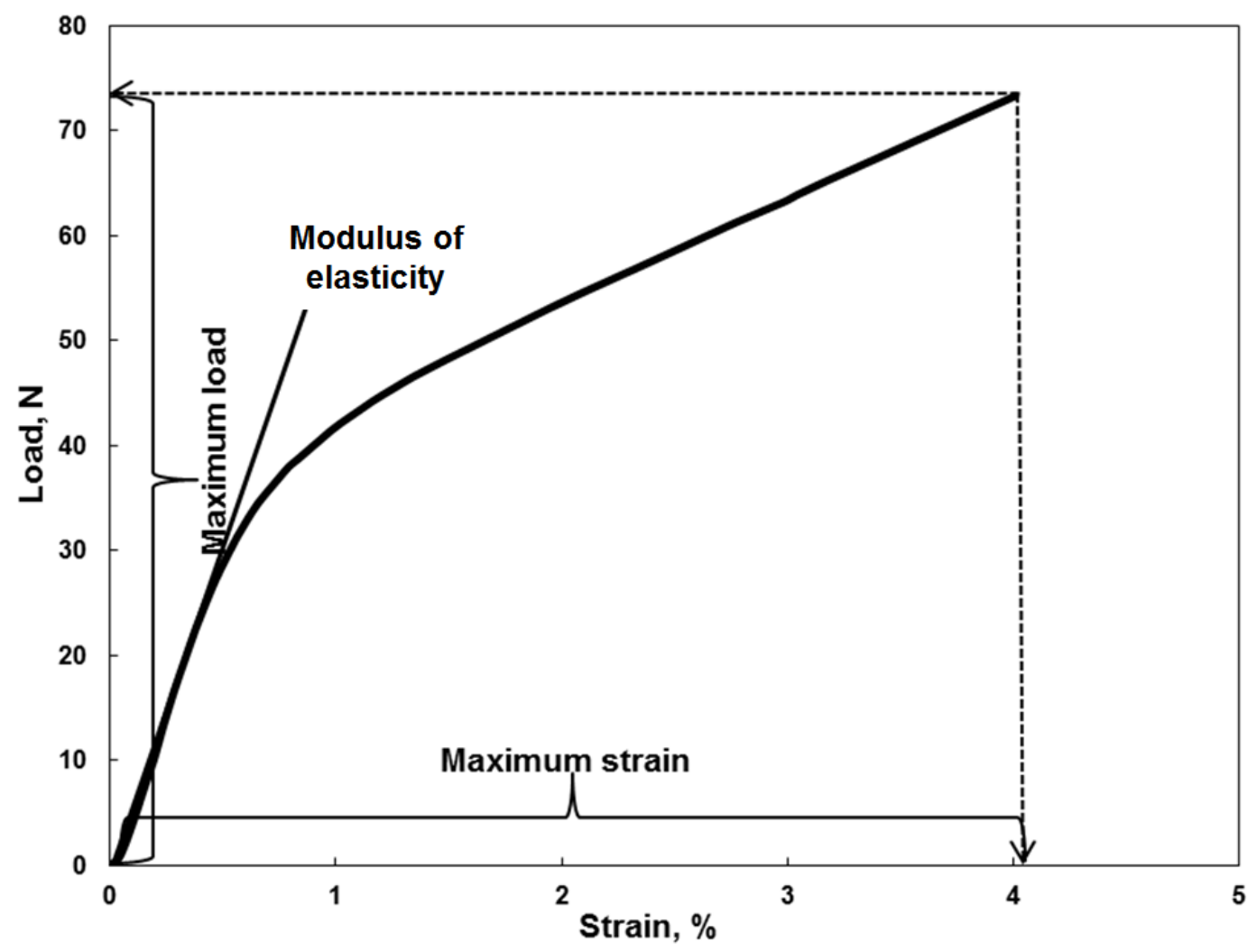

Fig. 1. A typical stress-strain curve for isotropic restrained-dried paper made from softwood pulp

The strain at break value of paper is determined at the point of maximum tension of the stress-strain curve (Fig. 1). Usually, at this point fracture of paper occurs. In this 
respect, strain at break value is closely associated with the tensile strength of paper, and factors that affect the tensile strength are likely to control the strain at break value as well. However, strong paper may be brittle, while extensible paper usually exhibits a decrease in tensile strength with increase in extensibility.

The extensibility of paper is defined by the fracture point. By considering the stress-strain curve of paper it is possible to suggest that extensibility is dependent on the same factors that are in charge for the shape of the curve and the fracture point of paper. However, the shape of the stress-strain curves may vary to a great extent in accordance with the fibre network properties and the straining conditions (sample dimensions, temperature and moisture content, strain rate, etc.). The influence of the straining conditions can be demonstrated via the stress-strain curve for non-immediate rupture of paper depicted in the Fig. 2.

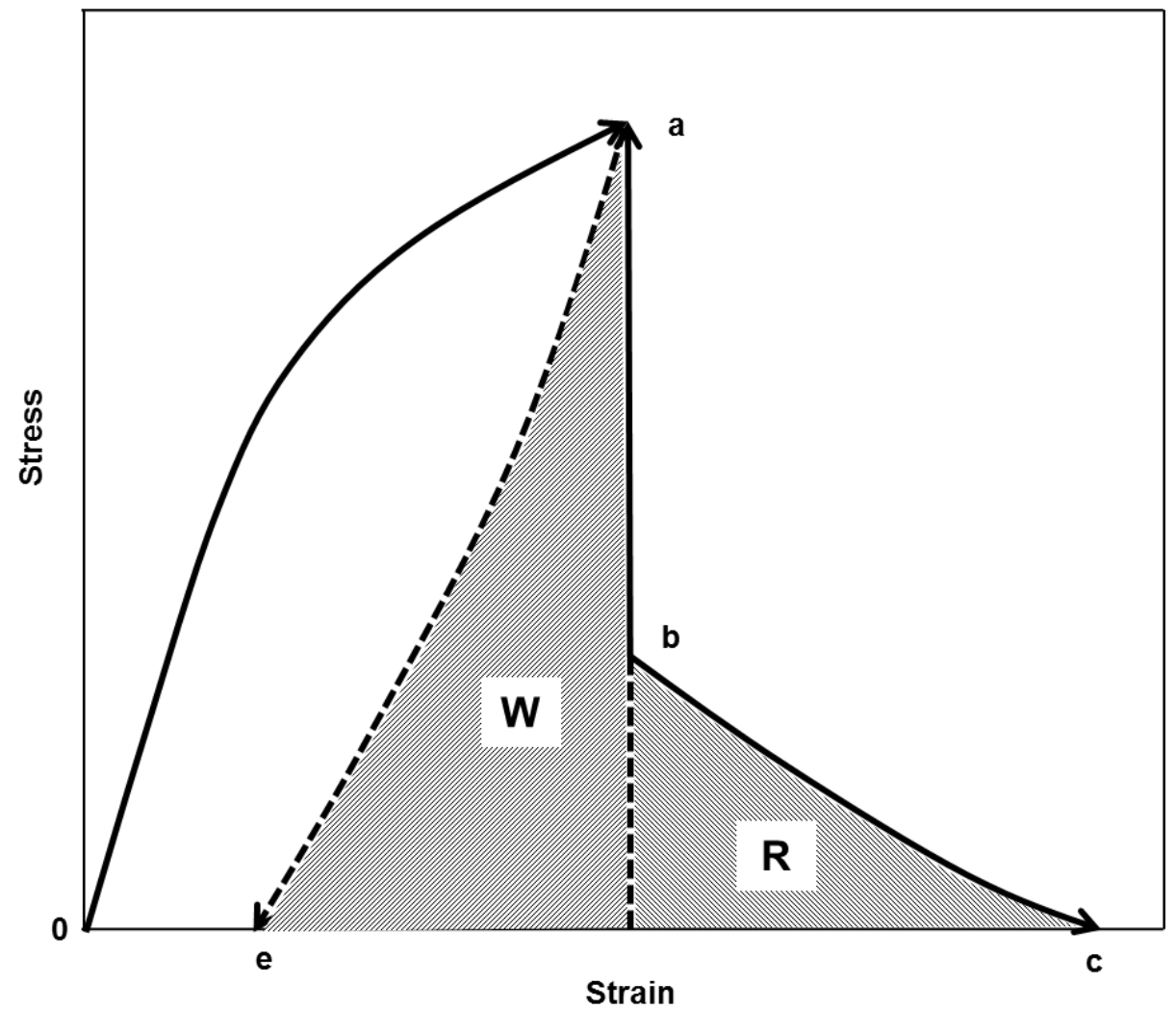

Fig. 2. A stress-strain curve of paper with a non-immediate rupture (redrawn from Goldschmidt and Wahren 1968)

The development of fracture in paper under tensile stress depends on the amount of elastic strain energy stored in the test sample (area W in Fig. 2), and the amount of energy needed for the propagation of the fracture line to complete the break. If the test specimen is sufficiently long and the elastic strain energy is large, then a brittle, catastrophic failure occurs. If the amount of elastic energy stored in the test strip is low or the energy needed for the propagation of the fracture line is high, for example, due to a short testing span, high fracture toughness or high moisture content, additional energy (area R) has to be delivered into the sample by further straining so as to complete the break (Robertson 1959; Goldschmidt and Wahren 1968; Kurki et al. 2004). It can be assumed that, in many converting and forming processes, the apparent testing span is actually shorter than in the standard tensile test. 


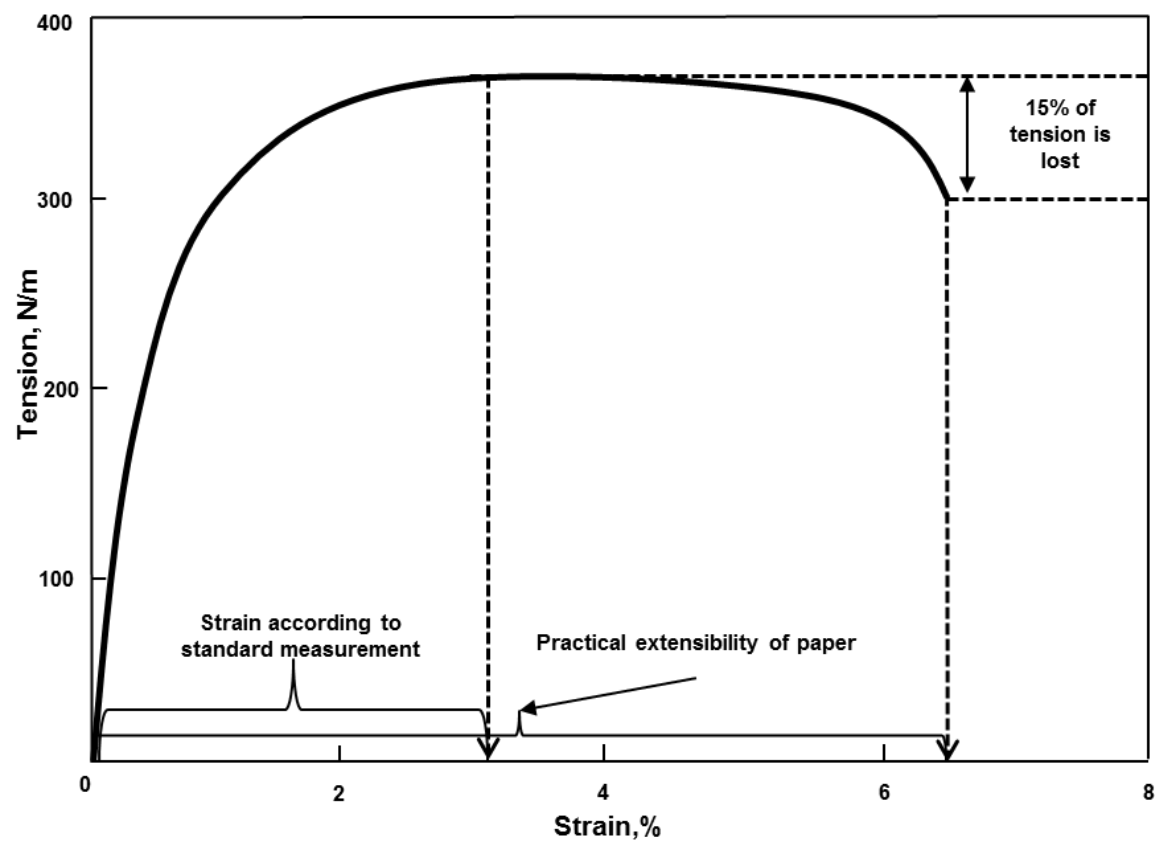

Fig. 3. A stress-strain curve of rewetted paper (55\% dryness) prepared from hydroxypropylated pulp (material produced in Vuoti et al. 2013)

From the example in Fig. 3, we can observe that the fracture of paper does not always occur at the point of maximum load. For example, wet paper can often be strained much further, and only a part of the tension is lost. Such behaviour is close to that of truly ductile materials.

This raises the question of how the extensibility of paper should be defined - at the point of maximum tension or at the point where a significant part of the tension is lost?

This is especially relevant for various converting processes, including 3Dforming. In these cases, extensibility should not be evaluated only through the maximum tensile strength of paper, but rather through the typical loading situation in accordance with the end-use of the paper. For the sack paper grades, extensibility is usually evaluated in connection with TEA (Tensile Energy Adsorption) i.e. gain/loss in strength or strain is compared with gain/loss in TEA.

The deformation of paper is usually divided into elastic, viscoelastic, and plastic components. In forming 3D structures, a large plastic deformation is preferred in order to avoid the springing back and deflexion of shapes (Vishtal and Retulainen 2012). With increase in overall deformation, the extent of all strain components also increases. However, the relative share of plastic deformation increases and the relative share of elastic deformation decreases with increase in overall deformation (Brecht et al. 1971; Skowronski and Robertson 1986). The development of the plastic and elastic components in overall deformation of paper is shown in Fig. 4, where $x$-axis represents overall strain in \%-points and $y$-axis is for \%-points of elastic or plastic deformation. Elastic deformation is defined as the immediately recovered component while plastic deformation component is approximated to be the rest of the deformation. 


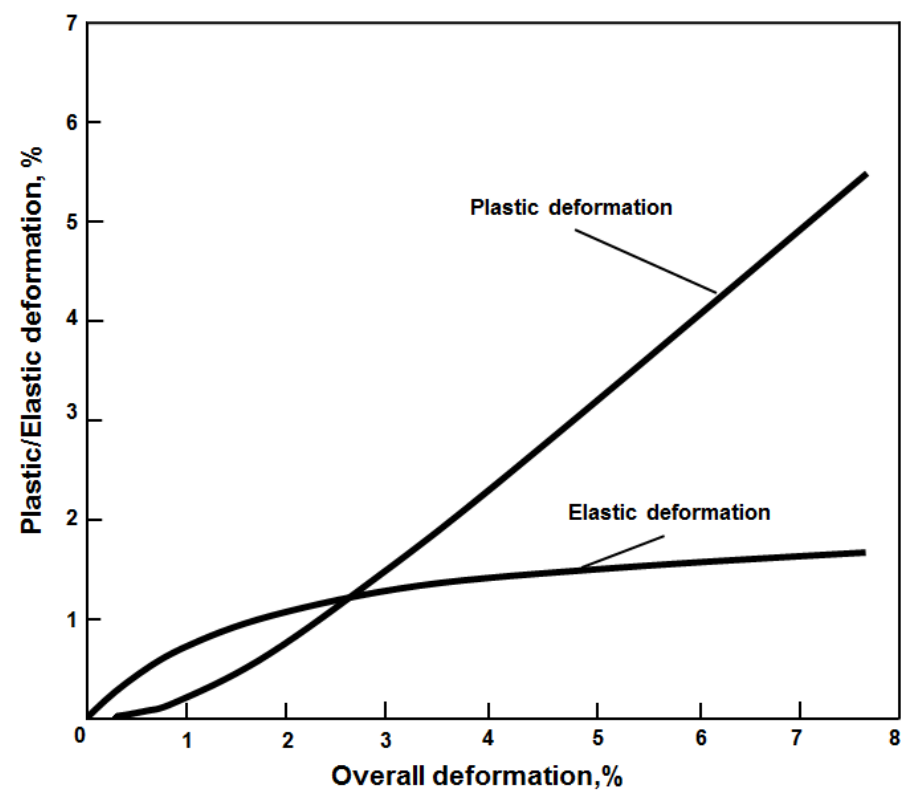

Fig. 4. The amounts of the apparent elastic and plastic deformations in overall tensile deformation of lightly creped paper for both MD and CD (redrawn from the data of Brecht et al. 1971)

When using only two components, apparent elastic and apparent plastic deformation (which also includes the viscoelastic deformation), it is possible to see that, at overall strains of 2 to $3 \%$ points, the amount of apparent plastic and elastic deformations are equal, and after that the apparent plastic component increases linearly. The elastic strain component is present at all deformation levels, but the plastic component starts to appear only at 0.2 to $0.3 \%$ strain. At strains higher than $3 \%$ the apparent plastic deformation is the dominating component, and it increases linearly. It is also interesting that, despite the different paper structures and different strains at break, the plastic deformation of several papers grades even in machine and cross machine directions was found to follow the same curve (Brecht et al. 1971).

\section{Factors Affecting the Shape of Stress Strain Curve and Final Failure}

Qualitatively, the non-linear shape of the stress-strain curve and plastic deformation of paper has been shown to depend mainly on the properties of the fibres in paper. It should be noted that the properties of fibres in paper are different from those of individual fibres because during the papermaking process the fibre properties are modified by wet straining and drying stresses. Ebeling (1976) stated that in well bonded paper "the plastic region in the load/elongation curve is not caused by the breakage of fibre-fibre bonds but is connected to the significant irreversible intra-fibre deformation on molecular and supramolecular level" (Ebeling 1976). The term "efficiency factor" has been used when analysing the shape of the stress strain curve (Seth and Page 1981; Coffin 2009, 2012). When isotropic paper made from a certain fibre material gives higher extensional stiffness, the material has a higher efficiency factor. The efficiency factor is closely related to the load-bearing activity of the material (Lobben 1975). When a fibre network has a higher load-bearing activity, the efficiency factor is also increased and the slope of the stress-strain curve is steeper. Seth and Page (1981) showed with well-bonded sheet that in cases where the slope of stress-strain curve and the initial load bearing activity of the material is changed, for example due to beating, wet pressing, or bonding agent, the stress-strain curves normalised by the efficiency factor (that is calculated from 
the elastic moduli) can be transposed to an apparently single curve. Bonding plays only a minor role; this is based on the statement that the stress-strain curve of paper is related to the stress strain curve of fibres through the factors that take into account the orientation of fibres and the efficiency of stress distribution of fibres. This suggests that, with a certain pulp, the straining behaviour of the material that actually bears the load is the same, although the amount of the load bearing material is initially different, and only the end point of the stress-strain curve, i.e. the fracture point, varies. The load-bearing activity (and efficiency factor) of the material, however, can change during straining, when the bonding level is low. Then even the stress-strain curves normalised by efficiency factor do not superimpose when transposed (Seth and Page 1981).

Skowronski and Robertson (1983) have concluded that, in addition to elastic, viscoelastic, and plastic behaviour, activation, deactivation, and failure phenomena are also needed in order to explain the tensile behaviour (including stress-strain cycling and relaxation) of paper. Activation of paper under tension can be related to the straightening of fibre segments and re-arrangement of the fibrillar material in the fibre wall, especially in dislocated and microcompressed areas. Straining of wet paper before drying is also known to be an efficient method to activate the load-bearing ability of fibre material (Parsons 1972).

During the straining of paper internal fractures take place. The most fractures are micro-failures and related to debonding. Debonding, i.e. partial or complete fracture of fibre-fibre bonds, is known to take place during straining of paper (Page et al. 1962). However (Ebeling 1976; Seth and Page 1981), the plastic behaviour of paper is not caused by the debonding, but is related to the irreversible intrafibre deformations. Although fibre bonding and debonding have only a minor effect on the shape of the stress-strain curve with well-bonded papers, in less bonded papers the debonding eventually plays a more important role in reducing the efficiency factor and altering the shape of the stress-strain curve. Debonding creates stress concentrations that may lead to the initiation of the final failure (Helle 1965). The first mechanism initiating the final macroscopic failure of paper is either a burst of bond failures or fiber failures (Alava and Niskanen 2006). This conclusion has also gained support from recent stress-strain simulations of paper (Borodulina et al. 2012). Additionally, other factors such as structural heterogeneity or unevenness (bad formation, holes, etc.) can also cause uneven stress distributions and lead to premature initiation of the final fracture (Nazhad et al. 2000).

To conclude this section, it can be claimed that especially in well-bonded sheets the general shape of the stress-strain curve is mainly determined by the properties of fibres in the network and their activity to bear load; but the end point of the curve is also determined by factors that trigger the final failure. Therefore the factors that affect the extensibility of paper are related to properties of fibres, fibre bonds, and network structure.

\section{FACTORS THAT CONTROL THE EXTENSIBILITY OF PAPER}

Numerous factors affect the extensibility of paper. In his excellent review paper Seth (2005) stated that the extensibility of paper depends on two principal components: fibres and interfibre bonding. However, from the point of controlling the extensibility of paper, we should also include the network structure as a separate factor. 
It is known that the fibre network and properties of individual fibres in the fibre network are modified by wet straining and drying stresses (Retulainen et al. 1998, Wahlström and Fellers 2000). But factors that modify the fibre network also affect the properties of fibres and bonds. Extensible fibres might be connected by strong bonds, but yet the paper would not be extensible due to restrictions arising from the fibre network structure. This fact is illustrated by conventional papermaking process in which the wet draws, fibre orientation anisotropy, and restrained drying limit the extensibility in MD (machine direction) to the range 1 to $3 \%$, while in $\mathrm{CD}$ (cross direction) paper can be strained two times more than in MD. The straining conditions have a major impact on the overall elongation of paper as well as on the share of elastic and plastic components of deformation.

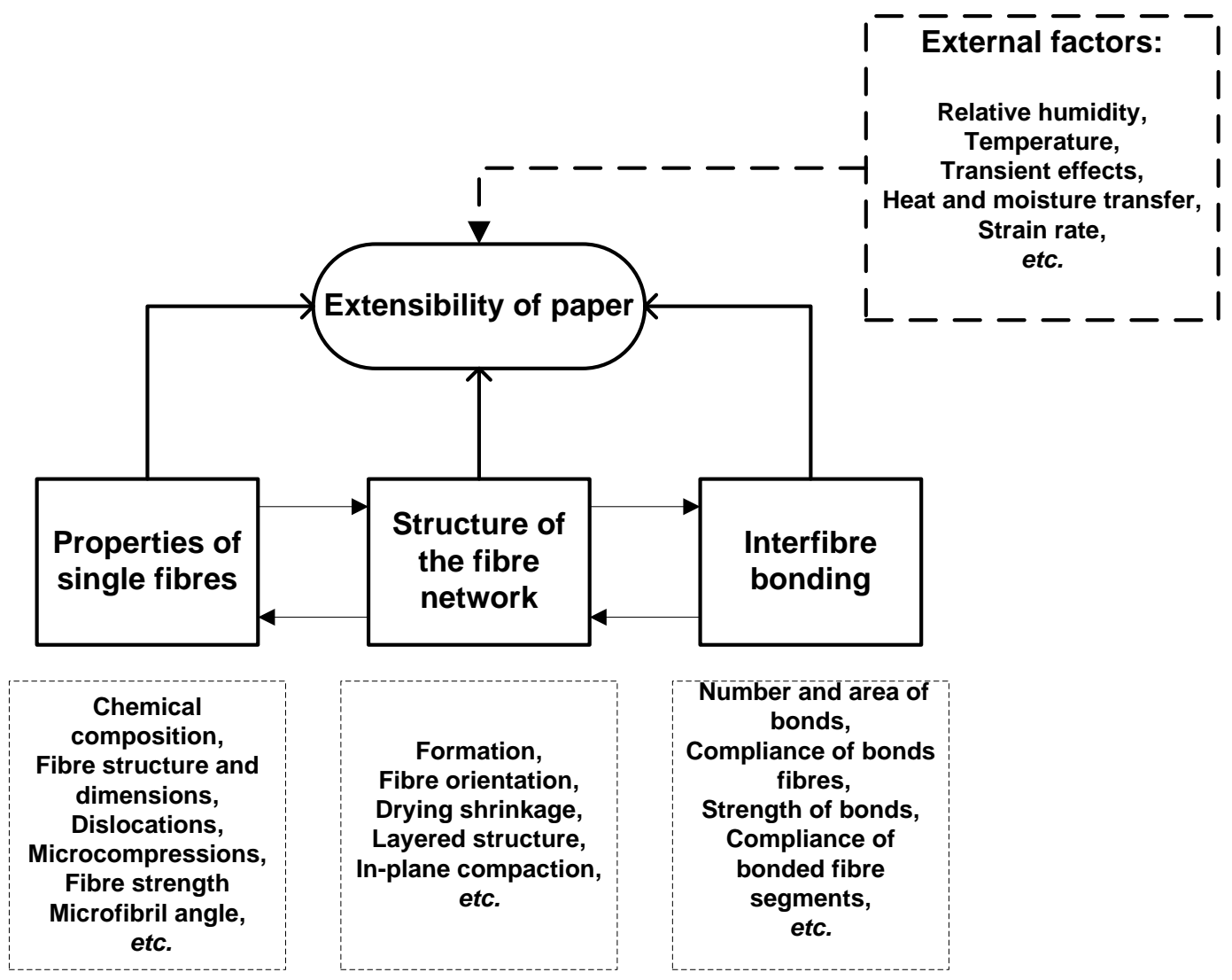

Fig. 5. Factors that affect the extensibility of paper

The scheme in Fig. 5 shows the three factors that affect the extensibility of paper. This scheme emphasizes the role of straining conditions in the overall extensibility potential of paper. Even though these factors are presented individually, they are in close interaction with each other in papermaking and converting processes. For instance, changes in the structure of single fibres due to high-consistency treatment (causing curl, kinks, dislocations, and axial microcompressions) affect the formation of paper and properties of interfibre contacts and the deformation behaviour of the whole network. And, on the other hand, drying shrinkage of the fibre network affects individual bonds and fibres.

In order to boost the extensibility potential of paper to a maximum level, one should design and adjust treatments in such way that they would complement each other. 


\section{Properties of Single Fibres that Affect Extensibility}

Fibres are the primary constituents and load-bearing elements of paper. They have a strong influence on all the mechanical properties of paper, and its extensibility is not an exclusion from this rule. Wood fibres are generally axially stiff and non-extensible. The typical strain of wood pulp fibres is about 3 to $6 \%$, but juvenile wood fibres may have extensibility up to 20\%-points (Hardacker and Brezinski 1973; Bledzki and Gassan, 1999). Also, certain non-wood and synthetic fibres have extensibility varying over a broad range, i.e. 50 to $800 \%$. However, extensible fibres are not necessarily able to form an extensible paper. In order to fulfil this requirement, fibres should be able to form sufficiently strong bonds and network structure with even stress distribution (Seth 2005; Zeng et al. 2013). The bonding potential of fibres depends on morphological, chemical, and mechanical properties. The features of single fibres, which are of high importance for extensibility, are discussed below.

\section{Fibrillar angle}

The morphological features of fibres are the key factors determining their mechanical properties. Cellulose, the main chemical component of fibres, is stiff in an axial direction, with a theoretical modulus of the chain around $250 \mathrm{GPa}$ (Vincent 1999). When the individual cellulose chains form a cellulose $\mathrm{I}_{\beta}$ crystallite structure, the stiffness decreases to $140 \mathrm{GPa}$ (Cintron et al. 2011). The stiffness is further decreased to around 55 to $65 \mathrm{GPa}$, when the cellulose $\mathrm{I}_{\beta}$ nanostructures are assembled into microfibrils (Sun $e t$ al. 2014), and finally to 20 to $40 \mathrm{GPa}$ for fibres (softwood latewood) (Page and ElHosseiny 1983; Altain 2014). It should be noted that the different cellulose crystalline allomorphs have different stiffness; it is decreasing in the order of Cel I (140 GPa) $>$ Cel II (88 GPa) > Cel III (87GPa) > Cel IV (58GPa) (Nishino et al. 1995).

The decrease in stiffness and the corresponding increase in the extensibility of fibres in comparison with the cellulose molecule is partially attributed to the spring-like alignment of the microfibrils in fibres. This alignment is described by the microfibrillar angle (MFA) that is determined as the angle between the axis of fibre and the direction of the cellulose fibrils in the S2 cell wall layer (Barnett and Bonham 2004) (Fig. 6). The increase in elongation of fibres due to high MFA is explained by the untwisting of the spring-like structure, sliding of fibrils under shear forces, and higher flexibility of such fibres (Horn 1974; Page and El-Hosseiny 1983; Gurnagul et al. 1990; Martinschitz et al. 2008).

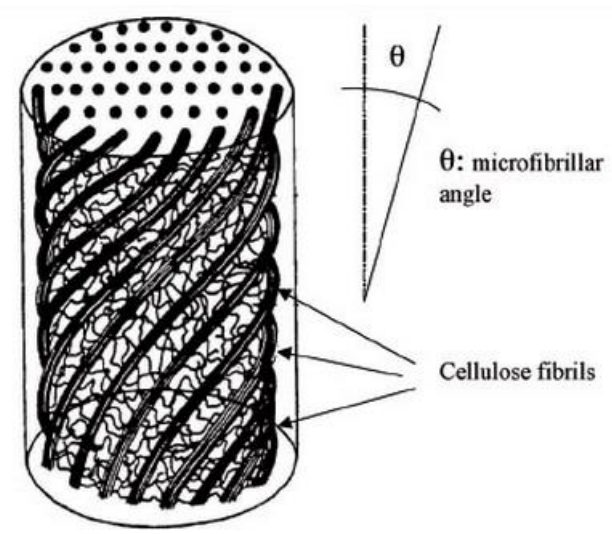

Fig. 6. Graphic representation of the MFA in fibre (Hearle 1963) 


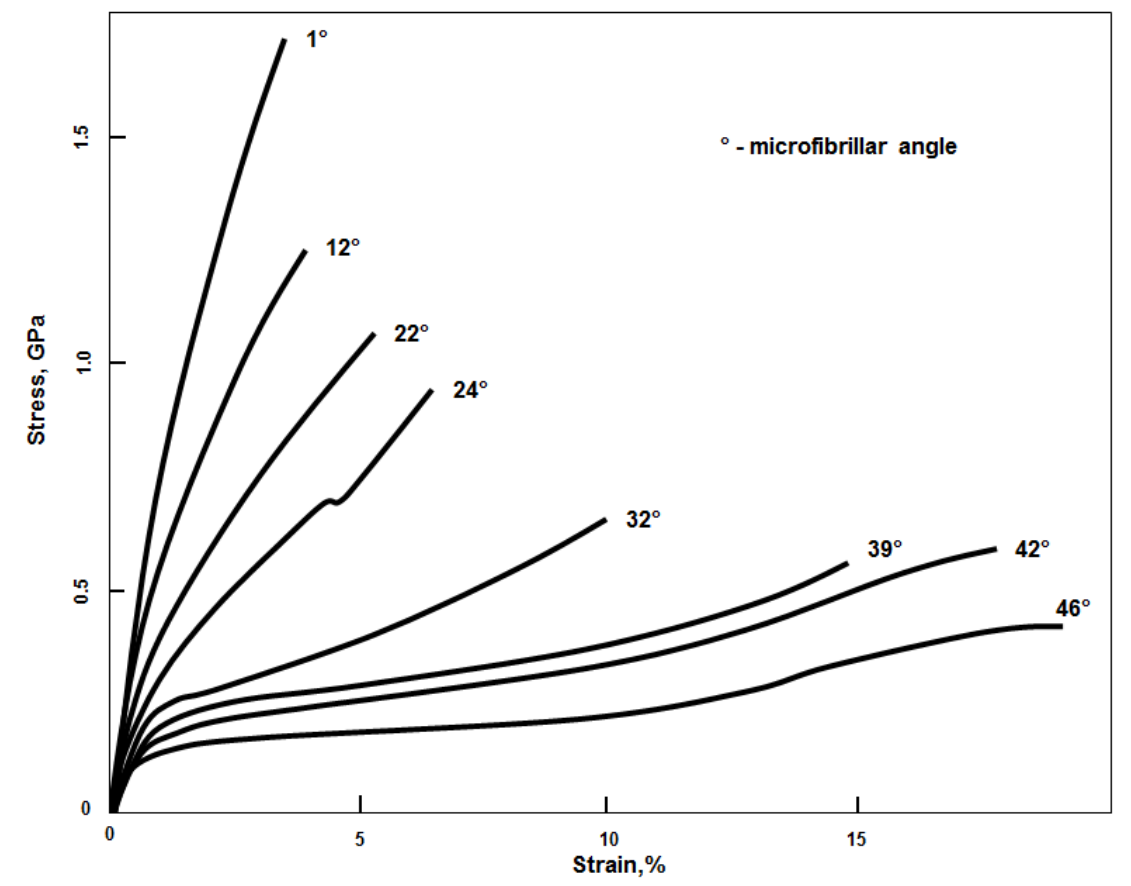

Fig. 7. The relation between MFA and extensibility of chemical pulp fibres of black spruce (redrawn from the data of Page and El-Hosseiny 1983)

Fibres with high MFA tend to have higher extensibility and lower stiffness than fibres with low MFA (Fig. 7), which is explained by unwinding of the structure of fibres with high MFA under the action of shear forces (Page and El-Hosseiny 1983). Juvenile softwood fibres have higher extensibility than latewood fibres, which is explained by the higher fibrillar angle of juvenile fibres (Wimmer 1992; Lindström et al. 1998; Reiterer et al. 1999; Ljungqvist et al. 2005; Donaldson 2008; Hänninen et al. 2011). For instance, extensibility of latewood fibres of Picea Abies is around 2\%-points (MFA 5 ${ }^{\circ}$ ), while for springwood fibres it is around 13\%-points (MFA 50 ) (Reiterer et al. 1998). It was also shown that the fibres with high MFA in Acacia mangium have lower glass transition temperature, which indicates certain differences in the composition and arrangement of wood polymers in the cell in comparison with latewood fibres (Tabet and Aziz 2013).

An additional factor contributing to the higher extensibility of paper made from springwood fibres is the higher longitudinal drying shrinkage (Dong 2009). Although fibres with a high fibril angle have generally lower axial stiffness, they do have better resistance to the shear forces than fibres with a low fibril angle (Satyanarayana et al. 1982; Page and El-Hosseiny 1983; Bledzki and Gassan 1999; Nishino et al. 2004). Interestingly, a trend analogical to the MFA of wood fibres can be observed with viscose fibres, in which the molecular orientation in major extent determines the elongation of the fibres (Lenz et al. 1994).

Fibre fraction with high MFA can be obtained by hydrocyclone separation, which allows separation of springwood and latewood fibre in an efficient way. This treatment was applied and found to be efficient both for softwood (Paavilainen 1992; Vomhoff and Grundström 2003) and hardwood pulps (Blomstedt and Vuorinen 2006). However, this method separates fibres according to their hydrodynamic properties, which are not always correlated with MFA. Utilization of the first-thinning wood (Kärenlampi and SuurHamari 1997) or tree species such as Juniperus communis (Hänninen et al. 2011) for pulping is also an option for obtaining extensible fibres with relatively high MFA. Recently, a method for production of cellulose nanofibrils filaments with controlled fibril 
alignment along the filament axis was proposed (Håkansson et al. 2014). In this case fibrillar alignment is artificially adjusted by process parameters such as flow velocity, flow acceleration and deacceleration, etc., which makes it possible to obtain fibres with desired stress-strain properties. Mechanical properties of the artificial fibres are in line with the natural wood fibres with the same degree of alignment (i.e. MFA) (Håkansson et al. 2014). This is an interesting approach allowing the design of mechanical properties of fibres for a certain applications.

\section{Chemical composition of fibres}

Chemical pulp fibres are composed of cellulose and hemicelluloses; lignin is present in very small amounts (less than $0.5 \%$ ). However, unbleached (2 to 5\%) and especially mechanical pulps (5 to $25 \%$ ) have significantly higher lignin content (Alén 2000). The alternation in the relative share and internal structure of different natural polymers which constitute fibres is of great influence for the mechanical properties of paper (Spiegelberg 1966).

Cellulose is the stiffest chemical component of fibres. Basically, the elongation of cellulose takes place through two mechanisms: by elastic axial elongation of the cellulose molecules and by irreversible, time-dependent slippage between cellulose molecules (Altaner et al. 2014). The axial elongation of the cellulose molecule is, in addition to covalent bonds, also dependent on the intramolecular hydrogen bonds and intermolecular hydrogen bonds. The slippage between molecules is dependent on the intermolecular hydrogen bonds. In fibres, slippage is more likely to occur between fibrils and fibril bundles, which are held together by amorphous cellulose and hemicellulose.

Cellulose in papermaking fibres is present in two states, crystalline and amorphous, with a respective ratio of around 3:1 for bleached wood pulp (Ward 1950; Fiskari et al. 2001). In addition to fully amorphous and crystalline cellulose, the regions with not fully amorphous cellulose can be found, and they are typically regarded as the paracrystalline regions (Kulasinski et al. 2014).

Crystallinity of cellulose in fibres depends to a great extent on the origin and type of the processing utilized for fibres. Increase in the crystallinity of cellulose increases the strength and stiffness of the fibres; at the same time, it negatively affects their extensibility and flexibility (Ward 1950; Lee 1960; Parker 1962; Thygesen 2006). High stiffness and respective low extensibility of crystalline cellulose regions is likely to originate from the $\mathrm{O}^{\prime}{ }^{\prime} \mathrm{H} \cdots \mathrm{O} 5$ and $\mathrm{O} 2 \mathrm{H} \cdots \mathrm{O} 66^{\prime}$ intermolecular hydrogen bonds and their interaction with the covalent bonds (Altaner et al. 2014). The hydrogen bonds are also responsible for the moisture sensitivity of the cellulose molecules and their extensibility. The mechanical properties and structure of the amorphous cellulose is known to a much smaller extent than that of crystalline cellulose. Generally amorphous cellulose is characterized by the absence of long range order and greater disorder in the orientation of the cellulose chains (Fink et al. 1987; Muller et al. 2000). The stiffness of the crystalline and amorphous parts of the cellulose differs significantly $(220 \mathrm{GPa}$ for crystalline $v s$. 10.4 for amorphous) (Sun et al. 2014). This great difference means that the softer amorphous part mainly determines the extensibility of cellulose (Fig. 8).

An increase in the proportion of amorphous cellulose in pulp is accompanied by an equivalent increase in extensibility and a decrease in elastic modulus, as is schematically depicted in Fig. 8. The same assumption is valid for the regenerated cellulose fibres. For instance, a decrease in the degree of crystallinity of regenerated cellulose fibres (Lyocell@) from 0.63 to 0.5 improves the extensibility of the fibres from 11 to $17 \%$ (Lenz et al. 1994). It is important to note that the actual nature of crystallinity is different 
for cellulose I (native fibres) and cellulose II (regenerated cellulose). In the Cel I cellulose, chains are aligned parallel, meaning that the reducing ends are all facing the same direction. However, upon swelling and dissolution, resulting in the transformation to the Cel II form, they develop an antiparallel arrangement, which is more thermodynamically stable (Kim et al. 2006). The anti-parallel arrangement of the cellulose chains leaves more space for alignment upon straining, and thus explains the higher elongation and lower stiffness of regenerated cellulose in comparison with the native form.

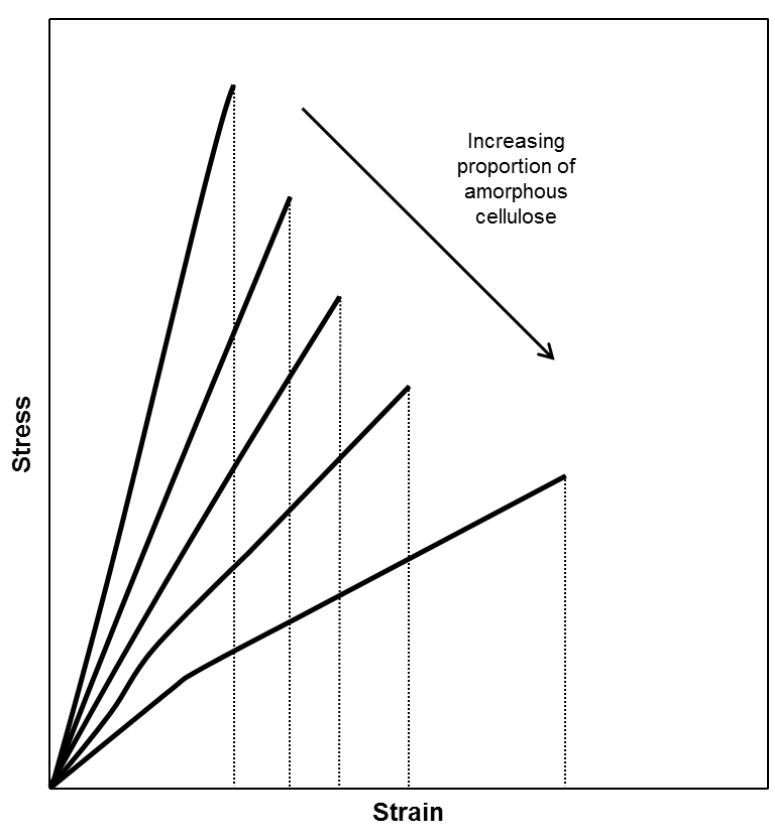

Fig. 8. Schematic representation of the influence of the increase in amorphous cellulose content on the extensibility and strength of pulp relation between fibres (redrawn from the data of Page 1983)

The crystallinity of the cellulose can be reduced by means of several chemical treatments; for example, concentrated acid treatment (Ioelovich 2012), $\mathrm{ZnCl}_{2}$ impregnation (Patil et al. 1965), or ethylamine decrystallization (Parker 1962). Also, the structure of crystalline cellulose can be transferred to a less-ordered one by treatment in water under severe conditions $\left(320^{\circ} \mathrm{C}, 25 \mathrm{MPa}\right)$ (Deguchi et al. 2006, 2008). Electronic beam irradiation also can be used to reduce crystallinity of cellulose. For instance a dose of irradiation of $200 \mathrm{kGy}$ has been found to reduce crystallinity of MCC, flax, cotton, and viscose by up to $12 \%$ (Alberti et al. 2005). At the same time, degradation of hemicelluloses and condensation of lignin is observed (Chung et al. 2012). The amount of energy needed to decrease the crystallinity by a certain value greatly varies in accordance with sample origin, type of the pre-treatment applied, moisture content, etc. (Driscoll et al. 2009). Irradiation has a considerable effect on the structure of cellulose; it causes chain scission and thus decreases DP (Saeman et al. 1952) and oxidizes cellulose by introduction of carboxyl and carbonyl groups (Morin et al. 2004; Bouchard et al. 2006; Henniges et al. 2013). Decrease in crystallinity is likely to be caused by substitution of hydroxyl groups with the oxidized ones, along with a consequent weakening of intramolecular and intermolecular hydrogen bonding (Henniges et al. 2013). 
However, reducing the cellulose crystallinity cannot be regarded as a feasible method for obtaining of highly-extensible fibres due to the associated costs of chemical treatments and rather poor selectivity in case of irradiation.

Xylans and mannans are the most common hemicelluloses in hardwood and softwood pulp fibres, respectively (Alén 2000). Hemicelluloses are amorphous polymers with a relatively low degree of polymerization (50 to 300) and elastic modulus (7 GPa) and significantly lower softening temperature. This is also reflected in the extensibility of hemicellulose; for instance strain at break of films prepared from arabinoxylan can be as high as $15 \%$ (Mikkonen et al. 2012).

Hemicelluloses improve the bonding potential of fibre and thus the extensibility of paper. According to Spiegelberg (1966) and Leopold and McIntosh (1961), high hemicellulose content in chemical pulp fibres is favourable to the extensibility and strength, while Helmerius et al. (2010) have not observed any decrease in the elongation of paper even after removal of $60 \%$ of the xylan from birch pulp. Obermanns (1934) in his pioneering work has claimed that there is a certain optimum for hemicellulose content in respect to the strength of paper, which then depends on the origin of pulp. Henriksson et al. (2008) showed that the MFC films with high hemicellulose content had the highest tensile strength and strain, which was attributed to decreased porosity of such films. Hemicellulose removal has also been found to relate to hornification (loss of the swelling ability due to drying) of fibres (Oksanen et al. 1997). The extensibility of fibres is often related to their swelling ability (WRV) and the corresponding shrinkage potential of fibres. Hemicellulose-rich pulps have a higher swelling ability. However, hemicellulose removal by hot water extraction has been shown to increase the WRV of fibres and the elongation of paper (Saukkonen et al. 2011). The explanation may be that, in this case, the fibres were not hornified and dried after the hemicellulose removal. Removal of the hemicelluloses makes dried and rewetted fibres stiffer, which results in a reduced amount of fibre-fibre contact and lowers the density of dry paper (Spiegelberg 1966). At the same time, the tensile elastic recovery of alkaline-extracted birch fibres decreases with the removal of xylan, i.e. deformation of fibres tends to be more plastic and come from rearrangements of cellulose microfibrils (Spiegelberg 1966). Cottrall (1954) reported that the mannan is more effective in the strength improvement of pulp than xylan, which is explained by higher amount of available non-acetylated hydroxyl groups per unit of mannose.

However, when it comes to the question of how low or high content of hemicelluloses in fibres affects the extensibility of fibre, there is no straightforward answer. It is likely that the hemicelluloses do not directly influence the elongation of fibres themselves but favour the elongation of paper.

The influence of lignin content on the extensibility of fibres and paper is of concern with mechanical, chemomechanical, semichemical, and unbleached pulps. It was found that selective removal of lignin from wood fibres improved their elongation by around 20\%; notably this effect was obtained already when $25 \%$ of total lignin was removed from fibre (Zhang et al. 2013). Further delignification did not improve extensibility or the tensile strength of fibre. The effect of lignin removal might be associated with the rearrangement of the microfibrillar structure due to slippage of fibrils in fibres, besides the fact that lignin is actually a stiff and non-extensible polymer in dry state (Zhang et al. 2013). High lignin content also negatively affects the extensibility of paper; mechanical pulps have much lower elongation than chemical pulps (Hatton 1997). In mechanical pulps, lignin is still present in the cell wall of fibres, which also negatively affects the fibre-fibre bonding and flexibility of fibres, and as a consequence the density 
of fibre network. Unbleached chemical pulp fibres (both kraft and sulphite) are capable of forming fibre-fibre bonds as strong as bleached ones (Mayhood et al. 1962; McIntosh 1963; Fischer et al. 2012). Hartler and Mohlin (1975) claimed that the maximum bond shear strength between fibres occurred at lignin contents of $7 \%$ for unbleached kraft and 10 to $12 \%$ for unbleached sulphite. In the practice of sulphite cooking, it is sometimes observed that lignin may adsorb on the surface of fibres restricting the formation of effective bonds, and thus negatively affect extensibility (Paasonen and Koivisto 1970; Koljonen et al. 2004). Additionally, the area of bonding and the strength of bonds should be considered. Stiffer fibres tend to make bonds with a smaller area; however, when fibres are pressed together with sufficient force, the specific strength bond can be as high as the more flexible bleached fibre.

Lignin as well as the hemicelluloses and the amorphous part of the cellulose soften under the action of elevated temperature, and the temperature-induced component of extensibility is thus higher in lignin- and hemicellulose-rich pulps (Waterhouse 1985; Salmén 1979; Back and Salmén 1989). However, water is not an effective plasticizer for the kraft lignin and thus it is not softened by moisture alone. The lowest softening temperature of moist lignin is around $80{ }^{\circ} \mathrm{C}$, and it is reached at around $10 \%$ moisture content (Scallan 1974; Kunnari et al. 2007). To summarise, fibres with high lignin content are not likely to demonstrate high extensibility.

\section{Fibre length and fibre strength}

The length, microfibrillar angle, strength, and coarseness of individual papermaking fibres have been found to correlate with each other (Karenlampi and Suurhamari 1997). Therefore, these properties may affect extensibility of fibres and the extensibility of paper prepared from such fibres. The effect of the fibre strength on extensibility is much greater than the effect of fibre length (Kärenlampi and Yu 1997). These effects are illustrated in Fig. 9.

The higher the strength of the fibres, the higher its extensibility paper (Fig. 9 "A"). In this case the fibre strength was varied by weakening them by acid vapour treatment. Therefore, this assumption is valid only in the case of strong bonds between weak fibres. In the case of strong fibres, the strength and extensibility of paper would be determined by the strength of the fibre bonds. The influence of fibre length on the extensibility of paper in zero-span test (Fig. 9 "B") is almost negligible; the strain at break is increased only slightly. But, on the other hand, there is a considerable increase in the work needed to complete the fracture after the stress maximum. The influence of the fibre length on the extensibility of paper is likely to be more evident in the case of wet paper or weakly bonded fibres. The simulation study of Kulachenko and Uesaka (2012) showed that increase in the fibre length from 1.5 to approximately $3 \mathrm{~mm}$ doubled the elongation to breakage of the paper.

\section{Mechanical treatments and fibre morphology}

Fibres experience mechanical stresses and deformations in many operations on their way from the wood yard to the paper machine (Rauvanto 2010). These stresses may cause both positive and negative changes in fibre morphology, in relation to fibre extensibility (Ljungqvist et al. 2003). High-consistency (ca. 30\% dry solids content) mechanical treatments are known to create deformations in fibres. The deformations are local structural changes in the fibre wall and MFA. Visually, they appear in the form of dislocations, microcompressions, curls, twists, folds, kinks, etc. 

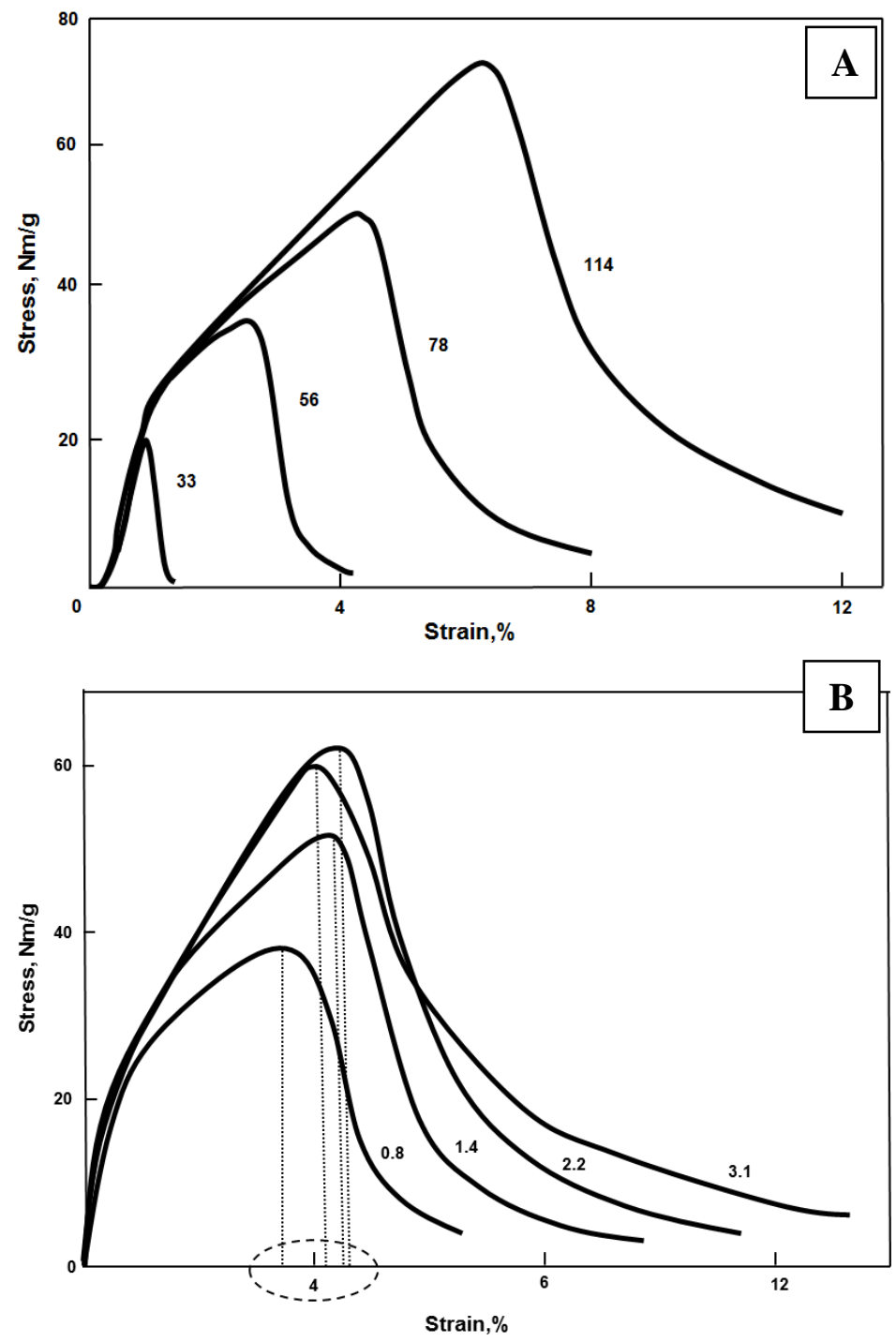

Fig. 9. The influence of the fibre strength of spruce pulp (measured as zero-span tensile strength of paper, number stands for $\mathrm{Nm} / \mathrm{g}$ ) on the elongation of paper $(\mathrm{A})$ and the influence of the fibre length (number stands for the length in $\mathrm{mm}$ ) of spruce fibres on its elongation (B) (redrawn from the data of Kärenlampi and Yu 1997).

Microcompressions (telescoping axial buckling along the fiber axis), curls, and dislocations (irregularities in fibres origination from the jams or bends of fibre) contribute to the improvement of extensibility of fibres. They have a definite effect on the elongation of wet paper (Barbe et al. 1984) and they may increase the elongation of dry paper (but they reduce the tensile stiffness and elastic modulus). These deformations occur due to the action of compressive forces oriented in the axial direction of the fibre (Dumbleton 1972; Page et al. 1976; Page and Seth 1980b; Barbe et al. 1984; Mohlin et al. 1996; Gurnagul and Seth 1997; Joutsimo et al. 2005; Seth 2005; Kunnari et al. 2007). Kinks in fibres have not been observed to have any effect on extensibility of paper. However, they impair the tensile strength (Kibblewhite and Kerr 1980). The influence of different fibre deformations on the shape of stress-strain curve of fibre is illustrated in Fig. 10. 

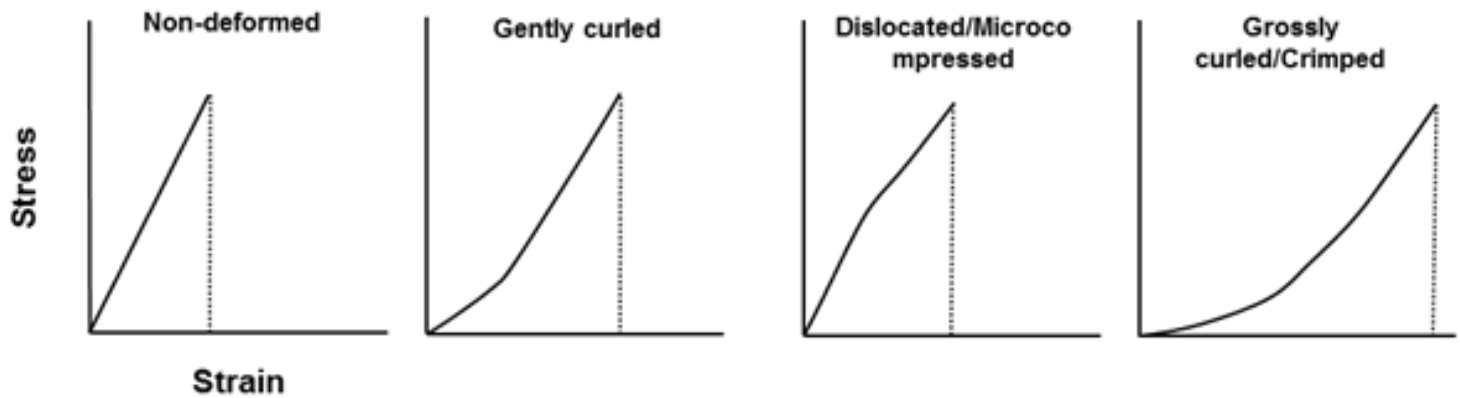

Fig. 10. The stress-strain curves of the fibres with different deformation types (redrawn from the data of Page and Seth 1980)

Page and Seth (1980) have stated that gently curled fibres impart high extensibility to paper, maintaining the stiffness. The influence of fibre deformations on the extensibility of paper have been discussed in more detail elsewhere (Mohlin et al. 1996; Seth 2005; Zeng et al. 2012, 2013).

High consistency treatments are known to cause deformations that reduce the straightness and increase the extensibility of single fibres. However, extensible fibres do not necessarily result in improved extensibility of paper, and in addition they usually lead to a decreased elastic modulus and tensile strength of paper (Seth 2005). Low consistency refining straightens fibres and does not increase fibre level extensibility, but induces fibre swelling that increases paper shrinkage, which can have a considerable effect on the extensibility of paper, as shown later.

Combined high- and low-consistency mechanical treatment is a well-known method for improving the extensibility of paper. It unites creation of fibre deformations in the high consistency treatment with the straightening of curled fibres in lowconsistency refining that improves the stress transfer ability of the fibre network and promotes bonding between fibres. This combination provides high extensibility to paper, while at the same time maintaining the dewatering resistance of the furnish at low level (Arlov and Hauan 1965; Jackson 1967; Ljungqvist et al. 2005; Sjöberg and Höglund 2007; Pettersson et al. 2007; Gurnagul et al. 2009).

Axial microcompressions can be observed in fibres that still appear to be straight (Fig. 11). Changes in fibre morphology are caused by deformations occurring to some extent in all pulp and papermaking processes in which shear and compressive forces are involved (Forgacs and Mason 1958, 1959; Seth 2005; Salmén and Hornatowska 2014). Industrially produced pulp generally gives paper with higher elongation than laboratorycooked pulp, due to the higher amount of deformations in the industrially made pulp (Ljungqvist et al. 2003; Duker et al. 2007).

\section{Comparison of different natural and synthetic fibres}

Based on the previous discussion, it is clear that chemical and structural properties of fibres have a definite effect on the rupture elongation of the fibres. In natural fibres, the content of cellulose, hemicelluloses, and lignin varies, but what is even more important is that they have a different cell wall structure and dimensions, which may have a detrimental influence on extensibility of fibres. 
Synthetic fibres are generally more homogeneous in terms of morphology, but their chemical composition and mechanical properties can vary over a wide range in accordance with the origin of such fibres. The mechanical, structural, and chemical properties of selected natural and synthetic fibres are shown in Table 1.

Table 1. Mechanical, Structural, and Chemical Properties of Selected Natural and Artificial Fibres

\begin{tabular}{|c|c|c|c|c|c|c|c|c|}
\hline \multicolumn{3}{|c|}{ Morphology } & \multicolumn{2}{|c|}{ Mechanical properties } & \multicolumn{3}{|c|}{ Chemical composition } & \multirow[b]{2}{*}{ Ref. } \\
\hline Origin & $\underset{\circ}{\text { MFA, }}$ & $\begin{array}{l}\text { Length, } \\
\mathrm{mm}\end{array}$ & $\begin{array}{c}\text { Elongation, } \\
\%\end{array}$ & $\begin{array}{c}\text { Elastic } \\
\text { Modulus, } \\
\text { GPa }\end{array}$ & $\begin{array}{c}\text { Cellulose, } \\
\%\end{array}$ & $\begin{array}{c}\text { Hemicelluloses, } \\
\%\end{array}$ & $\underset{\%}{\text { Lignin, }}$ & \\
\hline $\begin{array}{c}\text { Pinus } \\
\text { sylvestris }\end{array}$ & $5-20$ & $3-3.5$ & $1.5-3.5$ & 40 & \multirow{4}{*}{\multicolumn{3}{|c|}{$\begin{array}{l}\text { Varies significantly according to the } \\
\text { defibration and delignification method } \\
\text { and conditions }\end{array}$}} & 1,2 \\
\hline $\begin{array}{c}\text { Betula } \\
\text { pendula }\end{array}$ & $\begin{array}{c}10- \\
19\end{array}$ & $1-1.2$ & $2-5.5$ & - & & & & $\begin{array}{c}1,2,3 \\
16\end{array}$ \\
\hline $\begin{array}{l}\text { Juniperus } \\
\text { communis }\end{array}$ & $30-40$ & 0.83 & 5.4 & - & & & & $4,5,6$ \\
\hline $\begin{array}{c}\text { Eucalyptus } \\
\text { Grandis }\end{array}$ & $8-20$ & $0.8-1.1$ & $2-6$ & $4-11$ & & & & 17,18 \\
\hline Coir & $40-49$ & $20-150$ & $20-50$ & $4-6$ & 46 & 0.3 & 45 & $1,2,7,8$ \\
\hline Cotton & $25-35$ & $20-40$ & $7.0-8.0$ & $5.5-12.6$ & 83 & 6 & $\sim 1$ & 1,9 \\
\hline Flax & $8-11$ & $20-50$ & $2.7-3.2$ & $20-30$ & 64 & 12 & 12 & $1,11,10$ \\
\hline Viscose & - & Varies & $8-13$ & 11 & $98-100$ & $0.1-4$ & Traces & 2,12 \\
\hline $\begin{array}{l}\text { Micro- } \\
\text { fibrillated } \\
\text { cellulose }\end{array}$ & - & $\begin{array}{l}\text { Varies, in } \\
\mathrm{nm} \text { and } \\
\mu \mathrm{m} \text { scale }\end{array}$ & $6.7-10$ & $90-150$ & 99.9 & Traces & Traces & 13 \\
\hline Spandex & - & Varies & up to 800 & 0.025 & & lyurethane-based & & 14,15 \\
\hline Wool & - & $25-400$ & $25-50 \%$ & 3.4 & & Protein-based & & 9 \\
\hline $\begin{array}{l}\text { 1-Peel } 1995 \\
\text { Satyanaray } \\
\text { Haudek anc } \\
2010 ; 14-S i \\
2003\end{array}$ & $\begin{array}{l}\text { 2-Ble } \\
\text { la et } \\
\text { Jiti } 15 \\
\text { yha } 2\end{array}$ & $\begin{array}{l}\text { i and Ga } \\
2009 ; 6- \\
; 10-\text { Bos } \\
; \text {; } 15-\text { Sur }\end{array}$ & $\begin{array}{l}\text { an 1999; 3- } \\
\text { yanarayan } \\
\text { 04; 11-Bou } \\
\text { al. 16-Spie }\end{array}$ & $\begin{array}{l}\text { eura et al } \\
2010 ; 7-\Lambda \\
\text { naud et a } \\
\text { yelberg } 19\end{array}$ & $\begin{array}{l}008 ; 4-H a ̈ \\
\text { tinschitz } \epsilon \\
013 ; 12-L \\
17-\text { Hein }\end{array}$ & $\begin{array}{l}\text { ninen et al. 2011; } \\
\text { al. 2008; 8-Maha } \\
\text { iz et al. 1994; 13- } \\
\text { hd Lima 2012, 18 }\end{array}$ & $\begin{array}{l}5- \\
\text { o et al. } 2( \\
\text { Eichhorn } \\
\text { Downes }\end{array}$ & $\begin{array}{l}\text { o09; } 9- \\
\text { et al. } \\
\text { et al. }\end{array}$ \\
\hline
\end{tabular}

Some synthetic (spandex) and natural (coir) fibres have a notably high extensibility potential. These fibres, however, are not capable of creating a strong bonded network due to their limited ability to form hydrogen or covalent bonds. The differences in mechanical behaviour between natural and synthetic fibres are more evident when the stress-strain curves are compared (Fig. 12). 


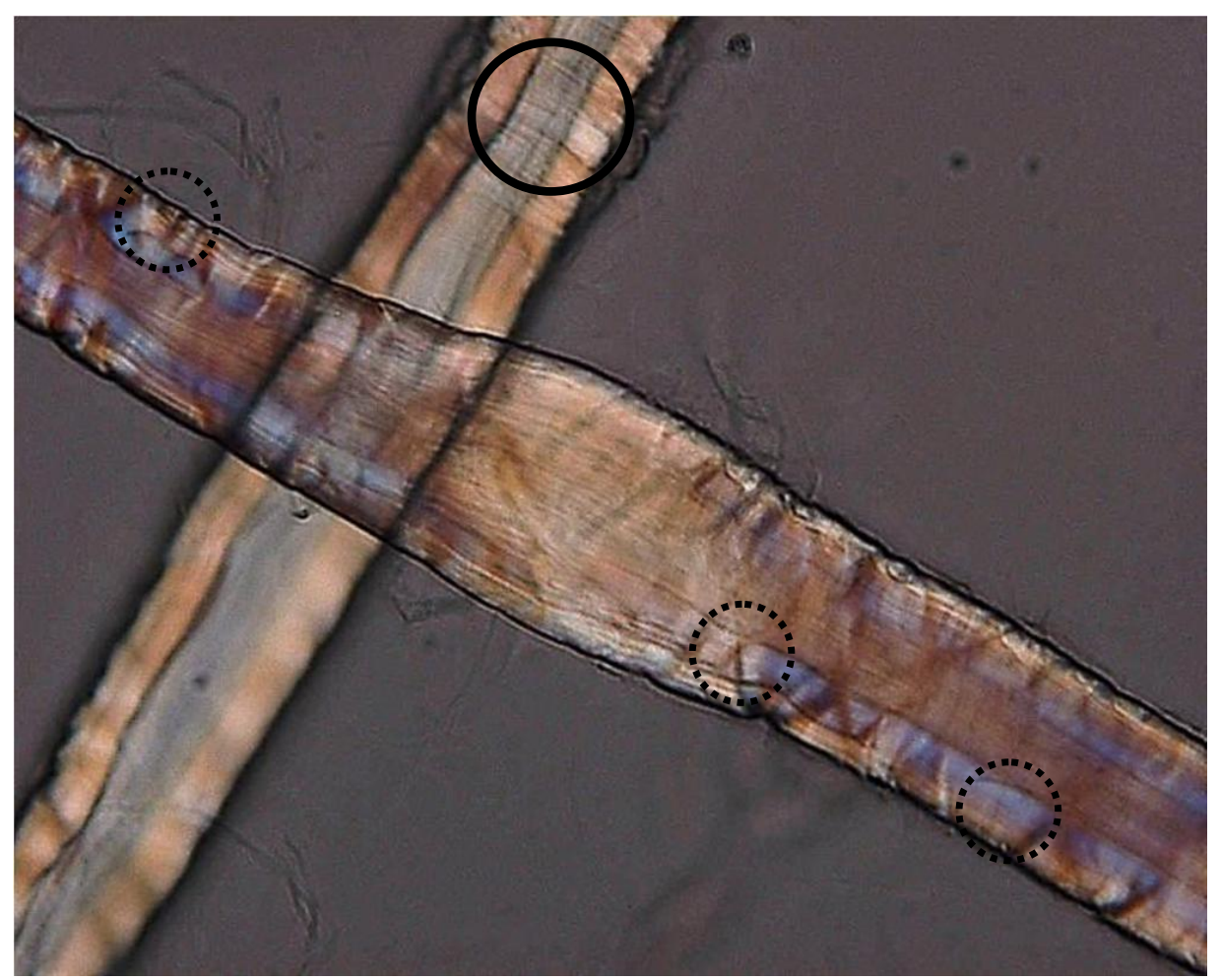

Fig. 11. Variations in the fibrillar orientation due to microcompressions (solid line circle) and dislocations (dashed line circle) in softwood latewood fibres after combined high and low consistency refining. Image taken with polarized light microscopy (courtesy of S. Heinemann, VTT)

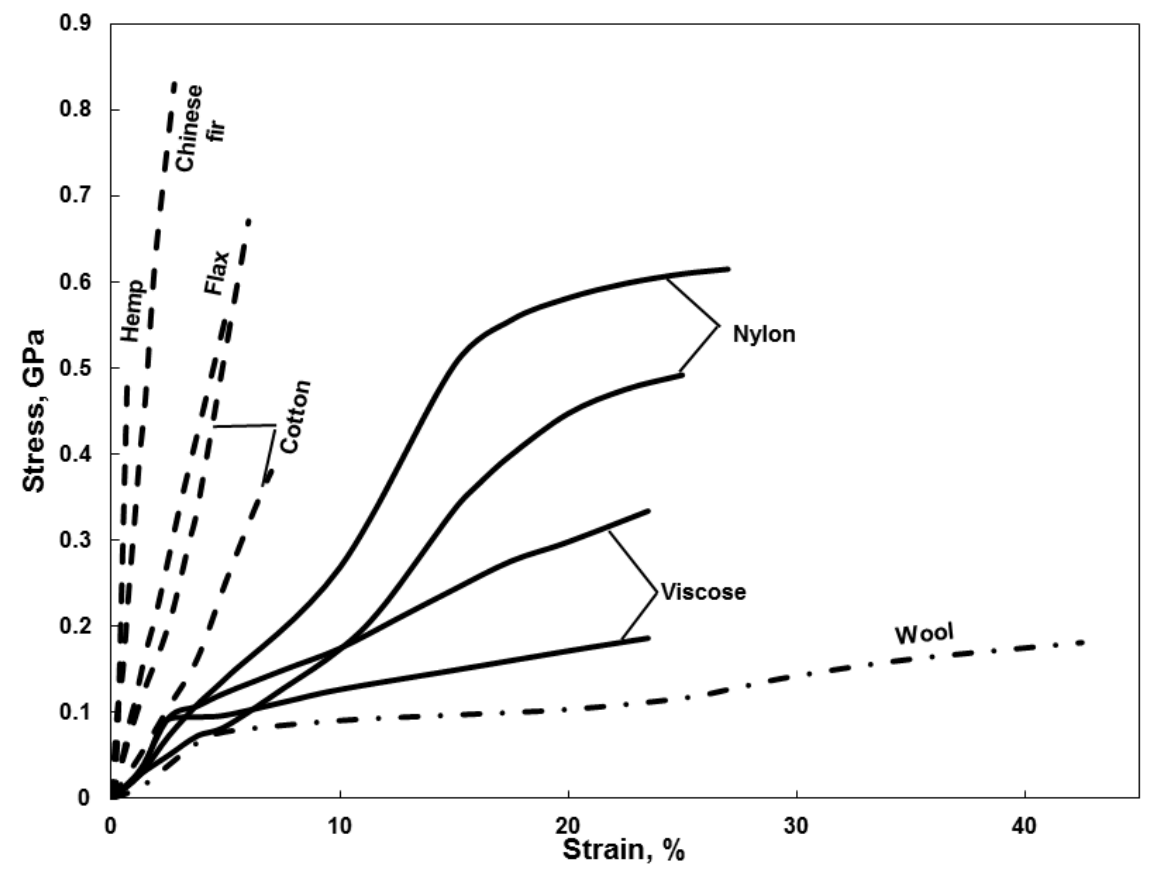

Fig. 12. The stress strain curves of different natural and synthetic fibres (redrawn from the data of Haudek and Viti (1978)) 
Figure 12 shows that the stiff and strong fibres seem to have low elongation, and natural fibres are obviously less stretchable than synthetic ones. However, viscose fibres, which are made of basically the same material as natural fibres, have much greater extensibility, which is likely due to lower crystallinity and less-pronounced microfibrillar structure (Dlugosz and Michie 1960). This emphasizes the importance of the internal structure of fibres over other factors affecting extensibility of fibres.

It is clear that extensible fibres are not the only prerequisite for the formation of strong and extensible paper; bonding and structure are equally, if not more important than extensibility of single fibres.

\section{Improvement of Fibre-Fibre Interaction towards Increased Extensibility of Paper}

In order to be able to form an extensible paper, fibres should have sufficient bonding and load-bearing activity to evenly distribute the load within the paper sheet. The effectiveness of the interfibre bonding can be improved by establishing more and/or stronger molecular bonds and by modifying the viscoelastic nature of the adhesive joints (Zhao and Kwon 2011). Such effects can be obtained either by means of chemical modification of the fibres, or by the addition of various compounds (strength agents) to the paper furnish. Both approaches are discussed in below.

\section{Chemical modifications on the fibre level}

Generally speaking, improvement of the extensibility via chemical modification of fibres comes through decreased crystallinity of cellulose and the secondary effects of increased swelling, drying shrinkage, improved bonding, improved compliance of bonds, etc., which are difficult to differentiate. In order to yield a paper with high extensibility, the fibres can be modified in a number of ways, including: grafting with various polymers, etherification, esterification, physicochemical adsorption of polyelectrolytes, blending with polymers, introduction of functional groups, etc. Some of these treatments (e.g. etherification, esterification) are quite tedious and require a waterless medium so as to perform the chemical reaction, which limits their usability in conventional pulp and papermaking processes.

Grafting (chemical or physical coupling of polymers on the surface of cellulose) of softwood fibres with methyl acrylate has been found to improve elongation of paper from $1.1 \%$ to $5.9 \%$-points. This treatment also provides better water absorbency, and improvements in wet and dry strength and extensibility are expected to come via increased swelling of fibres and drying shrinkage of paper. Grafting of cellulosic fibres with methyl acrylate increased the amount and strength of effective bonds in the paper (perhaps via increased interdiffusion), which yielded better utilization of extensibility potential of the paper (Rezai and Warner 1997a,b). Grafting copolymerization of hydroxypropylmethylcellulose (HPMC) with ethylacrylate (EA) can significantly improve extensibility of paper-like material made from HPMC. Elongation of paper increases with the increasing percentage of EA grafted onto HPMC. The highest value of elongation, 40\%-points, has been recorded when 100\% of HPMC was grafted; however, at the same time tensile strength decreased significantly (from $80 \mathrm{MPa}$ to $20 \mathrm{MPa}$ ). The effect is likely to come via the changes in the bonding, caused by modification of the interface (Wang et al. 2007). Paper can also be grafted with acrylamide; such treatment has been reported to increase extensibility by $150 \%$ in comparison to untreated pulp (Neimo et al. 1967). 
Hydroxyethylation and hydroxypropylation are beneficial for the strength and elongation of paper. The improvements in extensibility have been attributed to the improved fibre bonding, and increased drying shrinkage. Etherification of cellulose to a relatively low degree of substitution (DS) $(<1)$ increases flexibility and swelling of fibres, which provides additional interfibre contacts with a higher contact area, and thus increases the drying shrinkage and improves bonding (Didwania 1968; Vuoti et al. 2013).

Hexanoation of cellulose to a relatively high DS of 1.7 allows thermoformable and water resilient cellulose materials to be obtained, which after being compressed into sheets show strain at break values of around 30\%-points. The structure of the hexanoated cellulose sheet was found to represent a continuous cellulose ester matrix reinforced with the unmodified cellulose I. High extensibility values of such structures are likely to originate from the properties continuous matrix formed by cellulose ester upon hot pressing (Matsumura et al. 2000).

The selective oxidation of the C2-C3 hydroxyls of cellulose by periodate oxidation with sodium periodate to dialdehyde cellulose and further reduction of aldehyde groups with sodium borohydride to form dialcohol cellulose has been found to be effective in the improvement of extensibility of fibres and paper. The stretch of single fibres in zero-span test increased from $60 \mu \mathrm{m}$ to $180 \mu \mathrm{m}$. The increase in the extensibility of paper made from such fibres was more pronounced; the elongation of paper was increased from $4 \%$ (non-modified) to 23\%-points (oxidised and crosslinked). This indicates that the changes occur not only in the fibre structure but also in the character of interfibre bonding. The changes in the elongation of individual fibres are associated with the different core-shell structure of fibres, which increases the mobility and flexibility of the nanofibrils in the fibre wall (Larsson et al. 2014a). The same approach was applied for preparation of the films from surface-oxidized cellulose nanofibrils representing the crystalline core structure "wrapped" in the dialcohol cellulose; such films have extensibility of around 37\%-points (measured at 90\% RH) (Larsson et al. 2014b). Wu et al. (2014) have observed that oxidation causes formation of the coil-like curved structures in fibrils and decreases thickness of the fibrils.

Partial dissolution of the cellulose fibres can be used to produce extensible allcellulose composites with superior to original material strength, strain, and stiffness. Treatment of filter paper with $(\mathrm{LiCl}) / \mathrm{DMAc}$ increased the strain at break by $50 \%$ and decreased crystallinity of cellulose from $c a .80$ to 20\% (Nishino and Arimoto 2007). Swelling of the bacterial cellulose in $8 \%(\mathrm{LiCl}) / \mathrm{DMAc}$ for 60 minutes drastically changed the deformability properties of the resulting material; the strain at break was increased from 3.5\%-points to around 30\%-points. Such a shift was attributed to loss of fibrous structure of bacterial cellulose and decreased crystallinity, at the same time the pattern of hydrogen bonding is expected to change to a much more extensive one (Soykeabkaew et al. 2009).

In general, there is no clear understanding of which chemical modifications of fibres are especially effective in the improvement of the extensibility of paper, since the improvement often comes through the secondary effects of increasing strainability of fibers, swelling/drying shrinkage, improved bonding, and bond compliance.

\section{Different additives for improving the extensibility}

The specific strength of the bonds relies on the stereotopochemistry of the fibres and the type of binder present in the paper, if any (Akagane et al. 1979). In additive-free paper, the interactions between fibres are mainly assumed to be due to the hydrogen bonding and adhesion formed by the van der Waals forces (Stratton and Colson 1993). 
Also other mechanisms such as interdiffusion, mechanical interlocking, and Coulomb bonding cannot be excluded (Lindström et al. 2005; Hirn and Schennach 2014). A high degree of interfibre bonding allows distribution of tensile stresses in a more uniform way, utilizing the straining potential of the fibres in the paper more efficiently. Interfibre interactions during the distribution of the shrinkage stresses during drying also affect the fibre structure in the web. Stronger interfibre interactions in the wet state make it possible to transmit higher forces in wet paper, to modify the fibres, and to increase the shrinkage potential of the fibre network.

Introduction of various additives to the furnish or to the already formed paper is commonly used to enhance the dry and wet strength of paper as well as to provide certain functional properties. This approach dates back to the $19^{\text {th }}$ century, when paper was sized with a mixture of caustic, wax, turpentine, and fat so as to enhance stretchability (Nonnenmacher 1898).

Pelton (2004) in his excellent review provided interesting hypotheses regarding how polymeric compounds affect the fibre-fibre bonding. Apart from the general hypothesis that additives improve adhesion, he has considered three other possibilities. The first possibility is the lubrication - the presence of slippery surface polymer layer allow fibre-fibre slippage in drying, and thus reducing the built stress of the fibre network and possibly increasing drying shrinkage without the introduction of microcompressions to fibres. The second possibility is the viscous dissipation in which a polymer layer can form stretchable domains between the fibres; in this case significant energy needs to be brought in before fibres would separate from each other. This was found to be the case for the latex-impregnated paper and thick polymer multilayer systems; polymer monolayers are still likely to have brittle behaviour in this case. The third mechanism is the crack stopping, which is the inclusion of small stretchable domains between brittle ones (fibres in this case); this mechanism stops cracks from propagating. Thus, in order to increase extensibility one should consider whether the added polymer is promoting deformability of the fibre-fibre joints, and not only the adhesion itself. Several methods known to improve extensibility of paper using different additives are summarized in below.

Fines are readily available at the paper mill and are known to improve paper strength; the addition of fines increases RBA (relative bonded area) and drying shrinkage. The simultaneous addition of starch and kraft fines is especially beneficial for tensile strength improvement, and thus for extensibility, but also for drying shrinkage (Retulainen et al. 1993; Taipale et al. 2010). Films made from nanofibrillated cellulose (NFC, and the same applies to MFC-microfibrillated cellulose), have higher extensibility than paper made from chemical pulp fibres. MFC can be added to the paper furnish for the improvement of the strength and extensibility in a same way as fines (Klemm et al. 2011). The addition of $10 \%$ MFC to the bleached hardwood pulp increases the strain at break of the paper by 5\%-points, for the sheets dried under restraint. MFC increases RBA as fines do, but due to the higher specific surface area, MFC is even more effective in binding and modifying the stress distribution and in increasing drying shrinkage (Madani et al. 2011; Manninen et al. 2011). Addition of carboxymethyl cellulose (CMC) to unbeaten softwood kraft pulp may, in addition to the strength, also improves the elongation of the paper. For instance the addition of $7.3 \mathrm{mg} / \mathrm{g}$ of CMC (FinnFix WRH) has raised the strain at break of paper from 3.6\% to 5.8\% (Laine et al. 2002). Blending of cellulose fibres with poly (3-hydroxybutyrate-co-3-hydroxyvalerate)(PHBV) results in plastic-like materials with improved elongation. The addition of $40 \%$ of PHBV was found to improve the strain at break value from 4 to 5.2\%-points (Hameed et al. 2011). 
Starch is a well-known dry strength additive for the papermakers and its addition either to wet end or by surface sizing positively affects not only strength but also extensibility of paper. Lindström et al. 1985 claimed that wet end addition of cationic starch (4.2\% to fibres) improves extensibility of both filled (from $1.2 \%$ to $2.1 \%$-points) and unfilled (from $2.1 \%$ to $3.2 \%$ ) paper by improving sheet consolidation (bonded area) increasing specific bond strength and evens the stress concentration in paper (Lindström et al. 2005). The surface addition of starch also improves extensibility by $c a$. $1 \%$ for restrained dried paper and by $c a .4 \%$ for unrestrained dried paper; in the latter case the effect comes via increased shrinkage of paper (Lipponen et al. 2005).

Surface carboxymethylation of pulp may also be applied for the improvement of extensibility (Duker et al. 2007). The surface sizing of paper with methylcellulose has improved extensibility of base paper by $23 \%$ without deterioration in stiffness (Akim and Telysheva 1991). Recently, coating of paper with sodium caseinate was found to be effective in the improvement of extensibility; application of $5 \mathrm{~g} / \mathrm{m}^{2}$ caseinate coating on paper improved extensibility by approx. 2\%-points (Khwaldia et al. 2014). Spray addition of gelatine to the surface of wet paper can increase extensibility up to 8\%-points; the effect comes from the enhanced bonding caused by gelatine adsorbed on the surface of fibres and increased drying shrinkage of paper (Khakalo et al. 2014). In general, surface addition of the extensible material on the surface of paper, even in relatively small amounts, improves overall extensibility, because surface layers were found to be in charge of failure initiation in paper (Stockmann 1974). Thus by strengthening and increasing of extensibility of only the surface layer of paper one might postpone fracturing and thus improve overall extensibility.

The formation of polyelectrolyte multilayers from polyacrylic acid polyallylamine hydrochloride on the surface of fibres can significantly improve the tensile strength and extensibility of paper (from 4 to 8\%-points) (Gustafsson 2012). Polyethylene imine/NFC and polyallylamine hydrochloride/hyaluronic acid multilayer systems were also found to be effective in the improvement of extensibility (Marais et al. 2014). By introduction of the several consequent layers of deformable polymers on the cellulose, it is possible to modify the viscoelastic nature of the fibre joints and thus fibre bonding. This concept was previously verified with materials other than cellulose (Ankerfors et al. 2014).

\section{Fibre-based composites}

Due to their relatively high strength and stiffness, natural fibres have been used for decades for preparation of composite materials. Even small ( 0.5 to $10 \%$ by weight) amounts of fibrous materials can increase the strength and reduce the elongation of a composite. With an increasing amount of fibres in composites there is a certain point when the fibres are contacting each other and a kind of percolation threshold is reached. For a papermaking approach, the situation is the inverse. The target is to increase the elongation of fibre network with as small an amount of added polymeric material as possible so that the added amount is applicable in a papermaking process. There are two principal ways to introduce polymers to the paper: wet-end addition and impregnation of pre-formed fibre network. In the first case the effectiveness of the treatment is bordered by the limited adhesion of polymer (usually hydrophobic) to fibres in the aqueous medium, interference with the formation of hydrogen bonds between fibres, and by the retention of polymer upon dewatering. When the polymer is added to an already formed fibre network, the low extensibility of the network will limit the extensibility of the composite, but with increasing amounts of polymer, composites with higher extensibilities can be obtained. 
The addition of natural and synthetic latexes and resins can be used for the improvement of the elongation and strength of the paper. The addition of styrenebutadiene latex in the amount of $30 \mathrm{mg} / \mathrm{g}$ to kraft pulp has improved the elongation of paper from 1.8 to $4 \%$-points (Alince 1977). Addition of PLA latex dispersion in the amount of $20 \%$ to paper is capable of improving the elongation by 5 to $10 \%$-points, and such paper has also demonstrated convertibility in the 3D-forming process (Svensson et al. 2013).

Elastomeric polymers added in the amount of 20 to $40 \%$ to a fibre network can improve the extensibility of such material by up to 30 to $40 \%$-points (Waterhouse 1976). By coating paperboard with polyhydroxybutyrate, it is possible to obtain a material with high strain at break values. Materials made of $80 \%$ pulp and $20 \%$ PHB have elongation at break around 36\% (Cyras et al. 2009). The changes in the stress-strain behaviour of the cellulosic materials caused by addition of the thermoplastic polymers are shown in Fig. 13.

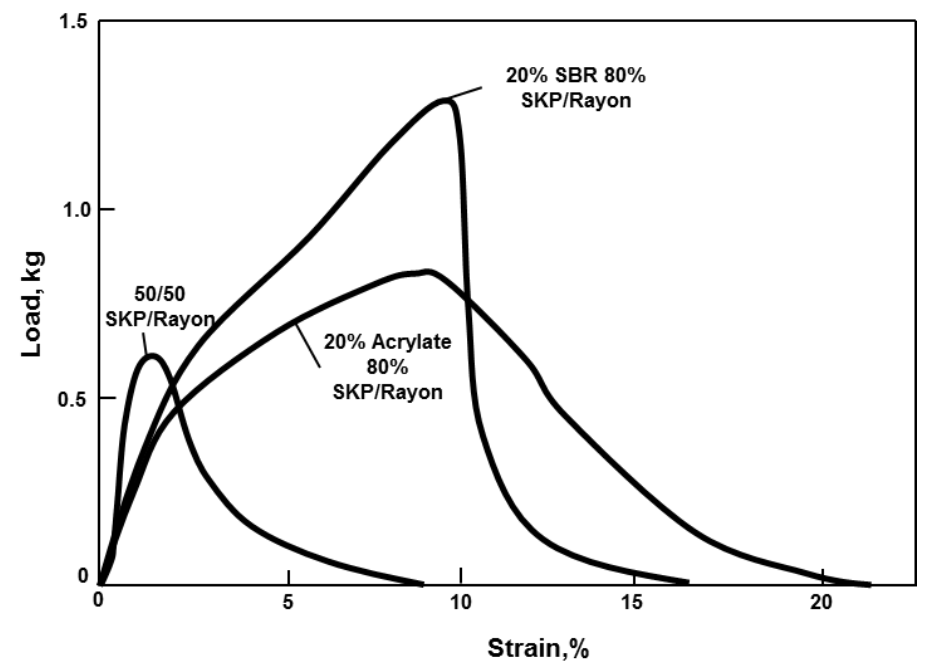

Fig. 13. The stress-strain curves of the non-woven type paper composed of $50 \%$ softwood kraft pulp (SKP) and $50 \%$ rayon impregnated with $20 \%$ of acrylate and $20 \%$ styrene-butadiene resin (SBR) emulsions (redrawn from the data of Fredricks 1971)

It is clear that the addition of polymers considerably improves elongation of the non-woven type of fibre network. It was found that the addition of polymers changes the character of the fibre bonding in such a way that the fracture of fibre network is caused by fibre failure; i.e. acrylate and SBR addition provides strong polymer-fibre and polymer-polymer bonds (Heyse et al. 1960). In addition to the elongation, also the work needed to complete the fracture after reaching the maximum tensile strength value is often increased. Another interesting class of polymers that may improve the extensibility of cellulosic materials is polyethylene/polypropylene carbonates (Xing et al. 2013). For instance, the blend composed of $90 \%$ of polypropylene carbonate with $10 \%$ of cellulose nanowhiskers has an elongation of around 950\%-points (Wang et al. 2013). However, the effect of the polypropylene carbonate should be still studied at much lower addition levels.

Despite the evident advantages and relative simplicity, the addition of thermoplastic polymers can introduce some unwanted features into the production of paper and its mechanical properties. Conventionally, thermoplastic polymers have a poor compatibility with the cellulosic fibres, and thus require an additional thermal treatment 
(curing) in order to amalgamate the polymer within the fibre matrix. In some cases when the film-forming temperature of latex is low, thermal treatment is not needed. Polymer melts and fills the free spaces between the fibres and forms fibre-polymer and polymerpolymer bonds, allowing a larger area for molecular contact between fibres, and thus improving stress distribution within fibre network (Anonymous 1954; Alince 1977, 1979, 1991, 1999). The filling of the free space between the fibres with the polymers reduces drying shrinkage. An addition of 5\% of polymer dispersion reduces shrinkage by $50 \%$ (de Ruvo 1979). The addition of the highly elastomeric polymers such as Nylon, Dacron, or Spandex can reduce the plastic deformation component of the stress-strain curve and increase the overall strain recovery of paper (Waterhouse 1976).

Utilization of various additives is a straightforward method for improving the extensibility of paper, but they will compromise the paper manufacturing process and some paper properties. The amount of the added substances generally is proportional to the increase in extensibility, which limits the operational window for this method. The efficiency could be improved if a method of depositing the additives precisely at the place of fibre-fibre contacts could be found. A reasonable percentage of addition can be set as $10 \%$ of the fibres, in order that the production process and environment are not severely affected by the change in furnish properties (drainage, sticking to roll surfaces, steam consumption, etc.).

\section{The Structural Aspects of the Fibre Network Affecting Extensibility of Paper} Drying shrinkage

The extensibility of paper is to a significant extent dependent on the drying method. Conventionally, the paper web is dried under tension on the heated metal cylinders of the paper machine. Due to the tension in MD, wet paper experiences straining deformations, which are further "frozen" in the paper structure during drying. However, the role of web tension required for smooth runnability is reduced with increasing basis weight and decreasing machine speed. It is also possible to dry paper without restraint or with only a minor restraint, thus allowing drying shrinkage and preventing the formation of built-in strains in the paper. Impingement, IR (infrared), and air float (e.g. Fläkt) drying can be used in combination with cylinder drying for such purpose. Float drying is most efficient for the development of drying shrinkage when applied to paper with a solids content of between 60 and 85\% (Flyate 1988; Steenberg 2006).

It is well known that the higher the drying shrinkage, the higher the elongation of the paper (Fujiwara 1956; Page 1971; Htun and de Ruvo 1981; Htun et al. 1989; Waller and Singhal 1999; Wahlström et al. 1999). Wet draw of the paper web and subsequent restrained drying reduces the extensibility of paper. High extensibility of unrestrained dried paper is attributed to the "release of shrinkage" in fibres during straining of the paper.

The mechanism of drying shrinkage of paper is believed to be the following: fibres shrink laterally, which in turn causes axial shrinkage of the single fibres bonded to it, and eventually shrinkage of the whole web by means of interfibre crossings. Fibres shrink anisotropically; fibres can shrink up to $30 \%$ in a transverse direction, though the axial shrinkage is limited to 1 to $3 \%$. Such a low value of longitudinal shrinkage can be attributed to the low microfibrillar angle and stiffness of crystalline microfibrils, which prevents lengthwise shrinkage (Page and Tydeman 1966; Page 1969, 1971). Drying shrinkage also causes axial microcompressions in fibres (Page and Tydeman 1966). The extent of the drying shrinkage of paper in unrestrained drying varies greatly, and can be between 3 and 10\%. This value is governed by lateral shrinkage of the single fibres, 
which depends on the initial swelling of fibres, the area, number and adhesion in fibre contacts that transmit the shrinkage forces from one fibre to another, and the axial stiffness of the fibres, which resists axial shrinkage. Swelling and shrinkage of fibres can be easily controlled by the extent of refining. The lower the freeness value, the higher the swelling of fibres, which primarily depends on the extent and type of refining (Zeng et al. 2012, 2013).

Apart from refining, swelling of fibres is also dependent on electrolyte concentration in white water, the type of counter ion on the carboxylic group (swelling of fibres and strength of paper increase in a row of $\left.\mathrm{Al}^{3+}, \mathrm{H}^{+}, \mathrm{Mg}^{2+}, \mathrm{Ca}^{2+}, \mathrm{Li}^{+}, \mathrm{Na}^{+}\right), \mathrm{pH}$, and amount of carboxylic groups in pulp (Scallan and Grignon 1979; Scallan 1983). The surface charge of the cellulosic is very important for the deformability and strength of the fibre joints. The higher the surface charge, the higher will be the strength and deformability of fibre joints. However, at the same time critical strain of the fibre is reduced. It was suggested that the effect of surface charge comes via surface softening of the fibre, which is increasing molecular contact and promoting a better interdiffusion of polymers (Torgnysdotter and Wågberg 2003). The swelling induced to the fibre by transferring into the $\mathrm{Na}^{+}$ionized form improves extensibility of paper by around $0.5 \%$; however this effect is further amplified by the refining (Bäckström et al. 2009). Increase in swelling is usually accompanied by improvement in bond strength, and thus might positively affect the extensibility of paper.

The axial stiffness of fibres can be reduced by certain high-consistency treatments, which create dislocations and microcompressions. Axially flexible fibres create smaller resistance to sheet shrinkage than do stiff ones. Also, at similar fibre diameters, fibres with a thick cell wall tend to shrink less than thin-walled fibres (Page and Tydeman 1962). Other methods that can be used to increase shrinkage of paper include addition of fines and micro- and nanofibrillated cellulose (Lobben 1977, 1978; Sampson and Yamamoto 2011) and the addition of agar (Vishtal and Retulainen 2014).

Paper shrinks more in CD due to a lower restraint and a higher shrinkage potential due to fibre orientation. Moreover, MD tension creates a Poisson contraction in CD. Fibres in MD are also subjected to wet straining during manufacturing, which reduces the elongation of paper in this direction (Nanko and Wan 1995; Seth 2005). On modern paper machines, paper is stretched by 2 to $3 \%$ on its way from the forming to the drying section. However, historically these values were as high as 6 to 8\% (Halme 1967). The relation between the wet draw (extent of straining in a paper machine in MD), drying shrinkage, and strain at break of paper can be seen from Fig. 14.

Strain at break of paper is shown to have an almost linear dependence on the wet draw and drying shrinkage. At higher shrinkage, the relationship may become exponential. The dryness at which the drying restraint has been applied or the shrinkage has taken place may also play a role in the extensibility of paper (Htun and De Ruvo, 1981). However, Mäkelä (2009) has stated that strain at break of paper is only controlled by total drying strain and that the dryness level at which draw has taken place does not have much influence on it. However, recent results of Kouko et al. (2014) suggest that although the strain at break depends linearly on the draws, the dryness at which the draws take place have some effect. A draw performed at dryness over $80 \%$ is more harmful for the MD strain at break than a draw of same size performed immediately after wet pressing at dryness below $60 \%$ (Kouko et al. 2014). This difference might originate from the furnishes that were used (Hardwood pulp vs. LWC (lightweight coated)-furnish) and the testing procedures applied. The influence of the wet straining on the stress-strain properties of paper has also been studied in detail, for example by Schulz (1961). 


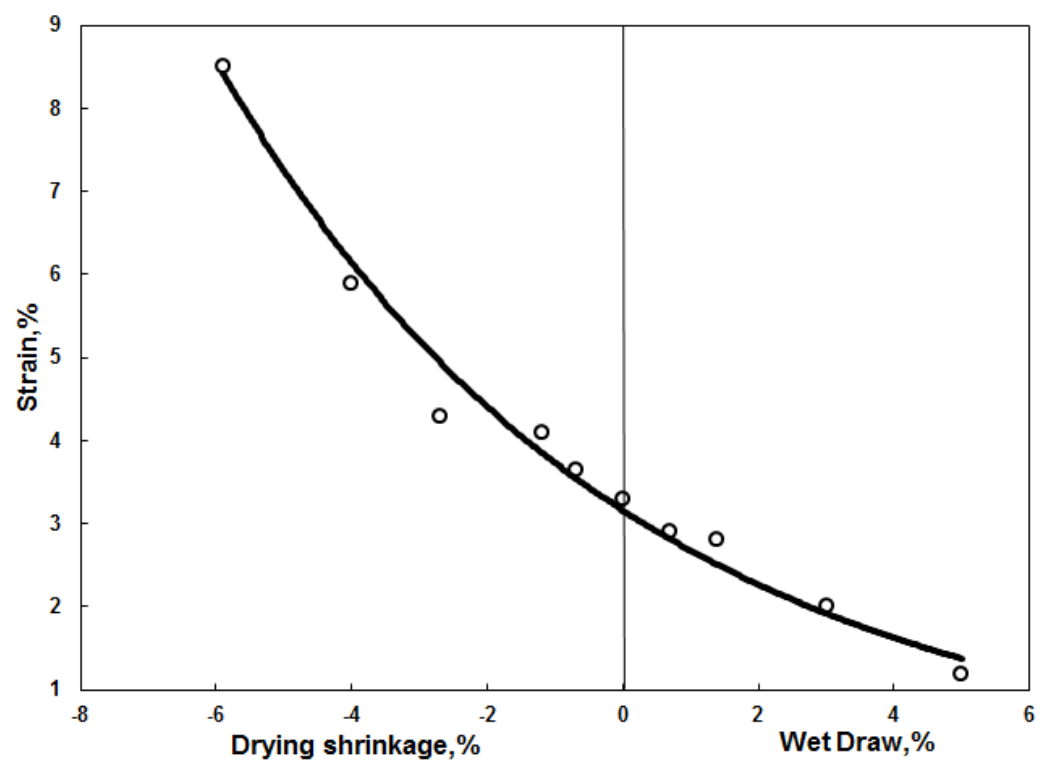

Fig. 14. The relation between the strain of paper and drying shrinkage and wet draw in a paper machine in MD (redrawn from the data of Silvy 1971)

Based on the findings just discussed, it is possible to conclude that unrestrained drying or low-restrained drying is a viable option for production of extensible paper products.

Modification of the fibre network by in-plane compression: compaction and creping

Paper can be compressed in-plane on a paper machine in order to improve extensibility. Compaction and creping are the best known methods of in-plane compression of the paper web.

Improvements in elongation obtained by in-plane compression have a linear correlation with a decrease in geometrical length and increase in the basis weight of the paper after treatment. Increase in extensibility is always accompanied by a decrease in tensile strength, and especially the elastic modulus of paper.

\section{Creping}

In creping, paper is attached to the drying cylinder (most often a Yankee cylinder), and dried until certain dryness (this varies based on the creping process, typically 70 to $85 \%$ ). Then it is released from the cylinder by means of a creping blade, which causes folding of the paper web, partial fibre-fibre bonds breakage, fibre rearrangements, and sheet buckling (Welsh 1965; Oliver 1980; Stitt 2002). Creping yields in highly-extensible papers with an elongation in range of 10 to 200\%, and it is mainly utilized in tissue products requiring a high softness of paper (Hollmark and Ampulski 2004). However, creped paper has a limited utilization in packaging applications due to the wrinkly surface, low stiffness, and significantly decreased tensile strength. It is mainly used for cushioning and decorative purposes (Hernandez and Selke et al. 2001; Welsh 1965). Straightening of the buckles in creped paper does not require much mechanical energy, and thus the stiffness and TEA of the creped paper is several folds lower than for compacted paper. As a result of creping, paper obtains a buckled structure with the length of each buckle around $1 \mathrm{~mm}$. However, no principal changes in the internal structure of paper can be found (Ramasubramanian 2011). The cross- 
sectional images of the creped and uncreped kraft paper, depicting the wrinkly appearance of creped paper, are shown in the Fig. 15.

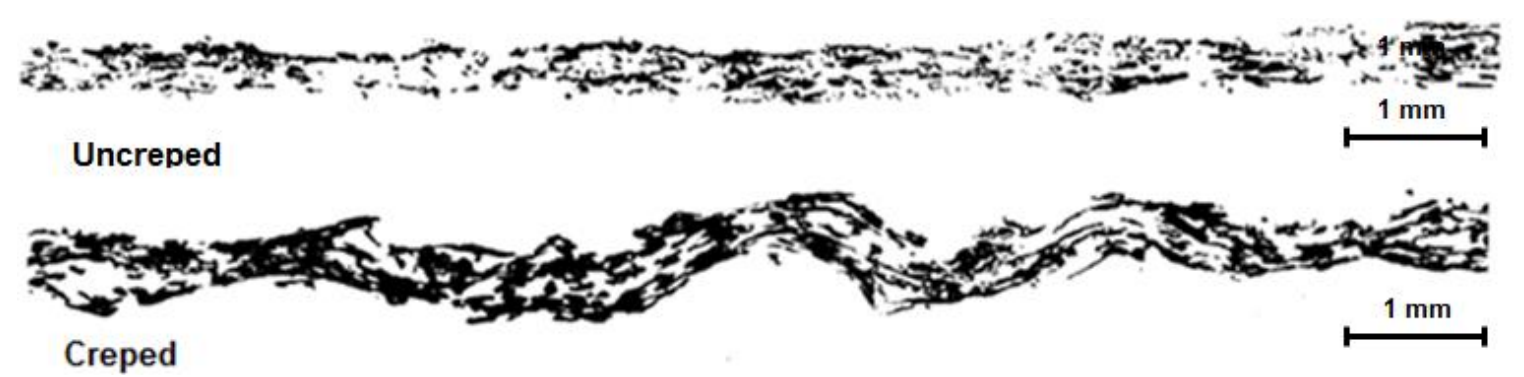

Fig. 15. The cross-sectional images of uncreped and creped paper (Welsh 1965)

The creping processes can be distinguished as having two main types: moist (wet) creping and dry creping. Moist creping (performed at 60 to $85 \%$ dry solids) provides a smaller decrease in tensile strength and stiffness; however, the increase in extensibility is lower in comparison with dry creping. This is explained by the ability of fibres to form hydrogen bonds after creping during the drying process. Among creping methods, dry creping (performed at 93 to 97\%) produces the greatest increase in elongation and the greatest decrease in strength and stiffness (Ramasubramanian 2001). The results of creping are mainly controlled by the percent crepe, the value that expresses the difference in speed between the Yankee cylinder and the reel. The higher the percent crepe, the higher is the extensibility of the resulting paper. Additional factors include crepe blade angle, temperature of cylinder and creping blade, chemical composition of pulp, application of adhesive, and adhesive release onto the Yankee cylinder (Boudreau and Germgård 2014, Boudreau and Barbier 2014).

\section{In-plane compaction of paper}

The compaction of paper is an in-plane compressive treatment of moist paper in MD. This process is also applied with wet-laid non-woven fibre networks. Paper is compacted either between the moving rubber blanket, steel roll, and non-rotating nip bar (Clupak®), or between the steel roll covered with a rubber blanket and the heated steel roll (Expanda $\left.{ }^{\circledR}\right)$. Modifications of the compaction process do exist; however, the principle is the same. Compaction improves extensibility, but reduces tensile strength, elastic modulus, and bending stiffness of paper to a lesser extent than in the creping. Compaction is mainly used in the production of sack and bag paper grades in order to increase the tensile energy absorption of such papers (Ihrman and Öhrn 1965; Welsh 1965; Hernandez and Selke 2001; Poppel et al. 2000; Ankerfors and Lindström 2011). The schematic principle of operation of the Clupak® compaction unit for paper is shown in Fig. 16.

At the beginning of the compaction process, the rubber blanket (Fig. 15) is stretched in front of the nip before it adheres to the paper fed into the nip. Once the paper with rubber blanket passes the nip, the rubber blanket recoils because the straining force is released. Due to adhesion, the paper shrinks together with rubber blanket. The typical dryness of paper entering the nip is 60 to $65 \%$, and the dryness is increased once the paper leaves the Clupak ${ }^{\circledR}$ unit. The influence of compaction on the mechanical properties of paper can be demonstrated with the stress-strain curves (MD and CD) of paper before and after compaction, as shown in the Fig. 17. 


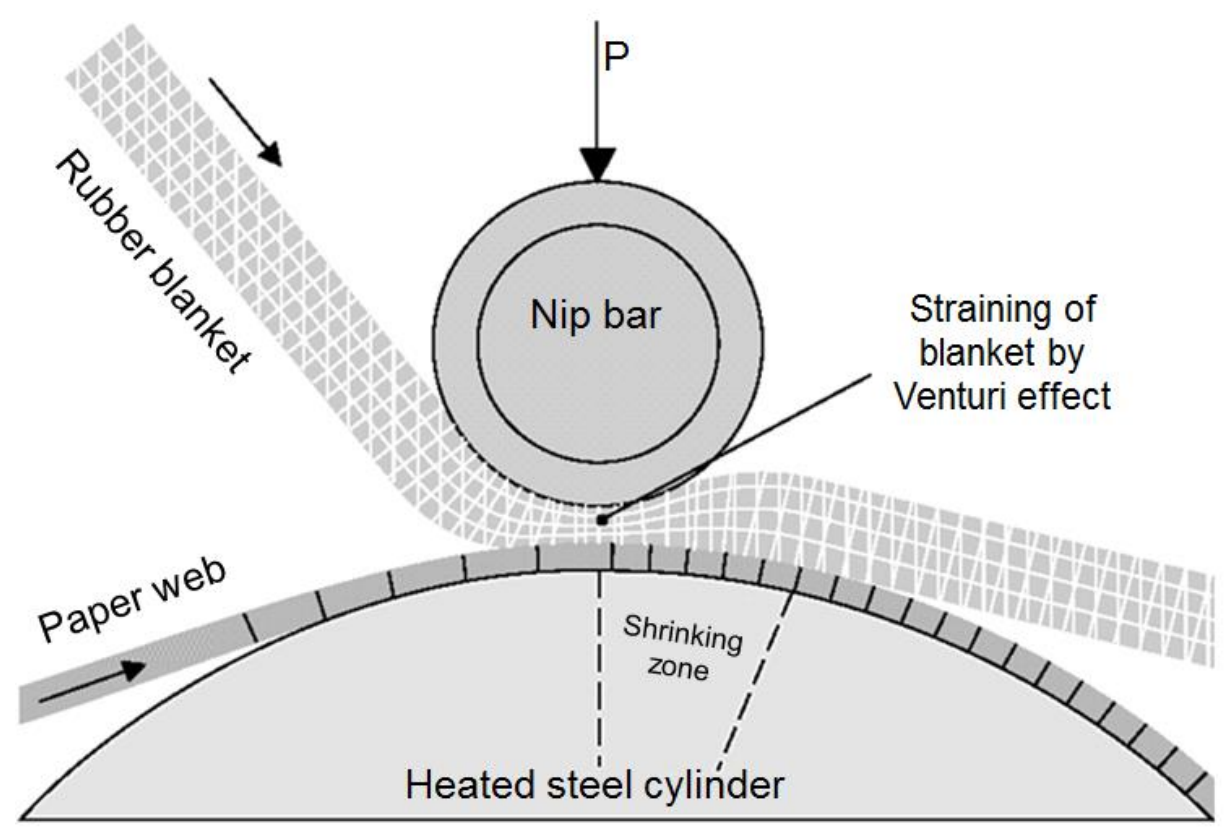

Fig. 16. The outline of Clupak ${ }^{\circledR}$ compaction process
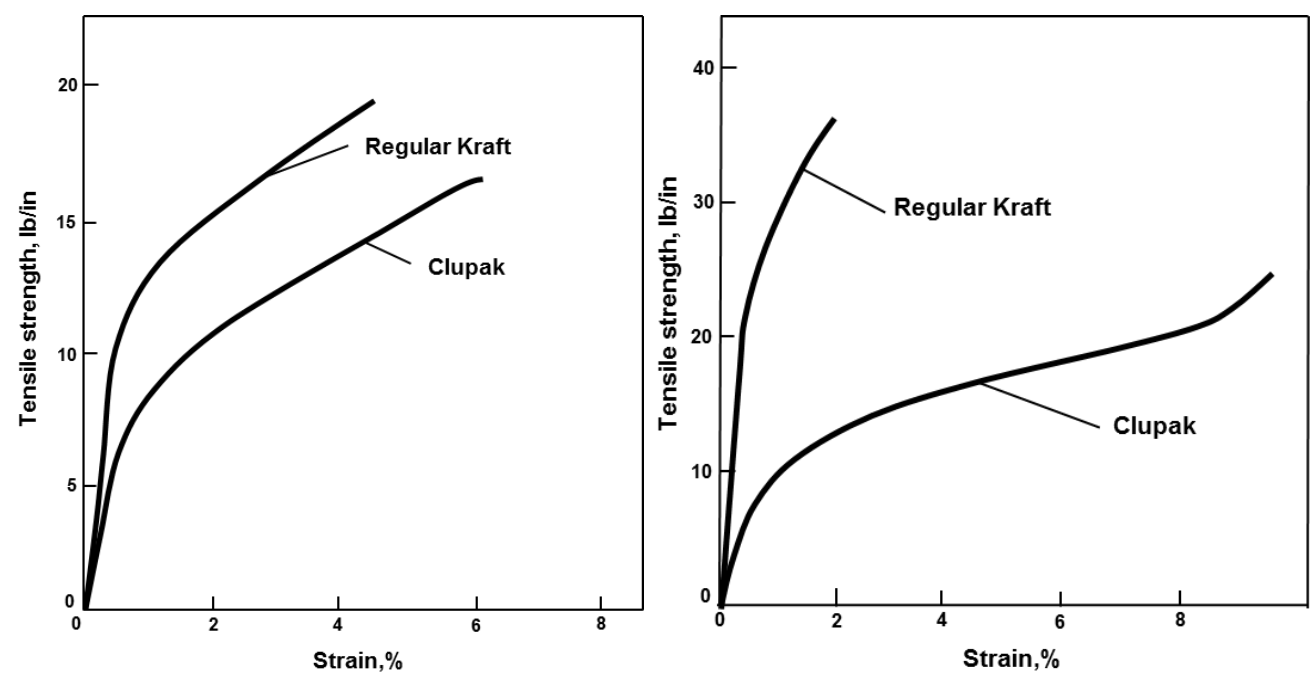

Fig. 17. The comparison of the stress-strain curves of the Clupak and Kraft sack paper in CD (left) and MD (right) (redrawn from the data of Shoudy 1959)

As can be seen from Fig. 17, compaction is an effective tool for the improvement of extensibility in MD, in exchange for a decreased ultimate tensile strength; however TEA (Tensile energy adsorption) is increased. In addition to the improvement in MD elongation, the extensibility also slightly increases in the CD. A $10 \%$-point gain in MD strain provides a 1 to $2 \%$ points increase in CD strain (Shoudy 1959; Welsh 1965). Paper can be compacted in both directions to produce paper with more isotropic properties. This can be achieved by controlling the recoiling of the rubber blanket in $\mathrm{CD}$ and by utilization of circumferentially grooved or inclined rolls (Welsh 1960; Cariolaro and Trani 2000; Kawasaki and Nagai 2003; Saitaka et al. 2006). The gain in elongation, a decrease in tensile strength caused by compaction, can be adjusted by varying the stretch of the rubber blanket, Z-pressure, and moisture content of the paper entering the nip. A 
high strain on the blanket leads to a higher gain in elongation, but to a major decrease in stiffness of paper. High z-pressure reduces the gain in elongation, but maintains stiffness at a higher level. Moisture content can be varied in the range of 40 to $75 \%$. Typically, the higher the moisture content of paper, the higher the elongation can be; however, it is accompanied by decreased stiffness (Welsh 1965; Ihrman and Öhrn 1965; Chen 1991; Lahti et al. 2014).

The elongation of paper is increased primarily due to the buckling of fibres and incorporation of microcompressions to fibres. A fine wrinkle pattern can be observed on the surface of paper. A decrease in the tensile strength is explained by the partial disruption of the fibre-fibre bonds (Chen 1991). The cross-sectional images of the double-roll compacted paper before and after compaction are shown in the Fig. 18.
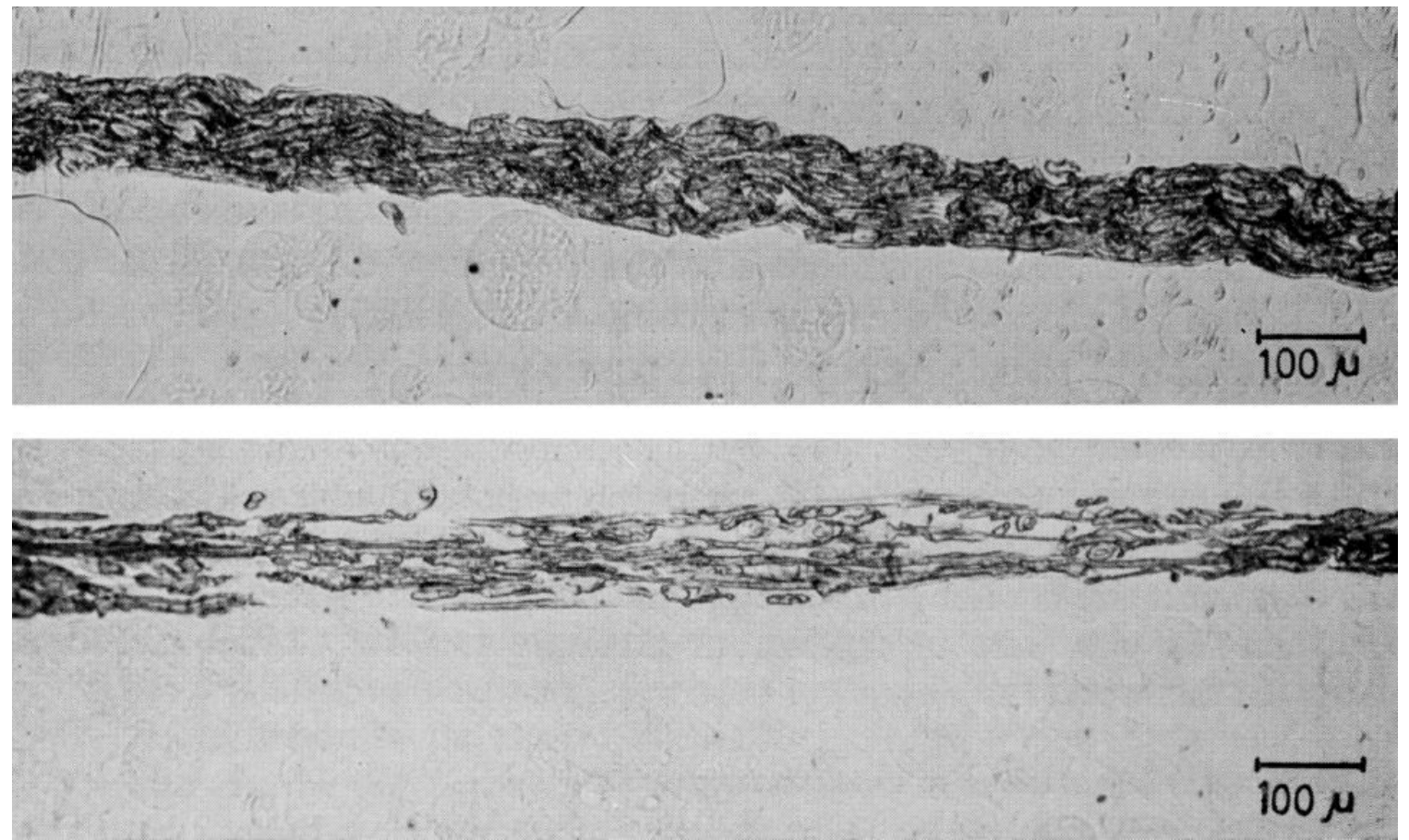

Fig. 18. The cross-sectional microscopic images of double roll compacted paper before (upper) and after straining (lower) Ihrmän and Öhrn (1965)

Steenberg (1949) has proposed that the extensibility of compacted paper comes through the extension of the creases in fibres between the fibre joints, which also can be observed in Fig. 18. The decrease in ultimate tensile strength of paper is explained by damage to the fibres and by partially disrupted fibre-fibre bonds. Another possible reason is the reduced efficiency in stress distribution of the network due to reduction or absence of activation (i.e. prestraining). Fibres after compaction appear to be curled, bent, and buckled, and they have higher plastic deformation and high-impact resistance due to high energy absorption of curled fibres (Dumbleton 1972; Page and Seth 1980b), which is also reflected in the decreased stress relaxation of compacted paper in comparison to uncompacted (Gregorova et al. 2013). However, after the straining, compacted paper appears to be quite smooth and no compaction marks can be observed in it (Fig. 18). Compaction results in densification of the paper, while its surface still appears to be rather planar (Shoudy 1959). In the case of paper with a relatively high basis weight $\left(>100 \mathrm{~g} / \mathrm{m}^{2}\right)$, the density of the surface and bottom layer of compacted paper may differ. 
The surface layer facing the rubber blanket may have a higher density (Kawasaki and Nagai 2003).

An additional benefit of compaction for the increased elongation of the paper is the reduced axial stiffness of the fibres, which can enhance the drying shrinkage of the paper (Dumbleton 1972). The use of the thermoplastic additives together with compaction may lead to formation of sticky deposits on blankets and rolls. Compaction of paper seems to be a feasible option for the production of extensible paper, it is widely used in manufacturing of sack paper and was recently applied for production of so-called "formable" paper for 3D-forming (Hado et al. 2001; Billerud 2012).

\section{Fibre orientation}

Most of the papers produced on modern paper machines have their fibres aligned more towards the MD than CD due to the flow patterns in wet end. The fibre orientation has a great influence on the tensile properties of paper. However, despite the common difference in strain at break in MD and CD, the effect of fibre orientation on the strain at break of restrained-dried paper was not observed, which can be noted from Fig. 19.

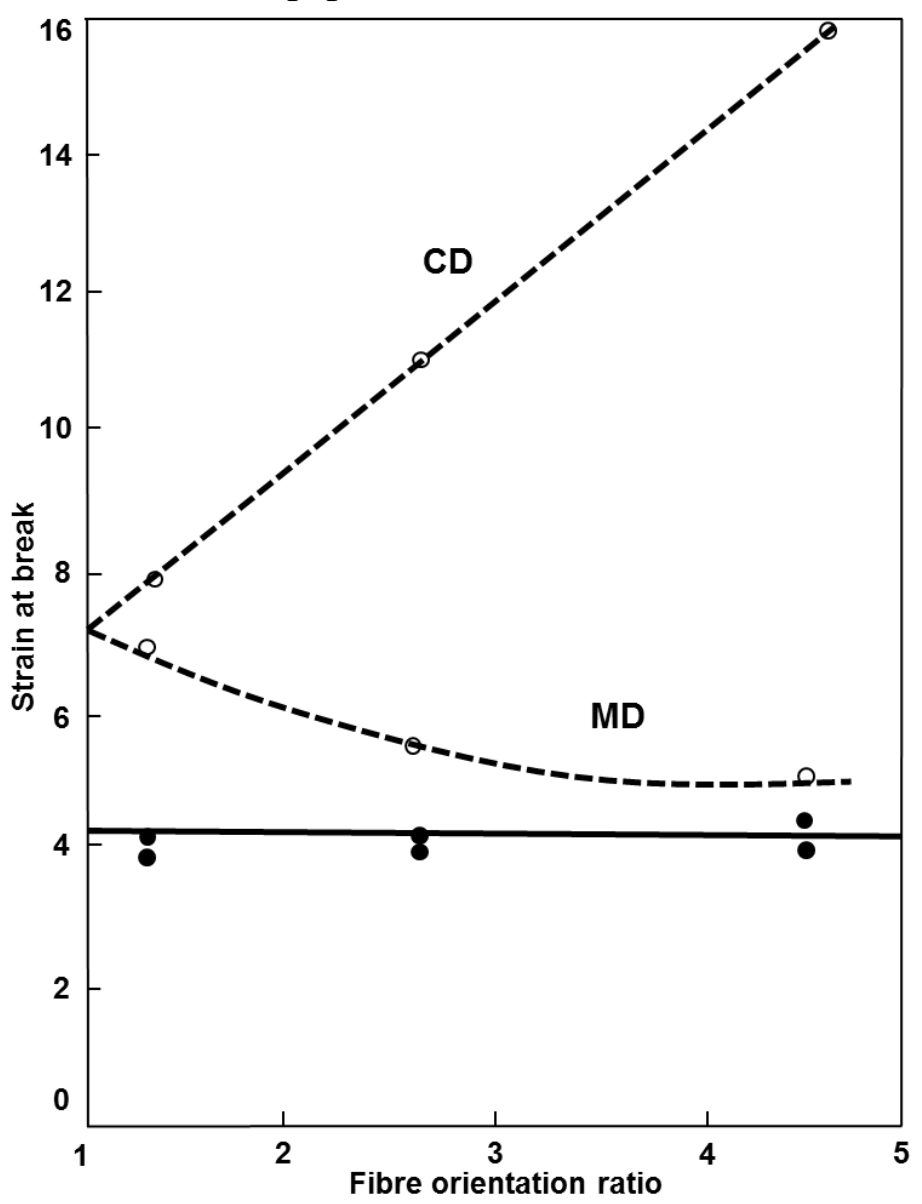

Fig. 19. The relation between the strain at break and fibre orientation ratio for the restrained (filled circles MD and CD) and unrestrained dried paper (empty circles), difference in orientation was obtained by varying the speed of the handsheet former (redrawn from Htun and Fellers 1982).

It is clear that the strain at break of the paper is determined by the extent of drying shrinkage and not directly by the fibre orientation in the sheet (Fig. 19), which is also in line with observations of Setterholm and Kuenzi (1970). Moreover, the relation between 
strain at break of paper and drying shrinkage is also not dependent on the fibre orientation (Gates and Kenworthy 1963). Nevertheless, large fibre orientation anisotropy leads to limited MD-shrinkage potential and thus strain, no matter how low the draw during drying is, which makes the question about influence of fibre orientation somewhat confusing.

\section{Influence of External Effects and Straining Conditions on Extensibility Of Paper}

In addition to the interfibre bonding, the structure of single fibres and network, the extensibility of paper is influenced by the straining situation and conditions at which straining is occurring. This section discusses the influence of strain rate and softening of polymers in the paper on its extensibility.

\section{Influence of the strain rate on the extensibility}

Individual fibres behave viscoelastically, and the strength and elastic modulus increase with the strain rate (Hardacker 1970). Therefore, it is no wonder that the same phenomenon occurs with paper (Andersson and Sjöberg 1953; Davison 1972). However, the influence of the strain rate on the extensibility of paper is not that straightforward and depends on the type of paper and other factors (Andersson and Sjöberg 1953). According to Okushima and Robertson (1979), the extensibility of blotting paper decreases with increasing strain rate. This effect is especially marked at high relative humidity, at which the share of plastic deformation is higher (Fig. 20).

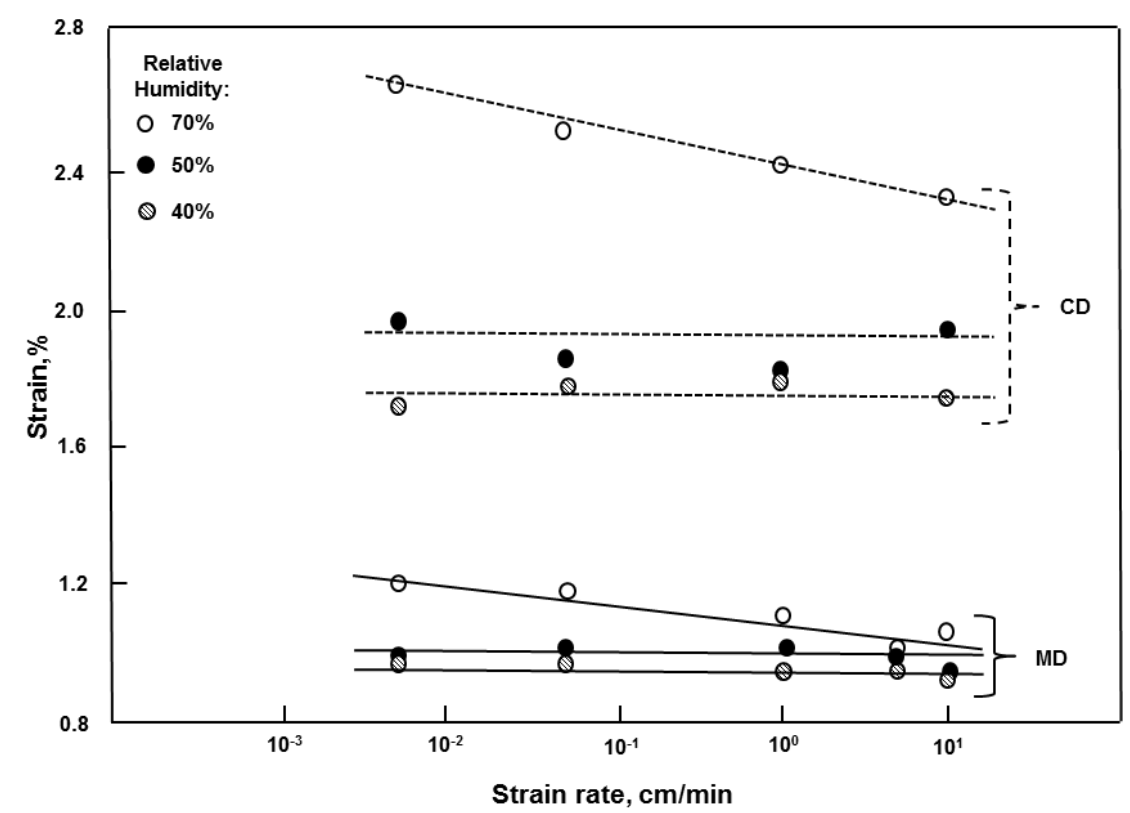

Fig. 20. The influence of strain rate on the extensibility of blotting paper conditioned at different $\mathrm{RH}$ levels (redrawn from the data of Okushima and Robertson 1979)

The decrease in overall strain with increasing strain rate is probably related to the reduction of the visco-elastic and plastic deformations of paper, which result in a reduced redistribution of stresses, higher stress concentrations at the rupture zone, and increased failure of the fibres themselves. With the increase in strain rate, the number of fibre breakages at the rupture zone has been found to increase and the number of failed bonds decreases (Helle 1965). Davison (1972) has shown that there is a certain optimum strain 
rate, $10000 \% / \mathrm{min}$, which gives the maximum extensibility for a given paper sample. The straining span length might also affect the overall extensibility; in general, with a decrease in span length, the strain increases slightly (Andersson and Sjöberg 1953), which could be explained by the lower probability of having weak spots.

To summarise, the strain rate does not generally affect the extensibility of the paper, but in certain cases and at extreme strain rates the extensibility decreases with increased strain rate. The decrease in elongation may be related to the difference in the structure and stresses, and the shorter time available for redistribution of stresses. Higher stress concentrations and higher elastic energy may lead to an earlier initiation and propagation of the fracture line.

\section{Influence of temperature and moisture on the extensibility of paper}

Straining of paper under elevated temperature or/and moisture level commonly occurs in production and converting processes. Temperature and moisture effects are not independent since at elevated temperature the equilibrium moisture content of paper changes. When paper is heated and/or moistened, the polymers in the fibre wall soften. Softening of paper as a phenomenon is related to the changes in the mechanical properties of paper, and can be characterized as the reduction in fibre stiffness, reduced strength of H-bonds, and increase in the mobility of polymeric components of fibres.

The chemical pulp fibres are mainly composed of hydrophilic polymers cellulose and hemicelluloses - and therefore they are susceptible to the action of moisture and elevated temperature. Lignin, the third constituent of paper, is not significantly affected by the action of moisture, but it softens under elevated temperature. However, lignin plays an important role only in the case of mechanical and chemomechanical pulps. The chemical composition of fibres and the internal structure of polymers to a great extent determine the softening behaviour of paper.

The effect of the increased temperature is mainly related to the reduction in the axial stiffness of the fibres, when the water acts as a plasticizer by interacting with intramolecular and intermolecular hydrogen bonds in cellulose and intermolecular bonds between fibres and fibrils, and thus allows the deformation and rearrangement of the cellulosic microfibrils (Tsuge and Wada 1962; Goring 1963; Crook and Bennet 1962; Salmén and Back 1977; Back and Salmén 1982; Waterhouse 1984; Caulfield 1990; Shiraishi 1991; Haslach 2000; Alava and Niskanen 2003). The data on the softening of wood polymers from the references (Andersson and Berkyto 1951a; Goring 1963; Ogiwara et al. 1970, Salmén and Back 1977a and 1982; Salmén et al. 1984; Back and Salmén 1989; Waterhouse 1984; Salmén 1990; Shiraishi 1991) allow the prediction that most wood polymers in paper at moisture content around 6 to $8 \%$ soften at a temperature in the range 150 to $180^{\circ} \mathrm{C}$. However, the crystalline part of the cellulose does not soften under elevated temperature/moisture, and starts to degrade at a temperature of around 240 ${ }^{\circ} \mathrm{C}$ (Beyler and Hirschler 2001; Szcześniak et al. 2008). The optimal temperature for the improvement of extensibility is highly dependent on the heating situation. In an open system, in which water can evaporate from the paper upon heating, the maximum improvement in extensibility can be observed at temperature ranges of 60 to $70{ }^{\circ} \mathrm{C}$ and 80 to $100^{\circ} \mathrm{C}$ for chemical and mechanical pulps, respectively (Kunnari et al. 2007). The dependence of softening temperatures of the wood polymers on the moisture content is shown in Fig. 21.

The softening temperatures of wood polymers in paper depend largely on the moisture content of the polymers. In the absolutely dry state cellulose, lignin, and hemicelluloses have softening temperatures of $230{ }^{\circ} \mathrm{C}, 205^{\circ} \mathrm{C}$, and $180{ }^{\circ} \mathrm{C}$, respectively. 
These values are significantly lower already at $6 \%$ moisture content, which is typical for air-dry paper. However, lignin cannot absorb more than $10 \%$ moisture content due to its network structure and limited amount of the exposed hydroxyl groups.

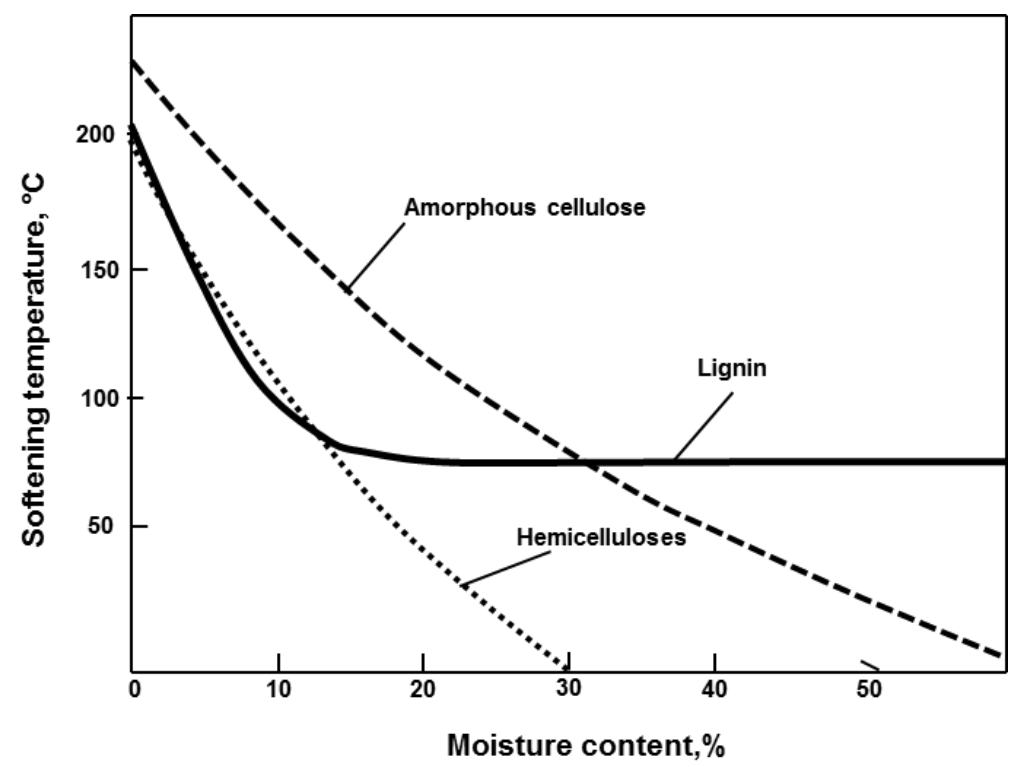

Fig. 21. A schematic representation of the relation between softening temperature of lignin, hemicelluloses, and amorphous cellulose and the moisture content (redrawn from the data of Salmén 1990)

Once paper is heated or moistened, the stiffness of the fibre wall decreases and interfibre bonds are weakened. Higher moisture amount also breaks fibre bonds, allowing a certain degree of sliding between the fibres. This changes the stress-strain behaviour of paper towards higher extensibility and less stiffness. This leads to the occurrence of an extended elongation region after the point of ultimate tensile strength (Brecht and Erfurt 1960; Johnson et al. 1983; Back and Salmén 1989; Retulainen et al. 1998; Uesaka et al. 2001; Sørensen and Hoffman 2003; Uesaka 2005; Alava and Niskanen 2006). Increased extensibility of paper in the softened state is primarily attributed to increased plastic deformation, while the elastic component is mitigated and ultimate tensile strength is reduced (Caulfield 1990). The amount of softening (reduction of elastic modulus) is higher, the higher the amount of amorphous cellulosic material. The elastic modulus of different cellulose-based materials decreases by around 0.18 to $0.64 \%$ for every $1{ }^{\circ} \mathrm{C}$ increase in temperature in a range of $-25^{\circ} \mathrm{C}$ and $175^{\circ} \mathrm{C}$ (Nissan 1977; Caulfield 1990). The effect of a change in moisture content from 0 to $25 \%$ is even more pronounced (Fig. 22).

From Fig. 22, NSSC fluting paper experiences a decrease of $60 \%$ of elastic modulus at a moisture content of around $23 \%$, while kraft sack paper and cotton linter paper experience the same decrease at $16 \%$ and $12 \%$, respectively. Such behaviour can be explained by the different content of crystalline material in these samples. Water is only absorbed in the amorphous regions, and therefore for the materials with lower crystallinity, drastic changes in the mechanical properties would occur at higher overall moisture content. Additionally, higher lignin content in kraft and NSSC paper may mitigate the effect of the elevated moisture content on the softening of the paper, which might be attributed to the inaccessibility of the cellulose surface covered by lignin to water vapour. 


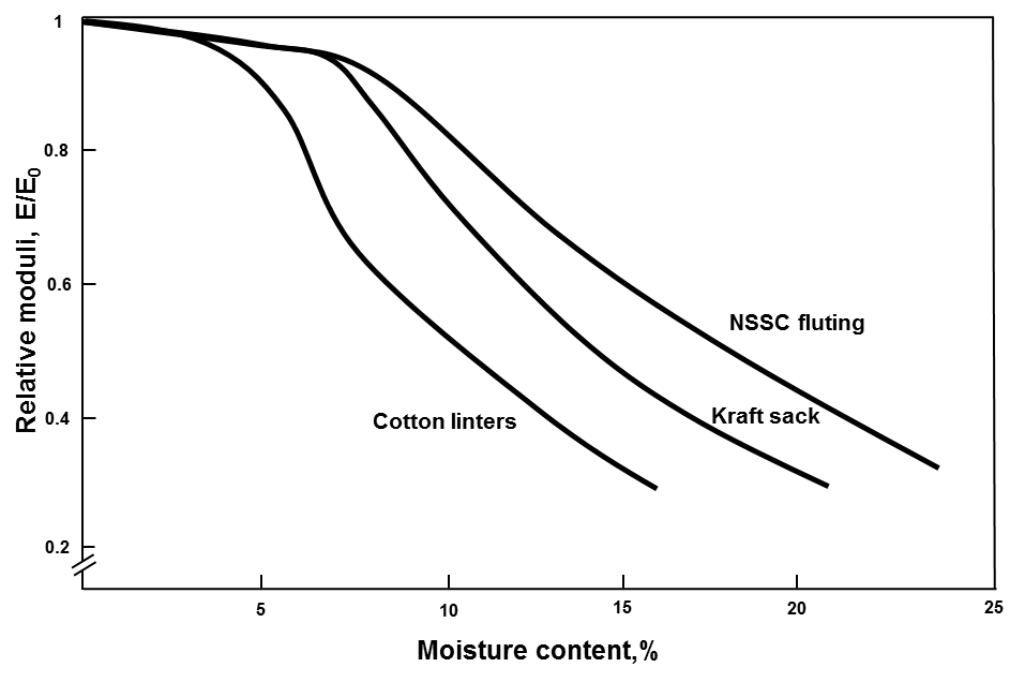

Fig. 22. The influence of the changes in the moisture content of cotton linter, kraft sack, and NSSC (Neutral Sulfite Semi Chemical) fluting paper on the relative moduli of paper ( $E_{0}$ is the dry modulus), the crystallinity of samples was $85 \%, 70 \%$, and $65 \%$, respectively (redrawn from the data of Salmen and Back 1980)

The sole effect of moisture on the extensibility of paper is much stronger than that of temperature (Salmén and Back 1980; Kunnari et al. 2007). In the recent study by Linvill and Östlund (2014) the authors claimed that the increase in temperature only decreases the strain at break value, in the temperature range of $23{ }^{\circ} \mathrm{C}$ to $170{ }^{\circ} \mathrm{C}$, while a gradual increase in moisture content of paper from $\mathrm{ca}$. $6 \%$ to $14 \%$ improves the strain at break of paper on $20 \%$. Negative action of elevated temperature in this case might be explained by insufficient amount of experimental points in the 23 to $100{ }^{\circ} \mathrm{C}$ temperature range and the mode of heating applied.

The changes in mechanical behaviour of paper exposed to a humid environment are related to transitions within the fibre wall and fibre bonds. As long as the interfibre bonding is strong enough, the fibre properties, especially of the bonded segments, probably explain the behaviour. With increasing moisture and especially when free water is present, the fibre bonds are weak, or are just based on frictional and capillary forces, and this explains a major part of the straining behaviour. Wet paper, although much weaker, can elongate much more than dry paper. This can be thought to be related to the properties of fibre contacts. In dry paper, the fibre contacts are bonded by H-bonds, and once broken they do not reform. In wet paper the fibre-fibre hydrogen bonds have not developed yet, the web strength is created by capillary forces and friction between the fibers, which does not disappear upon slippage between the fibers (van de Ven 2008). Unrestrained dried highly refined sulphite pulp (SR $88^{\circ}$ ) can have elongation of around $22 \%$-points at a dryness of $40 \%$, but the elongation gradually decreases to $8 \%$ when dryness increases to $90 \%$ (Brecht and Erfurt 1959). The characteristic change in the paper stress-strain curve of kraft paper occurs after it reaches around 50\% dry solids content; then the elastic component of the curve starts to increase, while plastic component decrease (Retulainen et al. 1998). The joint effect of the temperature and moisture can be demonstrated by failure envelopes for paper at different temperatures and moisture levels (Fig. 23). 


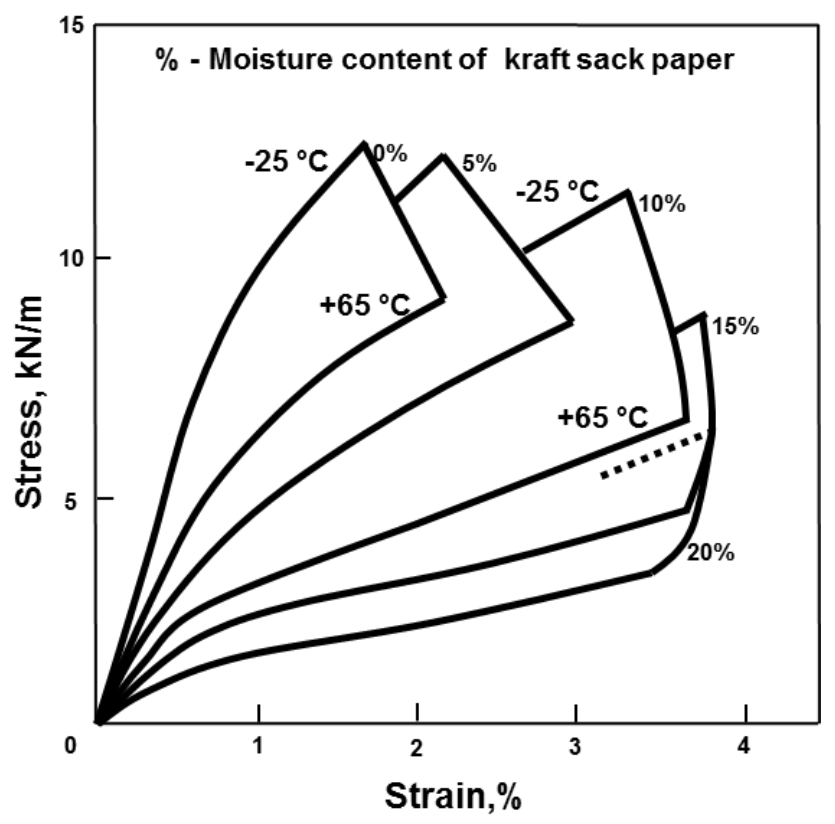

Fig. 23. Failure envelopes for a kraft sack paper in the machine direction at temperatures from minus 25 to plus $65^{\circ} \mathrm{C}$ and moisture contents of $0,5,10,15$ and $20 \%$ (redrawn from the data of Salmen and Back 1980).

The response of paper to elevated moisture content is different in remoistening. The maximum extensibility can be observed already at 85 to $90 \%$ dryness (Andersson and Berkyto 1951b). There is a clear difference in response to the high moisture content between unrestrained dried and restrained-dried paper. Extensibility of unrestrained dried paper is not affected by an increase in moisture content, while restrained dried paper, once moistened to $83 \%$ dryness, can be strained twice more than original value for dry paper (Kunnari et al. 2007). Part of this may also be associated with the partial relaxation of the drying stresses in paper (Kimura 1978).

The moisture and elevated temperature are of great importance for the 3Dforming of paper in such processes as hot pressing, vacuum forming, and deep-drawing. In these processes, paper is heated to reach an adequate formability, which enables straining or compressive folding (deep-drawing), and eventually production of the 3Dshapes. The typical temperature of the metal tools used in these processes is around 140 to $180{ }^{\circ} \mathrm{C}$, which corresponds to the softening temperature of amorphous cellulose at a given moisture content of 6 to $8 \%$. However, in the fast forming process, the temperature of the paper itself does not necessary reach values over $100{ }^{\circ} \mathrm{C}$ (Vishtal and Retulainen 2014). In several cases, the role of temperature is to dry the paper, create dried-in strains, and to "freeze" the formed shape.

\section{CONCLUSIONS}

The analysis presented in this paper has elucidated the nature of extensibility of fibre networks with a focus on paper and board. The aspects of fibre structure, bonding, network structure, fracture, and external conditions were considered in order to establish a solid basis for analysis. It can be concluded that the extensibility of the paper relies on three major factors: deformability of the single fibres, the ability of fibres to form a 
strong and flexible bond which delays the onset of fracture, and the three-dimensional structure of fibre network created during the manufacturing process. In addition to this, straining conditions, including the temperature, moisture content, strain rate, etc. directly affect the extensibility of paper. In order to maximise the extensibility, measures in all these areas should be undertaken. Also for several practical applications the strain at break (according to standard procedure) is not a correct measure of the extensibility of paper, because in many cases paper can be strained beyond the point of maximum tension without a major loss in tensile stress.

The aim of this paper was to identify methods for the improvement of the extensibility of fibre networks. The answer to this question depends on target extensibility values for paper. Extensibility of paper can relatively easily be increased in the range of 5 to $10 \%$-points by using high-consistency mechanical treatment and minimizing the wet draw on paper machine. However, if one is targeting values above $20 \%$-points or even above $30 \%$, then the solution would not be as easy. In order to boost extensibility of paper to such high levels, one would definitely require modifying the structure of paper by an in-plane compaction treatment, in addition to utilization of extensible fibres and modifying the character of the stress transfer between fibres by the addition of highly-extensible material. A common drawback with increased extensibility is that the tensile stiffness tends to decrease. It is essential that treatments should comply with each other and should correspond to the final use of the paper product. The approach to the production of highly-extensible paper can be compiled using the list of methods presented in Table 2.

Table 2. Methods for the Improvement of Elongation of Paper

\begin{tabular}{|c|c|c|c|c|c|}
\hline Treatment & $\begin{array}{c}\text { Description of the } \\
\text { effect }\end{array}$ & Advantages & Disadvantages & $\begin{array}{l}\text { Increase in } \\
\text { elongation }\end{array}$ & Ref * \\
\hline \multicolumn{6}{|c|}{ Treatments on the fibre level } \\
\hline $\begin{array}{c}\text { Utilization of fibres } \\
\text { with high fibrillar } \\
\text { angle }\end{array}$ & $\begin{array}{l}\text { Fibres with the high } \\
\text { fibril angle have better } \\
\text { elongation potential. }\end{array}$ & $\begin{array}{l}\text { Easy to apply. No } \\
\text { need for additional } \\
\text { treatments. }\end{array}$ & $\begin{array}{l}\text { Poor availability of } \\
\text { such pulp. }\end{array}$ & $\begin{array}{c}\text { Up to } 2-3 \% \\
\text { percent. Depends } \\
\text { on the added } \\
\text { amount of fibres } \\
\text { and fibrillar angle. }\end{array}$ & $1,2,3$ \\
\hline $\begin{array}{l}\text { Utilization of fibres } \\
\text { with optimum } \\
\text { hemicelluloses } \\
\text { content }\end{array}$ & $\begin{array}{c}\text { Hemicelluloses } \\
\text { provide better } \\
\text { bonding, increase } \\
\text { swelling and drying } \\
\text { shrinkage. }\end{array}$ & $\begin{array}{c}\text { Easy to apply. } \\
\text { Increased strength of } \\
\text { paper. }\end{array}$ & $\begin{array}{l}\text { Special cooking } \\
\text { conditions might } \\
\text { be needed to } \\
\text { preserve the } \\
\text { hemicelluloses. }\end{array}$ & $\begin{array}{l}\text { Minor effect, } \\
\text { Difference is clear } \\
\text { when compared } \\
\text { to hemipoor pulp. }\end{array}$ & $4,5,30$ \\
\hline $\begin{array}{l}\text { Mechanical } \\
\text { treatment of fibres }\end{array}$ & $\begin{array}{c}\text { Creation of } \\
\text { dislocations and } \\
\text { microcompressions } \\
\text { which decrease axial } \\
\text { stiffness of fibre and } \\
\text { promote shrinkage } \\
\text { and extensibility. }\end{array}$ & $\begin{array}{l}\text { Can be applied using } \\
\text { current equipment at } \\
\text { paper mill. Refining } \\
\text { may also improve } \\
\text { other paper } \\
\text { properties. }\end{array}$ & $\begin{array}{l}\text { Inferior tensile } \\
\text { strength and } \\
\text { stiffness (for HC } \\
\text { treatment). } \\
\text { Increased energy } \\
\text { consumption. }\end{array}$ & $\begin{array}{l}2-8 \% \text { points. The } \\
\text { effect is more } \\
\text { significant in case } \\
\text { of unrestrained } \\
\text { drying. }\end{array}$ & $6,7,2,8,9$ \\
\hline $\begin{array}{l}\text { Grafting of fibres } \\
\text { with polymers }\end{array}$ & $\begin{array}{l}\text { Chemical grafting with } \\
\text { acrylate polymers. } \\
\text { This treatment } \\
\text { increasing elongation } \\
\text { potential by stronger } \\
\text { and more extensible } \\
\text { bonds in the paper } \\
\text { web. }\end{array}$ & $\begin{array}{l}\text { Great improvements } \\
\text { in the extensibility. } \\
\text { Biodegradability and } \\
\text { recyclability of paper } \\
\text { is preserved. }\end{array}$ & $\begin{array}{l}\text { High cost. } \\
\text { Complex chemical } \\
\text { reaction. At high } \\
\text { grafting levels, } \\
\text { strength is } \\
\text { impaired } \\
\text { significantly. }\end{array}$ & $\begin{array}{l}2-6 \% \text {, depends } \\
\text { on grafting level. }\end{array}$ & $10,11,12$ \\
\hline
\end{tabular}


Table 2 (continued). Methods for the Improvement of Elongation of Paper

\begin{tabular}{|c|c|c|c|c|c|}
\hline Treatment & $\begin{array}{c}\text { Description of the } \\
\text { effect }\end{array}$ & Advantages & Disadvantages & $\begin{array}{l}\text { Increase in } \\
\text { elongation }\end{array}$ & Ref * \\
\hline $\begin{array}{l}\text { Amorphisation of } \\
\text { cellulose or } \\
\text { utilization of } \\
\text { cellulose with low } \\
\text { crystallinity }\end{array}$ & $\begin{array}{l}\text { The extensibility of } \\
\text { amorphous cellulose } \\
\text { is higher than for } \\
\text { crystalline. Fibres } \\
\text { have lower axial } \\
\text { stiffness which would } \\
\text { increase shrinkage. }\end{array}$ & $\begin{array}{c}\text { Relatively high } \\
\text { improvements in } \\
\text { extensibility. Effect is } \\
\text { scalable. }\end{array}$ & $\begin{array}{l}\text { Amorphisation } \\
\text { might require } \\
\text { expensive } \\
\text { chemical or harsh } \\
\text { physical treatment. } \\
\text { Associated with } \\
\text { decrease in } \\
\text { strength and some } \\
\text { side effects. } \\
\end{array}$ & $\begin{array}{l}\text { Up to } 20 \% \text {-points. } \\
\text { Proportional to } \\
\text { decrease in } \\
\text { crystallinity or/and } \\
\text { amount of } \\
\text { amorphous } \\
\text { cellulose added. }\end{array}$ & $32,33,34$ \\
\hline $\begin{array}{c}\text { Hydroxypropylation } \\
\text { and } \\
\text { hydroxyethylation } \\
\text { of fibres }\end{array}$ & $\begin{array}{l}\text { Direct etherification or } \\
\text { addition of etherified } \\
\text { fibre material } \\
\text { improves bonding. } \\
\text { Drying shrinkage is } \\
\text { increased. }\end{array}$ & $\begin{array}{l}\text { Great improvements } \\
\text { in the extensibility. } \\
\text { The physical and } \\
\text { chemical nature of } \\
\text { fibres is preserved. }\end{array}$ & $\begin{array}{l}\text { High cost of } \\
\text { chemical } \\
\text { synthesis. } \\
\text { Impaired } \\
\text { dewatering. }\end{array}$ & $\begin{array}{l}5-25 \% \text {, depends } \\
\text { on degree of } \\
\text { substitution and } \\
\text { drying method. }\end{array}$ & 13 \\
\hline Oxidation of fibres & $\begin{array}{l}\text { Periodate oxidation of } \\
\text { C2-C3 hydroxyls in } \\
\text { cellulose. Improved } \\
\text { bonding, decreased } \\
\text { crystallinity, changes } \\
\text { in microfibrillar } \\
\text { arrangement in the } \\
\text { cell wall. } \\
\end{array}$ & $\begin{array}{c}\text { Significant } \\
\text { improvements in } \\
\text { extensibility even in } \\
\text { case of restrained } \\
\text { dried paper. The } \\
\text { physical and chemical } \\
\text { nature of fibres is } \\
\text { preserved. }\end{array}$ & $\begin{array}{l}\text { Decreased MW of } \\
\text { cellulose. Cost } \\
\text { associated with } \\
\text { chemical } \\
\text { treatment. } \\
\text { Increased } \\
\text { susceptibility to } \\
\text { moisture. }\end{array}$ & $\begin{array}{c}2-10 \% \text {, depends } \\
\text { degree of } \\
\text { oxidation }\end{array}$ & 14 \\
\hline Hexanoation & $\begin{array}{c}\text { Esterification of } \\
\text { cellulose to DS } 1.7 \\
\text { leads to formation of } \\
\text { continuous cellulose } \\
\text { ester matrix with } \\
\text { inclusions of } \\
\text { unmodified cellulose. }\end{array}$ & $\begin{array}{l}\text { Thermoformable. } \\
\text { High improvements in } \\
\text { extensibility. }\end{array}$ & $\begin{array}{c}\text { Chemical } \\
\text { modification } \\
\text { associated cost. } \\
\text { Not compatible } \\
\text { with papermaking } \\
\text { process. }\end{array}$ & Up to $30 \%$-points & 31 \\
\hline \multicolumn{6}{|c|}{ Treatments on the fibre network level } \\
\hline $\begin{array}{l}\text { Unrestrained or } \\
\text { low restraint drying }\end{array}$ & $\begin{array}{l}\text { Effect comes from } \\
\text { drying shrinkage. }\end{array}$ & $\begin{array}{l}\text { Greater extensibility } \\
\text { and tensile energy } \\
\text { adsorption. }\end{array}$ & $\begin{array}{l}\text { Lower tensile } \\
\text { strength and } \\
\text { elastic modulus. }\end{array}$ & $\begin{array}{c}\text { Gains in the } \\
\text { extensibility are } \\
\text { proportional to the } \\
\text { amount of the } \\
\text { shrinkage. }\end{array}$ & $8,15,16$ \\
\hline Compaction & $\begin{array}{l}\text { In-plane compression } \\
\text { of wet paper web. } \\
\text { Fibres after } \\
\text { compaction appear } \\
\text { curved, bended and } \\
\text { buckled. }\end{array}$ & $\begin{array}{c}\text { Significant } \\
\text { improvements in MD } \\
\text { elongation. CD } \\
\text { elongation can be } \\
\text { also improved. Easy } \\
\text { to apply. } \\
\end{array}$ & $\begin{array}{l}\text { Decrease in tensile } \\
\text { strength and } \\
\text { stiffness. Need } \\
\text { additional } \\
\text { equipment. }\end{array}$ & $\begin{array}{l}\text { Gains up to } 10- \\
30 \% \text { in MD. CD } \\
\text { elongation can be } \\
\text { improved with } \\
\text { advanced } \\
\text { equipment. } \\
\end{array}$ & $17,18,19,20,29$ \\
\hline Creping & $\begin{array}{l}\text { Paper web is buckled } \\
\text { against the doctor } \\
\text { blade. By this web is } \\
\text { buckled, wrinkled and } \\
\text { compressed. }\end{array}$ & $\begin{array}{c}\text { Significant } \\
\text { improvements in MD } \\
\text { elongation. Easy to } \\
\text { apply. }\end{array}$ & $\begin{array}{l}\text { Wrinkly and rough } \\
\text { surface. Very low } \\
\text { tensile strength } \\
\text { and stiffness. }\end{array}$ & $\begin{array}{l}\text { Elongation of } \\
\text { crepe paper is in } \\
\text { range of 35- } \\
200 \% \text {. }\end{array}$ & 18 \\
\hline $\begin{array}{l}\text { Addition of latexes } \\
\text { and rubbers }\end{array}$ & $\begin{array}{l}\text { Latexes and rubbers } \\
\text { after curing can form a } \\
\text { polymer matrix within } \\
\text { paper. }\end{array}$ & $\begin{array}{l}\text { Easy to apply. } \\
\text { Strength and } \\
\text { extensibility are } \\
\text { improved. } \\
\text { Recyclability is } \\
\text { questionable. }\end{array}$ & $\begin{array}{l}\text { Needed to be } \\
\text { cured. High cost of } \\
\text { latexes. High } \\
\text { addition amount. }\end{array}$ & $\begin{array}{c}\text { At } 10-40 \% \\
\text { addition to fibres, } \\
\text { extensibility } \\
\text { increased to } 20- \\
40 \% \text {-points. }\end{array}$ & $21,22,23$ \\
\hline $\begin{array}{c}\text { Addition of NFC, } \\
\text { CMC, }\end{array}$ & $\begin{array}{l}\text { Improved bonding and } \\
\text { increased drying } \\
\text { shrinkage }\end{array}$ & $\begin{array}{l}\text { Easy to apply. } \\
\text { Cellulosic material }\end{array}$ & $\begin{array}{l}\text { Impaired } \\
\text { dewatering. Poor } \\
\text { availability and } \\
\text { high cost to } \\
\text { produce. }\end{array}$ & $\begin{array}{l}\text { Up to several \%- } \\
\text { points. }\end{array}$ & $24,25,26,27,28$ \\
\hline
\end{tabular}

Notes for Table 2 are given on the following page. 


\section{* NOTES for Table 2.}

1-Hänninen et al. 2011; 2-Joutsimo et al. 2005 3-Donaldson 2008; 4-Spiegelberg 1966, 5-Scallan 1974, 6-Dumbleton 1972, 7Page et al. 1976, 8-Seth 2005, 9-Ljungqvist et al. 2005, 10-Rezai and Warner 1997a, 11-Rezai and Warner 1997a, 12-Wang et al. 2007, 13-Didwania 1968, 14-Larsson et al.2014a and 2014b, 15-Htun et al. 1989, 16-Page and Tydeman 1966, 17-Ihrman and Öhrn 1965, 18-Welsh 1966, 19-Poppel et al. 2000, 20-Cariolaro and Trani 2000, 21-Waterhouse 1976, 22-Alince 1977 and 1979, 23-Svensson et al. 2013 24-Klemm et al. 2011, 25-Henriksson et al. 2008, 26-Duker et al. 2007, 27-Laine et al. 2002, 28-Madani et al. 2011, 29-Lahti et al. 2014, 30-Obermanns 1934, 31-Matsumura et al. 2000, 32-Page 1983, 33-Lenz et al. 1994, 34-Parker 1962.

\section{ACKNOWLEDGEMENTS}

The Future Biorefinery Programme and ACel project at Finnish Bioeconomy Cluster Ltd., and VTT Graduate School are acknowledged for providing financial support to this study.

\section{REFERENCES CITED}

Akagane, K., Allan, G., Dutkiewicz, J., Liu, T. M., and Palicka, J. (1979). "Fibre surface modification," Paperi ja Puи 61(10), 624-628.

Akim, M. E., and Telysheva, G. M. (1991). "Prospects for the use of lignosulfonates for production of cellulosic composite materials by surface sizing of paper," Bumazhnaya Promishlennost' 3, 14-16.

Alava, M., and Niskanen, K. (2006). “The physics of paper,” Rep. Prog. Phys. 69, 669723.

Alberti, A., Bertini, S., Gastaldi, G., Iannaccone, N., Macciantelli, D., Torri, G., Vismara, E. (2005). "Electron beam-irradiated textile cellulose fibers," Eur. Polym. J. 41 (8), 1787-1797.

Alén, R. (2000). "Structure and chemical composition of wood," In: Forest Products Chemistry, P. Stenius, (Ed.), Fapet Oy, Helsinki, 2000, 11-57.

Alince, B. (1977). "Effect of heat on paper reinforcement by styrene-butadiene latex," Svensk Papperstidning 13(10), 417-421.

Alince, B. (1979). "Cationic latex interaction with pulp fibres. II. Modification of sheet properties by styrene-butadiene latex with quaternized amino groups," J. Applied Polym. Sci. 23 (2), 549-560.

Alince, B. (1991). "Increasing tensile strength without losing opacity," Tappi J. 74(8), 221-223.

Alince, B. (1999). "Cationic latex as multifunctional papermaking wet-end additive," Tappi J. 82(3), 175-187.

Altaner, C. M., Thomas, L. N., Fernandes A. N., and Jarvis M. C. (2014). "How cellulose stretches: Synergism between covalent and hydrogen bonding," Biomacromolecules 15(3), 791-798.

Andersson, O., and Berkyto, E. (1951a). "Some factors affecting the stress-strain characteristics of paper. I. Influence of temperature," Svensk Papperstidning 54, 437440.

Andersson, O., and Berkyto, E. (1951b). "Some factors affecting the stress-strain characteristics of paper. I. Influence of relative humidity," Svensk Papperstidning 54, 441-444. 
Andersson, O. and Sjöberg, L. (1953). "Tensile studies of paper at different ratesof elongation," Svensk Papperstidn. 56(16), 615-624.

Ankerfors, C., Johansson, E., Pettersson, T., and Wågberg L. (2014). "Use of polyelectrolyte complexes and multilayers from polymers and nanoparticles to create sacrificial bonds between surfaces," Journal of Colloid and Interface Science 391(1), 28-35.

Ankerfors, M., and Lindström, T. (2011). "Mouldable material,” International patent WO 2011/087438 A1.

Arlov, A. P., and Hauan, S. (1965). "Mahlung bei hohen Stoffdichten in der PFI-Mühle," Norsk Skogindustri 19(7), 267-277.

Back, E. L., and Salmén, N. L. (1982). "Glass transition of wood components hold implication for molding and pulping processes," Tappi 65(7), 107-110.

Back, E., and Salmén, L. (1989). "The properties of NSSC-based and waste-based corrugating medium," Paper Technology 10(30), 16-23.

Bäckström, M., Hammar, L., Htun, M., (2009). "Beatability and runnability studies of ion-exchanged unbleached kraft pulps on a pilot scale," Nordic Pulp and Paper Research Journal 24(1), 94-100.

Barbe, M. C., Seth, R. S., and Page, D. H. (1984). "Curl setting - A process for improving properties of high-yield pulps," Pulp and Paper Canada 85(3), 44-51.

Barnett, J. R., and Bonham, V. A. (2004). "Cellulose microfibril angle in the cell wall of wood fibres," Biol. Rev. Camb. Philos. Soc. 79(2), 461-472.

Beyler, C. L., and Hirschler, M. M. (2001). "Thermal decomposition of polymers," chapter in: SFPE Handbook of Fire Protection Engineering ( $3^{\text {rd }}$ Edn.), Editor-inchief: P. J. DiNenno, NFPA, Quincy, MA.

Billerud. (2012). "Billerud Fibreform ${ }^{\circledR}$ standard product range," Brochure, available via: http://www.billerud.se/pagefiles/2499/fibreform_produktblad_sheets.pdf, (accessed 09.07.2014)

Bledzki, A. K., and Gassan, J. (1999). "Composites reinforced with cellulose based fibres," Progress in Polymer Science 24(2), 221-274.

Blomstedt, M. and Vuorinen, T. (2006). "Fractionation of CMC-modified hardwood pulp," Appita 59(1), 44-49.

Borodulina, S., Kulachenko, A., Galland, S., and Nygårds, M. (2012). "Stress-strain curve of paper revisited," Nordic Pulp and Paper Research Journal 27(2), 318-328.

Bos, H. (2004). "The potential of flax fibres as reinforcement for composite materials," Doctoral Thesis, Technische Universiteit Eindhoven.

Bouchard, J., Methot, M., and Jordan, B. (2006). "The effects of ionizing radiation on the cellulose of wood-free paper," Cellulose 13(5), 601-610.

Boudreau, J., and Barbier, C. (2014). "Laboratory creping equipment," Journal of Adhesion Science and Technology 28(6), 561-572.

Boudreau, J., and Germgård, U., (2014). "Influence of various pulp properties on the adhesion between tissue paper and yankee cylinder surface," BioResources 9(2), 2107-2114.

Bourmaud, A., Morvan, C., Bouali A., Placet, V., Perre, P., and Baley, C. (2013). "Relationships between micro-fibrillar angle, mechanical properties and biochemical composition of flax fibers," Industrial Crops and Products 44, 343-351.

Brecht, W., and Erfurt, H. (1959). "Wet-web strength of mechanical and chemical pulps of different form composition," Tappi J. 42(12), 959-968.

Brecht, W., and Erfurt, H. (1960). "Einiges über die Dehnung des Papiers," Das Papier 16(12), 739-746. 
Brecht, W., Knittweis, H. J., and Schmidt, W. (1971). "Neuere Untersuchungen über das Dehnungsverhalten verschiedener Papiere," Wochenblatt Fur Papierfabrikation 99(8), 287-292.

Cariolaro, N., and Trani, G. (2000). "Method and apparatus for producing extensible paper," US Patent 6024832.

Caulfield, D. (1990). "Effect of moisture and temperature on the mechanical properties of paper," in: Solid Mechanics Advances in Paper Related Industries, Proc. of the National Sci. Foundation Workshop, R. W. Perkins, R. E. Mark, and J. L. Thorpe (eds.), 50-62.

Chen, J. (1991). "The application of continuum mechanics to the stochastic modelling of fracture in fiber-fiber composites," Doctoral Thesis. Massachusetts Institute of Technology.

Chung, B. Y., Lee, J. T., Lee, S. S., Kim, U. J., Wi, S. W., Bai, H. W., and Cho, J. Y. (2012). "A comparison of the efficiency of electron beam irradiation on enzymatic hydrolysis between 4 doses of $25 \mathrm{kGy}$ and a single dose of $100 \mathrm{kGy}$ for bioethanol production," J. Korean Soc. Appl. Biol. Chem .55(3), 385-389.

Cintron, M. C., Johnson, G. P., and French, A. D. (2011). "Young's modulus calculations for cellulose Ib by MM3 and quantum mechanics," Cellulose 18(3), 505-516.

Coffin, D. W. (2009) "Developing a deeper understanding of the constitutive behavior of paper", Transactions of the 14th Fundamental Research Symposium Oxford, 841-876.

Coffin, D. (2012). "Use of the efficiency factor to account for previous straining on the tensile behavior of paper," Nordic Pulp and Paper Research Journal 27(2), 305-312.

Cottrall, L. G. (1954). "The bearing of the hemicelluloses of wood pulp fibers on their paper making properties," PaperMaker 128(2), 125-130.

Crook, D. M. and Bennett, W. E. (1962). "Effect of humidity and temperature on the physical properties of paper," British Paper and Board Industry Research Association. London.

Cyras, V.P., Commisso, M.S., and Vázquez, A. (2009). "Biocomposites based on renewable resource: Acetylated and non-acetylated cellulose cardboard coated with polyhydroxybutyrate," Polymer 50(26), 6274-6280.

Davison, R. W. (1972). "The weak link in paper dry strength," Tappi 55 (4), 567-573.

de Ruvo, A. (1979). "The use of polymers in paper-potential and restrictions," Pap. Technol. Ind. 20(1), 25-31.

Deguchi, S., Tsujii, K., and Horikoshi, K. (2006). "Cooking cellulose in hot and compressed water," Chem. Commun. 31, 3293-3295.

Deguchi, S., Tsujii, K., and Horikoshi, K. (2008). "Crystalline-to-amorphous transformation of cellulose in hot and compressed water and its implications for hydrothermal conversion," Green Chem. 10(2), 191-196.

Didwania, H. P. (1968). "A study of the effects of hydroxyethylation on bonding of paper," Doctoral dissertation. Institute of Paper Chemistry, Wisconsin.

Dlugosz, J., and Michie, R. I. C. (1960). "Microfibrillar structure in regenerated cellulose," in: Physikalisch-Technischer Teil, Springer, Berlin, Heidelberg, 715-718.

Dodson, C. T. J. (1970). "The nature of bonds in paper and the behaviour of paper under mechanical strain," Reports on Progress in Physics 33(1), 1-40.

Donaldson, L. (2008). "Microfibril angle: Measurement, variation and relationships - A review," IAWA Journal 29(4), 345-386.

Dong, F. (2009). "Mechano-sorptive creep - Structural origin on the single fiber level," M Sc. Thesis, KTH, Stockholm, ISSN 1402-7615. 
Downes, G., Evans, R., Wimmer, R., French, J., Farrington, A., and Lock, P. (2003). "Wood, pulp and handsheet relationships in plantation grown Eucalyptus globulus," Appita J. 56 (2), 221-228.

Driscoll, M., Stipanovic, A., Winter, W., Cheng, K., Manning, M., Spiese, J., Galloway, R. A., and Cleland, M. R. (2009). "Electron beam irradiation of cellulose," Radiation Physics and Chemistry 78(7-8), 539-542.

Duker, E., Brännvall, E., and Lindström, T. (2007). "The effects of CMC attachment onto industrial and laboratory-cooked pulps," Nord. Pulp Paper Res. J. 22(3), 356-363.

Dumbleton, D. F. (1972). "Longitudinal compression of individual pulp fibres," Tappi J. 55(1), 117-135.

Ebeling, K. I. (1976). "Distribution of energy consumption during the straining of paper," in: Bolam, F. (ed.), Fundamental Properties of Paper Related to its Uses, Vol. 1, Transactions of the symposium held at Cambridge, September 1973, Technical Division, The British Paper and Board Industry Federation, London, 1976, 304-335.

Eichhorn, S. J., Dufresne, A., Aranguren, M., Marcovich, N. E., Capadona, J. R., and Rowan, S. J. (2010). "Review: Current international research into cellulose nanofibres and nanocomposites," Journal of Material Science 45(1), 1-33.

Fink, H. P., Philipp, B., Paul, D., Serimaa, R., and Paakkari, T. (1987). "The structure of amorphous cellulose as revealed by wide-angle X-ray scattering," Polymer 28(8), 1265-1270.

Fischer, W. J. Hirn, U., Bauer, W., and Schennach, R. (2012). "Testing of individual fiber-fiber joints under biaxial load and simultaneous analysis of deformation," Nordic Pulp and Paper Research Journal 27(2), 237-244.

Fiskari, J. P. T, McDonough, T. J., Dyer, T. J., Ragauskas, A. J., and Waterhouse, J. F. (2001). "On the improved selectivity of oxygen delignification: 1. Fiber curl, crystallinity and length," In: 11th International Symposium on Wood and Pulping Chemistry (ISWPC) Nice, France June 11-14, 2001, 463-466.

Flyate, D. M. (1988). “Tehnologiya bumagi," (Lesnaya promyshlennost', 1988)(ISBN 5712000628), Book (In Russian), 344-348.

Forgacs, O. L., and Mason, S. G. (1958). "The flexibility of wood-pulp fibers," Tappi 41(11), 695-699.

Forgacs, O. L., and Mason, S. G. (1959). "Particle motions in sheared suspensions. IX. Spin and deformation of thread like particles," J. Colloid. Science 14(5), 457-472.

Fredricks, P. (1971). "An investigation of rupture mechanism in some nonwoven fabrics," Svensk Papperstid. 74(8), 233-237.

Fujiwara, Y. (1956). "Studies on the strength of kraft paper. II: Influence of the tension during drying on the mechanical properties of the paper sheet," J. of Japan. Tech. Assoc. Pulp Paper Ind. 10(11), 592-596.

Gates, E. R. and Kenworthy, I. C. (1963). "Effects of drying shrinkage and fibre orientation on some physical properties of paper," Paper Technol. 4(5), 485-493

Goldschmidt, J., and Wahren, D. (1968). "On the rupture mechanism of paper," Svensk Papperstidning 71(13-14), 477-481.

Goring, D. A. I. (1963). “Thermal softening of lignin, hemicellulose and cellulose,” Pulp and Paper Magazine of Canada 64(12), 517-527.

Gregorova, A., Lahti, J., Schennach, R., and Franz, S. (2013). "Humidity response of Kraft papers determined by dynamic mechanical analysis," Thermochimica Acta 570, 33-40.

Gurnagul, N., Page, D. H., and Seth, R. S. (1990). "Dry sheet properties of Canadian hardwood kraft pulps," Journal of Pulp and Paper Science 16(1), 36-41. 
Gurnagul, N., and Seth, R. (1997). "Wet web strength of hardwood kraft pulps," Pulp and Paper Canada 98(9), 44-48.

Gurnagul, N., Shallhorn, P., Omholt, I., and Miles, K. (2009). "Pressurized highconsistency refining of kraft pulps for improved sack paper properties," Appita J. 62(1), 25-30.

Gustafsson, E. (2012). "Tailoring adhesion and wetting properties of cellulose fibres and model surfaces," Licentiate Thesis KTH.

Hado, N., Nagai, T., Kojima, Y., and Yamamoto, T. (2001). "Easily moldable paper and method for molding paper mold product," JP2001277380.

Håkansson, K. M. O., Fall, A. B., Lundell, F., Yu, S., Krywka, C., Roth, S.V., Santoro, G., Kvick, M., Prahl, L., Wågberg, L., and Söderberg, D. (2014). "Hydrodynamic alignment and assembly of nanofibrils resulting in strong cellulose filaments," Nature Communications 5, DOI:10.1038/ncomms5018.

Halme, M. (1967). "Factors affecting strength anisotropy of paper (II)," Paperi ja Puu 49(4a), 147-150.

Hameed, N., Guo, Q., Tay, F., and Kazarian, S. (2011). "Blends of cellulose and poly(3hydroxybutyrate-co-3-hydroxyvalerate) prepared from the ionic liquid 1-butyl-3methylimidazolium chloride," Carbohydrate Polymers 86(1), 94-104.

Hänninen, T., Kontturi, E., Leppänen, K., Serimaa, R., and Vuorinen, T. (2011). "Kraft pulping of Juniperus communis results in paper with unusually high elasticity," BioResources 6 (4), 3824-3835.

Hardacker, K. W. (1970). "Effects of loading rate, span, and beating on individual wood fiber tensile properties" Tappi Stap Series 8, 201-216.

Hardacker, K. W, and Brezinski, J. P. (1973). "The individual fiber properties of commercial pulps," Tappi 56(4), 154-157.

Hartler, N. and Mohlin, U. B. (1975). "Cellulose fibre bonding. Part 2. Influence of pulping on interfibre bond strength," Svensk. Papperstid. 78(8), 295-299.

Haslach, H. W. Jr. (2000). "The moisture and rate-dependent mechanical properties of paper: A review," Mech. Time-dependent Mater. 4(3), 169-210.

Hatton, J. V. (1997). "Pulping and papermaking properties of managed second-growth softwoods," Tappi J. 80(1), 178-184.

Haudek, W., and Viti, E. (1978). Textilfasern: Herkunft, Herstelung, Aufbau, Eigenschafen, Verwendung, Bondi \& Sohn, Wien.

Hearle, J. W. S. (1963). "The fine structure of fibers and crystalline polymers. III. Interpretation of the mechanical properties of fibers," Journal of Applied Polymer Science 7(4), 1207-1223.

Hein, G. P. R., and Lima, T. J. (2012). "Relationships between microfibril angle, modulus of elasticity and compressive strength in Eucalyptus wood," Maderas, Cienc. tecnol. 14(3), 267-274.

Helle, T. (1965). "Paper fracture time dependencies," Norsk Skogindustri 19(3), 107-111.

Helmerius, J., Vinblad von Walter, J., Rova, U., Berglund, K. A., and Hodge, D. B. (2010). "Impact of hemicellulose pre-extraction for bioconversion on birch Kraft pulp properties," Bioresource Technology 101(15), 5996-6005.

Henniges, U., Hasani, M., Potthast, A., Westman, G. and Rosenau, T. (2013). "Electron beam irradiation of cellulosic materials - opportunities and limitations," Material 6(5), 1584-1598.

Henriksson, M., Berglund, L. A., Isaksson, P., Lindström, T., and Nishino, T. (2008). "Cellulose nanopaper structures of high toughness," Biomacromolecules 9(6), 15791585. 
Hernandez, R. J., and Selke, S. E. (2001). "Packaging: papers for sacks and bags," in: Encyclopedia of Materials: Science and Technology, Buschow, J., Cahn, R. W., Flemings, M .C., Ilschner, B., Kramer, E. J., Mahajan, S., and Veyssiere, P. (eds.), Elsevier, 6642-6650.

Heyse, W. T., Sarkanen, K., and Stannet V. (1960). "The mechanical properties of latextreated papers," J. Appl. Poly. Sci. 3(9), 282-289.

Hirn, U., and Schennach, R. (2014). "A quantitative analysis of different fiber-fiber bonding mechanisms," Progress in Paper Physics Seminar, Raleigh, North Carolina, U.S.A. September 8-11, 2014, available via: http://www.paperphysics.com/proceedings/9-08-2014/6005-HIRN.pdf [accessed 16.09.2014]

Hollmark, H., and Ampulski, R.S., (2004). "Measurement of tissue paper softness: A literature review," Nord. Pulp Paper Res. J. 19(3), 345-353.

Horn, R.A. (1974). "Morphology of wood pulp fiber from softwood and influence on paper strength," USDA Forest Service Research Paper FPL 242, Forest Products Laboratory, Madison, WI.

Htun, M., and de Ruvo, A. (1981). "The influence of drying strategies on the relationship between drying shrinkage and strain to failure of paper," The Role of Fundamental Research in Papermaking Symposium, Vol. 2, held September at Cambridge, 385374.

Htun, M., and Fellers, C. (1982). "The invariant mechanical properties of oriented handsheets," Tappi J. 65(4), 113-117.

Htun, M., Fellers, C., and Hansson, T. (1989). "Drying restraint and a new restraint technique to improve cross directional properties of paper," Transactions of the 9th Fundamental Research Symposium on the Fundamentals of Papermaking, Mechanical Engineering Publications, Cambridge, England, 1989, 743-781.

Ihrman, C., and Öhrn O. (1965). "Extensible paper by double-roll compacting process," in: Consolidation of Paper Web, Transactions of 3rd Fundamental research symposium Cambridge by F. Bolan (ed.), 410-434.

Ioelovich, M. (2012). "Study of cellulose interaction with concentrated solutions of sulfuric acid," ISRN Chemical Engineering, DOI: 10.5402/2012/428974

Jackson, M. (1967). "High consistency refining - A literature survey," Svensk Papperstidning 70(16), 507-510.

Johnson, J. A., Bennett, K. A., and Montrey, H. M. (1983). "Failure phenomena," in: Handbook of Physical and Mechanical Testing of Paper and Paperboard, Vol. 1, Mark, R. E. (ed.), Marcel Dekker, New York, NY, 1983; Chapter 5.

Joutsimo, O., Wathén, R., and Tamminen, T. (2005). "Effects of fiber deformations on pulp sheet properties and fiber strength," Paperi ja Puи 87(6), 392-397.

Kawasaki, H., and Nagai, T. (2003). "Elongation mechanism of the extensible paper: Elongation developed by sheet compaction," $\left(70^{\text {th }}\right)$ Pulp and Paper Research Conference, Tokyo, Japan, 16-17 June 2003, paper 10-B, 44-47.

Khakalo, A., Filpponen, I., Rojas, O.J., and Laine, J. (2014). "Modified cellulose for deep-drawn paper-based packaging materials," in: 247th ACS National Meeting \& Exposition, March 16-20, 2014, Dallas, Texas.

Khwaldia, K., Basta, A. H., Aloui, H., and El-Saied, H. (2014). "Chitosan-caseinate bilayer coatings for paper packaging materials," Carbohydrate Polymers 99, 508516.

Kibblewhite, P. R., and Kerr, A. J. (1980). "Fibre, wet web and paper properties of bisulphite pulps treated with gaseous ammonia," Appita J. 33(4), 275-283. 
Kim, N. H., Imai, T., Wada, M., and Sugiyama, J. (2006). "Molecular directionality in cellulose polymorphs," Biomacromolecules 7(1), 274-280.

Kimura, M. (1978). "Effect of restraint during drying on mechanical properties and dimensional stability of handsheets," J. JPN Wood Res. Soc. 24(10), 734-749.

Klemm, D., Kramer, F., Moritz, S., Lindström, T., Ankerfors, M., Gray, D., and Dorris, A. (2011). "Nanocelluloses: A new family of nature-based materials," Angew. Chem. Int. Ed. 50(24), 5438-5466.

Koljonen, K., Österberg, M., Kleen, M., Fuhrmann, A., Stenius, P. (2004). "Precipitation of lignin and extractives on kraft pulp: Effect on surface chemistry, surface morphology and paper strength," Cellulose 11(2), 209-224.

Kouko, J., Kekko, P., and Retulainen, E. (2014). "Influence of straining during wet pressing and drying on strength properties of paper," Nordic Pulp and Paper Research Journal 29(3), 453-462.

Kulachenko, A., and Uesaka, T. (2012). "Direct simulations of fiber network deformation and failure," Mechanics of Materials 51, 1-14.

Kulasinski, K., Ketent, S., Churakov, S. V., Derome, D., and Carmeliet J. (2014). "A comparative molecular dynamics study of crystalline, paracrystalline and amorphous states of cellulose," Cellulose 21(3), 1103-1116

Kunnari, V., Jetsu, P., and Retulainen, E. (2007). "Formable paper for new packaging applications," in: Proceedings of: $23^{\text {rd }}$ Symp. International Association of Packaging Research Institutes (IAPRI). Windsor, UK.

Kurki, M., Kouko, J., Kekko, P., and Saari, T. (2004). "Laboratory scale measurement procedure of paper machine wet web runnability, Part 1," Paperi ja Puu 86(4), 256262.

Kärenlampi, P., and Suur-Hamari, H. (1997). "Classified wood raw materials for diversified softwood kraft pulps," Paperi ja Puи 79(6), 404-410.

Kärenlampi, P., and Yu, Y. (1997). "Fiber properties and paper fracture - Fiber length and fiber strength," in: The Fundamentals of Papermaking Materials, Trans. XI ${ }^{\text {th }}$ Fund. Res. Symp. Cambridge, 1997, Baker, C. F. (ed.), 521-545.

Lahti, J., Schmied, F., and Bauer, W. (2014). "A method for preparing extensible paper on the laboratory scale," Nordic Pulp Paper Research Journal 29(2), 317-322.

Laine, J., Lindström, T., Nordmark, G. G., and Risinger, G. (2002). "Studies on topochemical of cellulosic fibres. Part 2. The effect of carboxymethyl cellulose attachment on fibre swelling and paper strength," Nordic Pulp and Paper Research Journal 17(1), 50-56

Larsson, P. A., Berglund, L. A., and Wågberg, L. (2014a). "Highly ductile fibres and sheets by core-shell structuring of the cellulose nanofibrils," Cellulose 21(1), 323333.

Larsson, P. A., Berglund, L. A., and Wågberg, L. (2014b). "Ductile all-cellulose nanocomposite films fabricated from core-shell structured cellulose nanofibrils," Biomacromolecules 15(6), 2218-2223.

Lee, C. H. (1960). "Studies on the crystallinity of wood cellulose by x-ray methods," Master of science thesis, Univ. of British Columbia.

Lenz, J., Schurz, J., and Wrentschur, E. (1994). "On the elongation mechanism of regenerated cellulose fibres," Holzforschung 48(1), 72-76.

Leopold, B., and McIntosh, D. C. (1961). "Chemical compositions and physical properties of wood fibres. III. Tensile strength of individual fibers from alkali extracted loblolly pine holocellulose," Tappi J. 44(3), 235-240. 
Lindström, T., Kolseth, P., and Näslund, P. (1985). "The dry strengthening effect of cationic starch wet-end addition on filled papers," in: Papermaking Raw Materials, Trans. VIII ${ }^{\text {th }}$ Fund. Res. Symp. Oxford, 1985, (V. Punton, ed.), 589-611.

Lindström, H., Evans, J. W., and Verrill, S. (1998). "Influence of cambial age and growth conditions on microfibril angle in young norway spruce (Picea abies [L.]Karst.)," Holzforschung 52(6), 573-581.

Lindström, T., Wågberg, L., and Larsson, T. (2005). "On the nature of joint strength in paper - A review of dry and wet strength resins used in paper manufacturing," in: Advances in Paper Science and Technology, Trans. 13th Fundamental Research Symposium, Cambridge, 2005, 457-562.

Linvill, E., and Östlund, S. (2014). "The combined effects of moisture and temperature on the mechanical response of paper," Experimental Mechanics, DOI:10.1007/s11340-014-9898-7.

Lipponen, J., Pakarinen, J., Jääskeläinen, J., and Grön, J. (2005). “Mechanical properties of woodfree paper sheets at different surface size starch amounts," Paperi ja Puu 87(3), 170-175.

Ljungqvist, C. H., Lyng, R., and Thuvander, F. (2003). "Measuring the strain to failure for wood fibres-influence of fibre wall damage," in: Proceedings of IPPC 2003, September 7-11, 2003, Victoria, British Columbia, Canada, 99-106

Ljungqvist, C. H., Lyng, R., and Thuvander, F. (2005). "Evaluation of PFI beating on the strain to failure of spruce fibres using single fiber fragmentation," Nordic Pulp and Paper Research Journal 20(4), 370-377.

Lobben, T. H. (1977). "Effects of fines on the paper strength properties of chemical pulps," Norsk Skogindustri 31(4), 93-97.

Lobben T. H. (1978). "On the influence of the pulp components on the shrinkage and elongation of paper," Norsk Skogindustri 32(4), 80-84.

Lobben, T. H. (1975). "The tensile stiffness of paper. Part 1. A model based on activation," Norsk Skogindustri 29(12), 311-315.

Madani, A., Kiiskinen, H., Olson, J. A., and Martine, D. M. (2011). "Fractionation of microfibrillated cellulose and its effects on tensile index and elongation of paper," Nordic Pulp and Paper Research Journal 26(3), 306-311.

Mahato, D. N., Prasad, R. N., and Mathur, B. K. (2009). "Surface morphological, band and lattice structural studies of cellulosic fiber coir under mercerization by ESCA, IR and XRD techniques," Indian Journal of Pure and Applied Physics 47(9), 643-647.

Manninen, M., Kajanto, I., Happonen, J., and Paltakari, J. (2011). "The effect of microfibrillated cellulose addition on drying shrinkage and dimensional stability of wood-free paper," Nordic Pulp Paper Res. J. 26 (3), 297-305.

Marais, A., Utsel, S., Gustafsson, E., and Wågberg, L. (2014). "Towards a superstrainable paper using the layer-by-layer technique," Carbohydrate Polymers 100(1), 218-224.

Matsumura, H., Sugiyama, J., and Glasser, W. G. (2000). "The cellulosic nanocomposites. I. Thermally deformable cellulose hexanoates from heterogeneous reaction," Journal of Applied Polymer Science 78(13), 2242-2253.

Martinschitz, K. J., Boesecke, P., Garvey, C. J., Gindl, W., and Keckes, J. (2008). "Changes in microfibril angle in cyclically deformed dry coir fibers studied in-situ synchrotron X-ray diffraction," J. Mater. Sci. 43(1), 350-356.

Mayhood, C. H., Kallmes, O. J., and Cauley, M. M. (1962). “The mechanical properties of paper - part II: measured shear strength of individual fiber to fiber contacts," Tappi 45(1), 69-73. 
McIntosh, D. C. (1963). "Tensile and bonding strengths of loblolly pine kraft fibers cooked to different yields," Tappi 46(5), 273-277.

Mikkonen, K. S., Pitkänen, L., Liljeström, V., Bergström, E. M. Serimaa, R., Salmén, L., and Tenkanen, M. (2012). "Arabinoxylan structure affects the reinforcement of films by microfibrillated cellulose," Cellulose 19(2), 467-480

Mohlin, U. B., Dahlblom, J., and Hornatowska, J. (1996). "Fibre deformation and sheets strength," Tappi Journal 79(6), 105-111.

Morin, F. G., Jordan, B. D., and Marchessault, R. H. (2004). "High-energy radiationinduced changes in the crystal morphology of cellulose," Macromolecules 37, 26682670.

Muller, M., Czihak, C., Burghammer, M., and Riekel, C. (2000). “Combined X-ray microbeam small-angle scattering and fibre diffraction experiments on single native cellulose fibres," J. Appl. Crystallogr. 33(3), 817-819.

Mäkelä, P. (2009). "Effect of drying conditions on the tensile properties of paper," Transactions of the 14th Fundamental Research Symposium Oxford, 1079-1094.

Nanko, H., and Wu, J. (1995). "Mechanisms of paper shrinkage during drying," International Paper Physics Conference, Niagara-on-the-Lake, Canada, 103-113.

Neimo, L., Harva, O., and Sivola A. (1967). "Graft copolymers of cellulose polymerization initiated by decomposition of cellulose peroxides," Paperi ja Puu 49(3), 509-516.

Nishino, T., Takano, K., and Nakamae K. (1995). "Elastic modulus of the crystalline regions of cellulose polymorphs," Journal of Polymer Science Part B: Polymer Physics 33(11), 1647-1651.

Nishino, T., Matsuda, I., and Irao, K. (2004). “All cellulose composite," Macromolecules 37(20), 7683-7687.

Nishino, T., and Arimoto, N. (2007). "All-cellulose composite prepared by selective dissolving of fiber surface," Biomacromolecules 8(9), 2712-2716.

Nissan, A. H. (1977). "Lectures on fiber science in paper, pulp and paper technology," Series No. 4, Joint Textbook Committee TAPPI CPPA.

Nazhad, M. M., Harris, E. J., Dodson, C. T. J., and Kerekes, R. J. (2000). "The influence of formation on tensile strength of papers made from mechanical pulps," Tappi J. 83(12), 63-70

Nonnenmacher, F. (1898). "Sizing,” US Patent 599726 A 18980301.

Obermanns, H. E. (1934). "A study of the effect of hemicelluloses on the beating and strength of pulps," Doctoral Thesis, Institute of Paper Science and Technology.

Ogiwara, Y., Kubota, H., Hayashi, S., and Mitomo, N. (1970). "Temperature dependency of bound water of cellulose studied by a high-resolution NMR spectrometer," J. Appl. Polym. Sci. 14(2), 303-309.

Oksanen, T., Buchert, J., and Viikari, L. (1997). "The role of hemicelluloses in the hornification of bleached kraft pulps," Holzforschung 51(4), 355-360.

Okushima, S., and Robertson, A. A. (1979). "Humidity and the tensile behaviour of paper," in: Proceedings of IPPC 1979, British Columbia, September 17-19, 83-88.

Oliver, J. (1980). "Dry-creping of tissue paper - A review of basic factors," Tappi 63(12), 91-95.

Östlund, M., Borodulina, S., and Östlund, S. (2011). "Influence of paperboard structure and processing conditions on forming of complex paperboard structures," Packaging Technology and Science 24(6), 331-341.

Paasonen, P., and Koivisto, P. (1970). "On wet web strength of sulphite pulp," Paperi ja Рии 52(11), 757-764. 
Paavilainen, L. (1992). "The possibility of fractionating softwood sulphate pulp according to cell wall thickness," Appita J. 45(5), 319-326.

Page, D. H., Tydeman, P. A., and Hunt, M., (1962). "The behaviour of fibre-to-fibre bonds in sheet under dynamic conditions," in: The Formation and Structure of Paper, Bolam, F. (ed.), Vol.1, Tech Sect B. P. and B.M.A, 249-263.

Page, D., and Tydeman, P.A. (1962). "A new theory of the shrinkage and properties of paper," in: The Formation and Structure of Paper, Bolam, F. (ed.), Vol. 1, Tech. Sect. B. P. and B. M. A, 397-425.

Page, D. H., and Tydeman, P.A. (1966). "Physical processes occurring during the drying phase," in: Consolidation of the Paper Web, Vol. 1, Bolam, F. (ed.), British Paper and Board Makers' Assoc. London, 371-396.

Page, D. H. (1969). "The structure and properties of paper: Part 1 - The structure of paper," Trend 15, 7-12.

Page, D. H. (1971). "The structure and properties of paper, Part II. Shrinkage, dimensional stability and stretch," Trend 18, 13-19.

Page, D. H., El-Hosseiny, F., Kim, C. Y., Winkler, K., Bain, R. Lancaster, P., and Vondrankova, M. (1976). "The behaviour of single wood pulp fibres under tensile stress," in: Fundamental Properties of Paper Related to its Uses, Bolam, F. (ed.), 407.

Page, D. H., and Seth, R. S. (1980). "The elastic modulus of paper III: The effects of dislocation, microcompressions, curls, crimps and kinks," Tappi J. 63(10), 99-102.

Page, D. H. (1983). "The origin of the difference between sulphite and kraft pulps," $J$. Pulp Paper Sci. 9(3), 15-20.

Page, D. H., and El-Hosseiny, F. (1983). "The mechanical properties of single wood pulp fibres. Part VI. Fibril angle and the shape of the stress-strain curve," J. Pulp Paper Sci. 9(4), 99-100.

Parker, J. L. (1962). "The effects of ethylamine decrystallization of cellulose fibres on the viscoelastic properties of paper," Doctoral Thesis, The Institute of Paper Chemistry, Appleton WI.

Parsons, S. R. (1972). "Effect of drying restraint on handsheet properties," Tappi 55(10), 1516-1522.

Patil, N. B., Dweltz, N. E., and Radhakrishnan, T. (1965). "Studies on decrystallization of cotton," Textile Res. J. 35(6), 517-523

Peel, J. D. (1999). "Pulp types and pulping processes," in: Paper Science and Paper Manufacture, Appendix 5, Angus Wilde Publications Inc., Vancouver, BC, Canada, 245-250.

Pelton, R. (2004). "On the design of polymers for increased paper dry strength - A review," Appita J. 57(3), 181-190.

Pettersson, G., Sjöberg, J., Wågberg, L., Höglund, H., and Averheim, A. (2007). "Increased joint-forming ability of ductile kraft pulp fibres by polyelectrolyte multilayer treatment - Influence of refining and drying strategies, "Nordic Pulp \& Paper Research Journal 22(2), 228-235.

Peura, M., Andersson, S., Salmi, A., Karppinen, T., Torkkeli, M., Häggström, E., and Serimaa, R. (2008). "Changes in nanostructure of wood cell during deformation," Materials Science Forum 599, 126-136.

Poppel, E., Malutan, C., Malutan, T., and Orleschi, N. (2000). "Correlation between the standard, rheological and technological parameters in Clupack extensible paper manufacturing," Cellulose Chem. Technol. 34(3-4), 385-398. 
Post, P.-P., Huttel, D., Groche, P., and Schabel, S. (2011). "Paper characteristics influencing the deep drawing ability of paper," in proceedings of: Progress in Paper Physics 2011, September 5-8 ${ }^{\text {th }}$, 2011, Graz Austria, 137-145.

Reiterer, A., Lichtenegger, H., Tschegg, S. and Fratzl, P. (1998). "Experimental evidence for a mechanical function of the cellulose microfibril angle in wood cell walls," Philosophical Magazine A 79(9), 2173-2184.

Ramasubramanian, M. K. (2001). "Physical and mechanical properties of towel and tissue," in: Mark et al., (eds.), Handbook of Physical Testing of Paper, Vol. 2, CRC Press, 661-696.

Ramasubramanian, M. K. (2011). "Modelling and simulation of the creping process," PaperCon 2011, Cincinnati, USA, 2011.

Rauvanto, I. (2010). "The intrinsic mechanisms of softwood fiber damage in brown stock fiber line unit operations," Doctoral thesis, Lappeenranta University of Technology.

Retulainen, E., Moss, P., and Nieminen, K. (1993). "Effect of fines on the properties of fibre networks," Baker, C. F. (ed.), Products of Papermaking, Vol. 2. Transactions of the $10^{\text {th }}$ Fundamental Research Symposium held at Oxford: September 1993, Pira International 1993, 727-769.

Retulainen, E., Niskanen, K., and Nilsen, N. (1998). "Fibers and bonds," in: Niskanen, K. (ed.), Paper Physics, Papermaking Science and Technology, Book 16, Fapet Oy, Jyväskylä, 55-87.

Rezai, E., and Warner, R. R. (1997a). "Polymer-grafted cellulose fibers. I. Enhanced water absorbency and tensile strength," Journal of Applied Polymer Science 65(8), 1463-1469.

Rezai, E., and Warner, R. R. (1997b). "Polymer-grafted cellulose fibers. II.Interactions of grafted and ungrafted fibers in handsheets," Journal of Applied Polymer Science 65(8), 1487-1492.

Robertson, A. A. (1959). "The physical properties of wet webs. Part 1. Fiber-water association and wet-web behavior," Tappi J. 42(12), 969-978.

Saitaka, K., Hatoh, N., Kawasaki, H., and Sataka, T. (2006). "The development of new extensile paper for heavy duty sack that helps material saving," Japan Tappi J. 60(12), 86-94.

Salmén, N. L., and Back, E. L. (1977). "The influence of water on the glass transition temperature of cellulose," Tappi J. 60(12), 137-140.

Salmén, L., and Back, E. L. (1977). "Simple stress-strain measurements on dry papers from $25^{\circ} \mathrm{C}$ to $250^{\circ} \mathrm{C}$," Svensk. Paperstidn. 80(6), 178-183.

Salmén, L. (1979). "Thermal softening of the components of paper: Its effect on mechanical properties," Pulp and Paper Canada, Transactions 5(3), 45-50.

Salmén, L., and Back, E. (1980). "Moisture-dependent thermal softening of paper, evaluated by its elastic modulus," Tappi 63(6), 117-120.

Salmén, L. Carlsson, L. A., de Ruvo, A., Fellers, C., and Htun, M. (1984). "A treatise on the elastic and hygroexpansional properties of paper by a composite laminate approach," Fibre Science and Technology 20(4), 283-296.

Salmén, L. (1990). "On the interaction between moisture and wood fibre materials," In: Caufield, D. F. et al. (eds.), Materials Interactions Relevant to the Pulp, Paper and Wood Ind., Pittsburgh., Materials. Res. Soc., 193-201.

Salmén, L., and Hornatowska, J. (2014). "A comparison of fibre deformations from mill like and laboratory kraft cooking of softwood," Nordic Pulp Paper Research Journal 29(2), 211-217. 
Sampson, W. W., and Yamamoto, J. (2011). "The influence of fines, fibre contact and grammage on the free shrinkage of handsheets," Appita J. 64(1), 76-82.

Satyanarayana, K. G., Pillai, C. K. S., Sukumaran, K., Pillai, S. G. K., Rohatgi, P. K., and Vijayan, K. (1982). "Structure property studies of fibres from various parts of the coconut tree," Journal of Materials Science 17(2), 2453-2462.

Satyanarayana, K. G., Arizaga, G. G. C., and Wypych, F. (2009). "Biodegradable composites based on lignocellulosic fibers - An overview," Progress Polymer Science 34(9), 982-1021.

Satyanarayana, K. G. (2010). "Biodegradable polymer composites based on Brazilian lignocellulosic," Revista Matéria 15(2), 88-95.

Saukkonen, E., Lyytikainen, K., Käyhkö, J., and Kajanto, I. (2011). “Papermaking performance of a mixture of low hemicelluloses content and normal birch kraft pulp," in proceedings: Third Nordic Wood Biorefinery Conference (NWBC 2011), Stockholm, Sweden, 22-24 March 2011, 300-301.

Scallan, A. M. (1974). "The structure of the cell wall of wood - A consequence of anisotropic inter-microfibrillar bonding?" Wood Science 6(3), 266 -271.

Scallan, A. M., and Grignon, P. (1979). "The effect of cations on pulp and paper properties," Svensk Papperstidning 82(2), 40-47.

Scallan, A.M. (1983). "The effect of acidic groups on the swelling of pulps. A review," Tappi 66(11), 73-75.

Schulz, J. H. (1961). "The effect of strain applied during drying on the mechanical behaviour of paper," Doctoral thesis, Institute of paper chemistry.

Seth, R. S., and Page, D. H. (1981). "The stress-strain curve of paper," in: Brander, J. (ed.), The Role of Fundamental Research in Papermaking, Transactions of the symposium held at Cambridge. Mechanical Engineering Publications Ltd., London 1983, 421-452.

Seth, R. S. (2005). “Understanding sheet extensibility,” Pulp \& Paper Canada 106(2), 33-40.

Setterholm, V., and Kuenzi, E.W. (1970). "Fiber orientation and degree of restraint during drying," Tappi J. 53(10), 1915-1920.

Shiraishi, N. (1991). "Wood plasticization," in: Wood and Cellulosic Chemistry, Shiraishi, N., and Hon, D. N.-S. (eds.), Marcel Dekker, New York, 861-906.

Shoudy, C. A. (1959). "The Clupak paper story," Tappi 42(1), 108-110.

Silvy, J. (1971). "Effects of drying on web characteristics," Paper Technol. 12(6), 445452.

Singha, K. (2012). "Analysis of spandex/cotton elastomeric properties: Spinning and applications," International Journal of Composite Materials 2(2), 11-16.

Sjöberg, J., and Höglund, H. (2007). "High consistency refining of kraft pulp for reinforcing paper based on TMP furnishes," in: 2007 International Mechanical Pulping Conference, 6-9 May, Minneapolis, Minnesota, USA

Skowronski, J., and Robertson, A. A. (1986). "The deformation properties of paper: Tensile strain and recovery," J. Pulp Paper Sci. 12(1), 20-25.

Skowronski, J., and Robertson, A. A. (1983). "A phenomenological study of the tensile deformation properties of paper," in: Proceedings of 1983 International Paper Physics Conference, Harwichport, MA, 95-105.

Sørensen, G., and Hoffmann, J. (2003). "Moisture sorption in moulded-fibre trays and effect on static compression strength," Packag. Technol. Sci. 16(4), 159-169.

Soykeabkaew, N., Sian, C., Gea, S., and Peijs, T. (2009). "All-cellulose nanocomposites by surface selective dissolution of bacterial cellulose," Cellulose 16(3), 435-444. 
Spiegelberg, H. L (1966). "The effect of hemicelluloses on the mechanical properties of individual pulp fibers," Doctoral Thesis, The Institute of Paper Chemistry Lawrence University, Appleton, Wisconsin.

Steenberg, B. (1947). “Importance of stress relaxation in paper," Svensk Papperstidning 61(13), 127-140.

Steenberg, B. (1949). "Behaviour of paper under stress and strain," Pulp and Paper Magazine of Canada, Convention issue, 207-214

Steenberg B. (2006). "Rheomembrances," Annual Transactions of the Nordic Rheology Society, 14, available via: http://www.nordicrheologysociety.org/Open_transactions/2006/NRS_AT_2006_vol1 4/Invited\%20papers/Steenberg.pdf [accessed 20.03.14]

Stitt, J. (2002). "Better bond quality between sheet and Yankee dryer coating creates softer tissue," Pulp Pap. 76, 54-57.

Stockmann, V. E. (1974). "Effect of bonding intensity profile variations on performance of paper," Tappi 1974 Annual meeting. Preprints, 39-45.

Stratton, R. A., and Colson, N. C (1993). "Fiber wall damage during bond failure," Nord. Pulp Pap. Res. J. 8(2), 245-249.

Saeman, J. F., Millet, M. A., and Lawton, E. J. (1952). "Effect of high energy cathoderays on cellulose," Ind. Eng. Chem. 44, 2848-2852.

Sun, Z., Zhao, X., Wang, X., and Ma, J. (2014). "Multiscale modeling of the elastic properties of naturalfibers based on a generalized method of cells and laminate analogy approach," Cellulose 21, 1135-1141.

Sun, J., Xu, Y., Liu, Y., and Leng, J. (2012). "Spandex fiber reinforced shape memory polymer composites and their mechanical properties," Advanced Materials Research 410, 370-374.

Svensson, A., Lindström, T., Ankerfors, M., and Östlund, S. (2013). "3D-shapeable thermoplastic paper materials," Nordic Pulp and Paper Research Journal 28(4), 602 610.

Szcześniak, L., Rachocki A., and Tritt-Goc J. (2008). “Glass transition temperature and thermal decomposition of cellulose powder," Cellulose 15(3), 445-451.

Tabet, T. A., and Aziz, F.A. (2013). "Cellulose microfibril angle in wood and its dynamic mechanical significance," In: Cellulose - Fundamental Aspects, van de Ven, T., and Godbout, L. (eds), DOI: 10.5772/51105, Available via: http://www.intechopen.com/books/cellulose-fundamental-aspects/cellulosemicrofibril-angle-in-wood-and-its-dynamic-mechanical-significance [Accessed 14.08.2014].

Taipale, T., Österberg, M., Nykänen, A., Ruokalainen, J., and Laine J. (2010). "Effect of microfibrillated cellulose and fines on the drainage of kraft pulp suspension and paper strength," Cellulose 17(5), 1005-1020.

Thygesen, A. (2006). "Properties of hemp fibre polymer composites - An optimization of fibre properties using novel defibration methods and fibre characterization," Doctoral thesis, Ris $\varnothing$ National Laboratory, 146 pp.

Torgnysdotter, A., and Wågberg, L. (2003). "Study of the joint strength between regenerated cellulose fibres and its influence on the sheet strength," Nordic Pulp and Paper Research Journal 18(4), 455-459.

Tsuge, K., and Wada, Y. (1962). "Effect of sorbed water on dielectric dispersion of cellulose at low frequencies," J. Phys. Soc. Japan 17(1), 156-164.

Uesaka, T. (2005). "Principal factors controlling web breaks in pressroom-qualitative evaluation," Appita J. 56(6), 425-432. 
Uesaka, T., Ferahi, M., Hristopolus, D., Deng, N., and Moss, C. (2001). "Factors controlling pressroom runnability of papers," in: Transactions of the $12^{\text {th }}$ Fundamental Research Symposium, Baker, C. F. (ed.), Vol. 2, 1423-1440.

van de Ven, T. (2008). “Capillary forces in wet paper," Ind. Eng. Chem. Res. 47(19), 7250-7256.

Vincent, J. F. V. (1999). "From cellulose to cell," The Journal of Experimental Biology 202(23), 3263-3268.

Vishtal, A., and Retulainen, E. (2012). "Deep-drawing of paper and paperboard: The role of material properties," BioResources 7(3), 4424-4450.

Vishtal, A., and Retulainen, E. (2014). "Improving the extensibility, wet web and dry strength of paper by addition of agar," Nordic Pulp and Paper Research Journal 29(3), 434-444.

Vishtal, A., Hauptmann, M., Zelm, R., Majschak, J.-P., and Retulainen, E. (2013). "3D forming of paperboard: The influence of paperboard properties on formability," Packag. Technol. Sci. 27(9), 677-691.

Vomhoff, H. and Grundström, K.J. (2003). "Fractionation of a bleached softwood pulp and separate refining of the earlywood- and latewood-enriched fractions, Int.Papwirtch. 2, 37-41.

Vuoti, S., Laatikainen, E., Heikkinen. H., Johansson, L. S., Saharinen E., and Retulainen, E. (2013). "Chemical modification of cellulosic fibers for better convertibility in packaging applications," Carbohydrate Polymers 96(2), 549-559

Wahlström, T., Adolfsson, K., Östlund, S., and Fellers, C. (1999). "Numerical modelling of the cross direction shrinkage profile in a drying section, a first approach," 1999 International Paper Physics Conference, September 26-30, San Diego, CA, 517-531.

Wahlström, T., and Fellers, C. (2000). "Biaxial straining of handsheets during drying Effect on in-plane mechanical properties," Tappi J. 83(8), 91-105.

Waller, M. H., and Singhal, A. S. (1999). "Development of paper properties during restrained drying of handsheets," In Proceedings of 1999 TAPPI Engineering/Process and Product Quality Conference, Anaheim, September 13-16.

Wang, L., Dong, W., and Xu, Y. (2007). "Synthesis and characterization of hydroxypropyl methylcellulose and ethyl acrylate graft copolymers," Carbohydrate Polymers 68(4), 626-636.

Wang, D., Yu, J., Zhang, J., He, J., and Zhang, J. (2013). “Transparent bionanocomposites with improved properties from poly(propylene carbonate) (PPC) and cellulose nanowhiskers (CNWs)," Composites Science and Technology 85, 8389.

Ward, K. Jr. (1950). "Crystallinity of cellulose and its significance for the fibre properties," Text. Res. J. 20(6), 363-372.

Waterhouse, J. F. (1976). "The deformation characteristics of polymer reinforced fiber networks," Tappi 59(7), 106-109.

Waterhouse, J. F. (1984). "The ultimate strength of paper," in: Progress in Paper Physics - A Seminar, Design Criteria for paper performance, Stockholm, Sweden June 25-29

Waterhouse, J. F. (1985). "Paper properties and converting," Technical Paper. IPC Technical Paper № 162.

Welsh, H. S. (1960). "Isotropic paper nears commercial production," Paper Trade Journal 146(31), 30-32.

Welsh, H. S. (1965). "Fundamental properties of high stretch papers," in: Consolidation of the Paper Web, Trans. III ${ }^{\text {rd }}$ Fund. Res. Symp., Bolam, F. (ed.), Cambridge, 397409. 
Wimmer, R., (1992). "Multivariate structure property relations for pinewood," IAWA Bull. 14(3), 265-266.

Wu, J., Zheng, Y., Yang, Z., Lin, Q., Qiao, K., Chen, X., and Peng, Y. (2014). "Influence of dialdehyde bacterial cellulose with the nonlinear elasticity and topology structure of ECM on cell adhesion and proliferation," RSC Adv. (4), 3998-4009.

Xing, C., Wang, H., Hu, Q., Cao, X., You, J., and Li, Y. (2013). "Mechanical and thermal properties of eco-friendly poly(propylene carbonate)/cellulose acetate butyrate blends," Carbohydrate Polymers 92(2), 1921-1927.

Zeng, X., Retulainen, E., Heinemann, S., and Fu, S. (2012). "Fibre deformations induced by different mechanical treatment and their effect on zero-span strength," Nordic Pulp and Paper Research Journal 27(2), 335-342.

Zeng, X., Vishtal, A., Retulainen, E., Sivonen, E., and Fu, S. (2013). "The elongation potential of paper - How should fibres be deformed to make paper extensible?" BioResources 8(1), 472-486.

Zhang, S. Y., Fei, B. H., Yu, Y., Cheng, H. T., and Wang, C. G. (2013). "Effect of the amount of lignin on tensile properties of single wood fibers," For. Sci. Pract. 15(1), 56-60.

Zhao, B. X., and Kwon, H. J. (2011). "Adhesion of polymers in paper products from the macroscopic to molecular level - An overview," J. Adhes. Sci. Technol. 25(6-7), $557-$ 579.

Article submitted: July 7, 2014; Peer review completed: August 6, 2014; Revised version received and accepted: September 18, 2014; Published: September 29, 2014. 